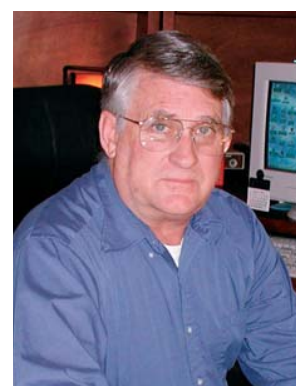

By Gary Frasier

\section{Frasier's Philosophy}

The newspapers and TVs are all full of the new assessment on global warming and what it will mean to our lifestyle. As evidenced by clues of past ices ages, global climate change is not new. There is evidence that the world has been in a warming trend since the last ice age. What may be new is the rate of global climate change and, more specifically, global warming. What does all this mean in relation to our rangeland resources and their use?

There is a tendency to think that what we now see on our rangelands has always been here. Our life span is relatively short compared to the time that rangeland plants have evolved. The present native rangeland vegetation is a result of plant evolution under specific sets of precipitation and temperature regimes. As these regimes change, then so does the native vegetation.

It is generally agreed that as the vegetation undergoes a change the animals that live in an area must adapt. This means that they change their diet, migrate to other areas, or die. Ample archaeological data show that all these scenarios have occurred in the past. There are signs in some areas that animals can cause a vegetation change at least on a local level. This probably most often occurs when there is a change in the precipitation patterns (droughts) causing a reduction in plant growth. In the short term, the animals will consume all the plant material. If the drought persists, the animals will die or leave the area. This may or may not cause a change in the plant composition of an area. It all depends on the duration of the "climate" change. If the change is for a few years, the plants may recover. Extended droughts may cause a more permanent change in the plant species. Some plant species may adapt, and others will pass out of being. This is evolution.

Humans have a record of speeding the change of plant resources in an area. This has most frequently been done on rangelands by allowing overgrazing by domestic animals. This is well recognized, and in most places in the world, efforts are being made to reduce destructive use of the plant resources. We are making progress.

Now we are told that climate change over the next 100 years will materially affect the temperature and precipitation regimes of many areas. One scenario is that the location of arid and semiarid areas will change. In some areas there will be greater extremes of precipitation amounts (droughts) and temperature (highs and lows). What does this mean to rangeland resource managers?

I think there is no doubt that there will be some climate change over the next couple of centuries. This in turn means that there will be changes in the "native" vegetation of some areas. How we manage rangeland areas will influence how fast some of the vegetation changes might occur under the postulated climate change.

There is a group of people who believe that the vegetation composition on our rangelands in the past was good and that any changes toward a new vegetation species composition is bad. As a result, we spend enormous energy and money trying to restore the vegetative conditions of the past. What is not taken into account is that there may have already been some slight climate change that has occurred and reestablishing the past vegetation composition is not feasible today. As long as we have the mind-set that the past is the best, we can never adapt to climate change. We must use our best knowledge of what plant species are adapted to the current climate regime and move forward. Only by looking forward can we cope with whatever climate change is coming. 


\section{King Ranch Institute for Ranch Management Symposium on Ex- cellence in Ranch Management}

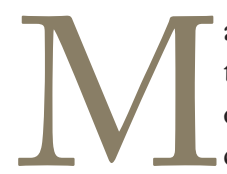

anagement of rangeland resources has proven to be challenging because of the complexity of the resources themselves and the divergent demands of dynamic societies. In the last quarter of a century, much of the focus of the management of these resources has been with processes like ecosystem management, Holistic Resource Management, and Integrated Resource Management. A logical next step is the application of a relatively simple but highly effective tool known as the Balanced Scorecard.

The Balanced Scorecard was first introduced to the business community in the early 1990s by two Harvard Business School professors, Drs. Robert Kaplan and David Norton. It has been successfully adopted by organizations of all types and in countries around the globe. The Balanced Scorecard has been recognized as one of the most important concepts in business in the 20th century. Its application to the management of rangeland resources is not only logical but also criti$\mathrm{cal}$, as the expectations of both the ranching businesses based on their use and governmental organizations charged with their care are broadened and deepened by various stakeholder groups. Seven of the articles in this month's Rangelands were papers presented by the speakers at the 2006 HOLT CAT/ King Ranch Institute for Ranch Management Symposium on Excellence in Ranch Management. The theme of the symposium was "Business Planning for Successful Ranch Management."

The goal of the symposium was to introduce rangeland managers to the Balanced Scorecard. The keynote speaker was Nicola Shadbolt, Senior Lecturer in Farm and Agribusiness Management, Massey University, New Zealand. Ms. Shadbolt is the world's leading expert in applying the Balanced Scorecard to farm and ranch management. Using a workshop format, the attendees rotated through a series of breakout sessions designed to help them apply this tool to the different perspectives that contribute to a ranch, such as: wildlife management, natural resource management, livestock production, and human resources. Each session was led by a team of successful ranchers and experts in the topics they discussed. They were assisted by students in the King Ranch Institute for Ranch Management. DVDs of the 2006 symposium can be obtained by contacting the Institute at 361-593-5401 or emailing krirm@tamuk.edu.

The goal of publishing these papers in Rangelands is to expose a broader audience to the Balanced Scorecard and to widen its potential adoption. The management of rangelands is the responsibility of a wide array of professionals. The Balanced Scorecard can be an effective tool in all of their management tool boxes.

Barry H. Dunn, Guest Editor Rangelands, Executive Director and Robert J. Kleberg Jr. and Helen C. Kleberg Endowed Chair, King Ranch Institute for Ranch Management, MSC 137, Texas A\&M University-Kingsville, Kingsville, TX 78364, (361) 593-5400,kabbd00@tamuk.edu. 


\section{The Balanced Scorecard: A Strategic Management Tool for Ranchers}

\section{By Nicola M. Shadbolt}

he Balanced Scorecard is a commonly used strategy tool in business. Strategic management is an essential skill if long-term aims are to be achieved.

1 Yet neither can be discussed before they are put into context of a ranching business. This paper sets out to do this by first defining the different levels of management and the role of strategic management in particular. It then describes the role strategy tools play in strategic management with specific reference to the Balanced Scorecard, relating it to the multiple perspectives typical of farming and ranching businesses.

\section{Strategic Management}

The three levels of management that occur in farming and ranching businesses (described in Table 1) are operational (technical), tactical (middle management), and strategic (leadership). ${ }^{1}$ Operational management focuses on specific activities, and the outcome of the best operational managers (be they cowboys, fencers, tractor drivers, or electricians) is excellence. Their expertise is their power over employers and

This article has been peer reviewed. peers. Tactical management, on the other hand, determines within-year adjustments to a farm strategy (policy) so that it fits with the prevailing circumstances. Tactical managers need to deliver consistent results, a "no surprises" outcome, devise processes and systems that will enable resources to be efficiently organized, and use their authority to get things done. The final level is that of strategic management, which encompasses the leaders of the business. A distinction that is often made between managers and leaders is that it is the managers who improve the efficiency of the business and the leaders who improve its effectiveness. ${ }^{2}$ The best strategists are the big picture people and their outcome is not status quo but positive change. They make this happen through influencing others to buy into their dreams. Strategic management is different from other levels of management in several ways: it is nonroutine; nonprogrammable; unique and creative; ${ }^{3}$ more ambiguous, uncertain, and complex; ${ }^{4}$ and yet it has the greatest impact on the future of the business. ${ }^{5}$ Strategy defines the logical case for how value will be created for shareholders, and it defines actions and resource use. Inevitably, it is based on a set of assumptions about the future that must be put to the test.

Porth suggests that the strategic management process (Fig. 1) includes five interrelated tasks: to develop a mission

\section{Table 1. Levels of management ${ }^{1}$}

\begin{tabular}{llll} 
& Technical & Management & Leadership \\
\cline { 2 - 4 } Outcome & Excellence & Consistent results & Positive change \\
Focus & How (hands) do & What (head) organizes & Why (heart) dreams \\
Power & Expertise & Authority & Influence \\
Levels & Operational & Tactical & Strategic
\end{tabular}




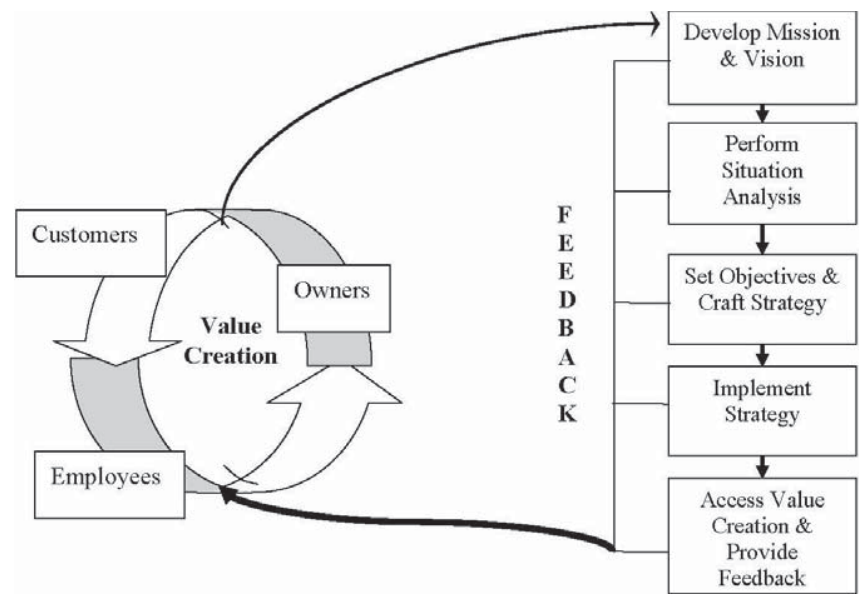

Figure 1. The strategic management framework. ${ }^{6}$

and a vision, to perform a situation analysis (internal and external audit), to set objectives and to craft the strategy, to implement the strategy, and to assess value creation and provide feedback. He suggests that the ultimate purpose of each of these tasks is to create value for the company's key stakeholders: employees, customers, and owners. ${ }^{6}$ The process illustrated in Figure 1 might appear to be a defined and formal process but in practice it can be haphazard and informal. ${ }^{7}$

The key words describing strategic management are summarized below: ${ }^{8}$

1. Continuous: the plan is not the final product

2. Systematic: the process has a deliberate and specific methodology and sequence of events

3. Process: the value of planning lies more in the journey than the destination, and from teamwork, vision, and commitment gained through the process

4. People: the process must involve the right people

5. Decisions: decisions must be made; as a result "decisionmaking is the most significant activity engaged in by managers"

6. Outcomes: the effects of the business on its customers and the outside world

7. How outcomes are to be accomplished: selecting the right road

8. How success is measured and evaluated: the plan will describe intended future outcomes either quantitatively or qualitatively, and it always defines criteria for success

In a larger organization it is expected that leadership is delivered by the CEO and the Board of Directors, management is delegated to the senior and middle managers, and operational issues are delegated to staff at the "coalface." In smaller companies such distinctions, although still relevant, can be lost. It is easy to understand how the most frequent issues that, by definition, are operational ones can dominate over less frequent ones. There sometimes is a strong focus at the operational and, sometimes, the tactical level of the business, and a weak strategic focus. ${ }^{1,9}$ These businesses run the risk of falling into the trap of being very efficient at getting the wrong job done.
To belittle ranch or farm managers for having this shortterm focus is to misunderstand the complexity of their role. Operational and tactical management are essential skills on all ranches and must be mastered. If the business is small, it is they who must master them, because delegation cannot occur. However, they must also deliver to the dream that they and their family have, so leadership skills are essential. Recognizing how their operational and tactical activities deliver to that dream by determining the cause-and-effect relationships that exist is an acquired activity.

\section{The Importance of Vision}

Although it is not the purpose of this paper to describe in detail the strategic management process, it is relevant to dwell for a moment on the "mission and vision" stage. There is significant debate in the literature as to what constitutes a mission and a vision. For family businesses, this author prefers to take the approach of ensuring the core values of the business (and family) are understood and reconciled before defining what they term the "organizational purpose." ${ }^{4}$ Family businesses frequently have stakeholders with opposing value sets. Thus it is important that those differences are recognized before a value set relevant to the business is devised. Gasson lists a number of goals and values commonly found in farming family businesses and groups them into four categories as follows: ${ }^{10}$

1. Instrumental (business) values: where farming is viewed as a means of obtaining income and security with pleasant working conditions

2. Social values: where farming is undertaken for the sake of interpersonal relationships in work

3. Personal (expressive) values: where farming is a means of self-expression or personal fulfilment

4. Intrinsic (lifestyle) values: where farming is valued as an activity in its own right

Studies of farmers' goals and objectives discussed by Gasson and Errington have shown that intrinsic aspects of being a farmer typically are ranked higher than the instrumental aspects. They conclude that autonomy, independence, survival, and succession thus mingle with the more orthodox economic issues. ${ }^{11}$

Examples of vision statements from New Zealand farms are shown in Table 2 . Note how clearly the differing value sets become obvious from the words they have chosen to use.

\section{The Balanced Scorecard as a Key Part of Strategic Management}

The shift from the industrial economy towards an economy characterized by intangible assets, such as knowledge and innovative capability, has increased the levels of complexity, mobility, and the uncertainty that organizations face. Atkinson summarizes that the transformation from the industrial age to the information age is signalled by increasingly sophisticated customers and management practices, escalating globalization, more prevalent and subtle product differentiation, and an emphasis on intellectual capital and enhanced 
employee empowerment. ${ }^{12}$ A range of new strategy tools and performance measurement frameworks have evolved to assist strategy implementation. Nonfinancial measures have combined with or replaced traditional financially oriented metrics as strategic controls providing useful short-term targets on the long-term strategic road. ${ }^{13}$

One such tool, the Balanced Scorecard, is described by Atkinson as arguably the dominant framework in performance management. ${ }^{12}$ Devised by Kaplan and Norton, it was proposed as an approach to tracking a firm's performance that takes into account process, innovation, and customer objectives as well as the financial position. ${ }^{14}$ In working with the scorecard they also found it performed an integrative function by bringing together disparate measures in a single report, and hence helped the senior management team to clarify and operationalize strategy. ${ }^{15}$ They identified significant weaknesses in performance management systems at that time that were dominated by short-term, backward-looking, or "lag" financial metrics which were internally oriented and not linked to organizational strategy. ${ }^{12}$ Based on case study research of leading companies, they concluded that financial numbers alone were no longer sufficient to run a business effectively because they lacked predictive power. They devised a scorecard with four perspectives that permitted a balance to be struck between short- and long-term objectives; between desired outcomes and the performance drivers of those outcomes; and between hard objective measures and the softer, more subjective, measures. ${ }^{8}$ In response to the tension that exists between the rigor necessary for effective strategy implementation and the flexibility required for timely strategic adjustment ${ }^{12}$ they also claimed that the Balanced Scorecard "...provides a framework for managing the implementation of strategy while also allowing the strategy itself to evolve in response to changes in the company's competitive market and technological environment..."16

The Balanced Scorecard has been so effective and widely accepted that the Harvard Business Review hailed it as one of the most influential management ideas of the 20th century. ${ }^{17}$ The first book of the series describing the framework has translations into more than 18 languages.

\section{Balanced Scorecard Framework}

According to Kaplan and Norton, a Balanced Scorecard should have the following components: ${ }^{16}$

Core vision: The value-based purpose that strategy delivers to the organization.

Perspectives: There are typically four perspectives: learning and growth, internal processes, customer, and financial. Others can be added based on specific needs. A perspective often represents a stakeholder category or point of view.

Objectives: An objective states how a strategy will be made operational. They usually form the building blocks for the overall strategy of the organization.

Measures: They must be quantifiable. They communicate the specific behavior to achieve the objective and become the
Table 2. Vision statements of several New Zealand family farm businesses

- To pursue excellence and growth in sustainable agriculture, thereby providing for diversification, succession, and a continuously improving standard of living for all stakeholders in the business.

- To have a farm business that is growing, is financially profitable, and is environmentally sustainable, while enabling us to maintain our lifestyle and enjoy time with our children and friends and continue our involvement in the community.

- To increase sustainable net income by being a preferred supplier of high-quality milk and dairy livestock, by adopting excellence in farm management practices and technologies, and by developing beneficial partnerships with our team of staff, while embracing the values of integrity, honesty, and the pursuit of knowledge.

- To grow the family farm business by profitably marketing quality products to ensure that the future generation has a viable farming business.

actionable statement of how the strategic objective will be accomplished. Lead measures are predictors of future performance (drivers), whereas lag measures are outcomes.

Strategic initiatives: These activities (discretionary investments or projects) will focus on the attainment of strategic results. All initiatives in an organization should be aligned with the strategy in the Balanced Scorecard.

Cause and effect linkages: It is similar to "if-then" statements. These cause-and-effect linkages should be explicit.

With each perspective Kaplan and Norton pose a question:

- Learning and Growth: "To achieve our vision, how will

we sustain our ability to change and improve?" This infers of course, that the business does have an ability to change and improve; for some, developing that skill might be the first initiative. The focus here is on the capacity of the business to learn and grow, improve its flexibility, and invest for future development.

- Internal Business: "To satisfy our shareholders and customers, what business processes must we excel at?" The question prompts the business to define critical skills and core competencies, processes, and technologies, both current and still to be developed.

- Customer: "To achieve our vision, how should we appear to customers?" How the customer currently perceives the business must be known before any improvement is targeted.

- Financial: "To succeed financially, how should we appear to our shareholders?" The impact of performance on traditional financial measures such as return on capital and cash flow, shareholder value and shareholder satisfaction are emphasised in this final perspective. ${ }^{16}$

Some authors suggest having only four perspectives is a weakness in the Balanced Scorecard. Haapasalo et al. identi- 


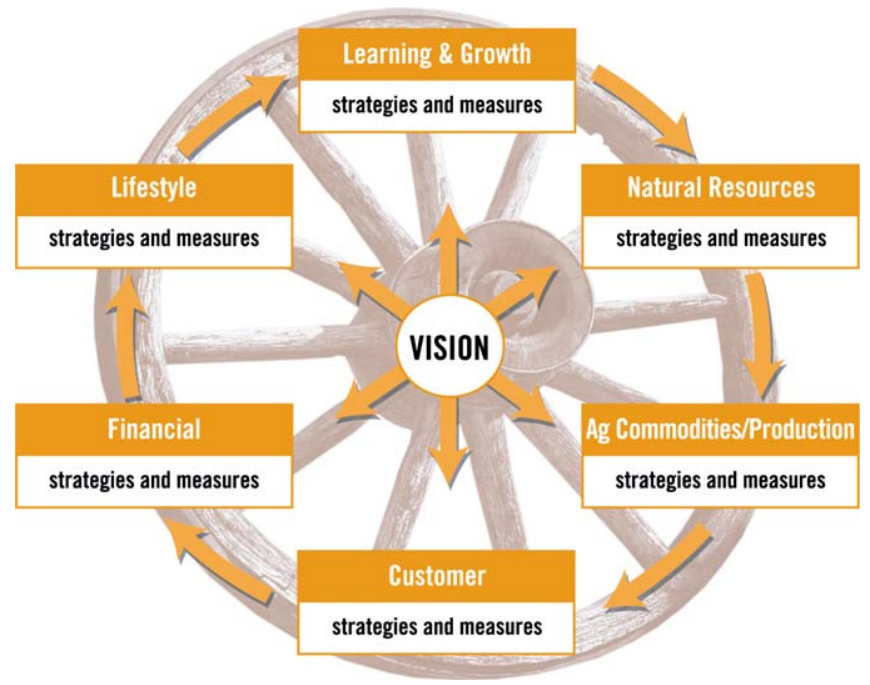

Figure 2. Relationships between parts of the Balanced Scorecard. ${ }^{23}$

fied additional perspectives such as human resources, environmental and supplier perspectives, and innovation processes, and then explained how each can be included in one or two of the original perspectives. ${ }^{8}$ Gifford added a fifth "core values" perspective. ${ }^{18}$ Russell added a supplier perspective in automobile companies. ${ }^{19}$ Similarly, Creelman emphasizes that organizations should not blindly adopt the normal four Balanced Scorecard perspectives, but rather choose the number of perspectives that reflect their own strategic needs. ${ }^{20}$ Some organizations have expanded or changed the basic model to include other perspectives relating to their business type (examples of this in the Finnish energy sector were found by Haapasalo), ${ }^{8}$ the community, or society. Others have changed the order of the perspectives. For example, not-for-profit organizations have reversed the roles of the financial and customer perspectives as the latter more accurately reflects their objectives. ${ }^{21}$ Working with on-farm agribusinesses Shadbolt et al. found that an extension of the customer perspective to include the suppliers (more of a supply chain approach) was relevant, as was an extension of the shareholder/financial perspective to include nonfinancial shareholder goals such as lifestyle and environmental/ethical issues. ${ }^{22}$ Dunn captured these issues by suggesting six perspectives suitable for ranch strategic management (Fig. 2) to ensure the lifestyle and environmental (natural resources) aspects of the business were given equal weight with the more traditional financial, livestock production, customer, and learning and growth. ${ }^{23}$

Therefore, the Balanced Scorecard allows executives to manage a company from several perspectives simultaneously. Shadbolt states it has evolved into a useful framework because it forces the perspectives of human resources (innovation, continuous improvement, and learning), internal processes (turning inputs into outputs), the market (customer relationships, product, and service criteria), and shareholders (profitability, return on assets, wealth, nonfinancial, and ethical goals) to be explored and the linkages between them to be determined. ${ }^{24}$ The term "Balanced Scorecard" reflects the balance between short- and long-term objectives, financial and nonfinancial measures, lag and lead indicators, and external and internal performance perspectives. ${ }^{25}$ It provides a balanced organizational assessment by recognizing a variety of stakeholder views.

The Balanced Scorecard design process builds upon the premise of strategy as hypotheses. Strategy implies the movement of an organization from its present position to a desirable but uncertain future position. Because the organization has never been to this future position, its intended pathway involves a series of linked hypotheses. The scorecard enables the strategic hypotheses to be described as a set of cause and effect relationships that are explicit and testable. ${ }^{26}$ An example of this for on-farm agribusiness was given by Shadbolt as she described how the assumptions made of the cause and effect relationship between process (farm practices) and state (environmental impacts) indicators could be explored. ${ }^{24}$

Having a sound vision for the business is the key to the success of the Balanced Scorecard. ${ }^{8}$ As already stated, a common vision is a challenge in farm family businesses where conflict often exists between business and family visions and purpose. ${ }^{10} \mathrm{~A}$ solution proposed by Andersson was separate visions for business and for farm family lifestyle issues and to add a fifth perspective to the Balanced Scorecard, called "life." ${ }^{27}$ However, having two visions could be divisive and lead to family business dysfunction. Atkinson identifies from the literature that in all businesses, regardless of size, strategic change requires a shared vision and consensus; failures are inevitable if competence, coordination, and commitment are lacking. ${ }^{13}$

The absence of goals or abundance of goals in any perspective gives a quick, visual indication of whether the business is "in balance." Key metrics are also specified for each goal, and include both the outcomes (lag indicators) and the drivers (lead indicators). If too many metrics are defined in a Balanced Scorecard, it too quickly turns from a management system into a monitoring system. If it is to be used effectively as a management tool with strategic purposes, the number of metrics must be low. ${ }^{8}$ Nonfinancial measures are usually drivers, informing the manager of likely future performance. For example, learning new knowledge and skills, a lag indicator for learning and growth, is a lead indicator of the farm staff's ability to ensure best practices at "harvest" are in place. ${ }^{22}$ Without investment in staff learning and personal growth, the business has less ability to deliver to the productquality specifications identified in its customer-related goals. The under-utilization of nonfinancial key performance indicators in business control was one of the key findings that led to the development of the Balanced Scorecard by Kaplan and Norton. ${ }^{14}$

\section{Making the Balanced Scorecard Work}

Knott defines the Balanced Scorecard as a strategy tool that involves substantial commitment of people and funds and 


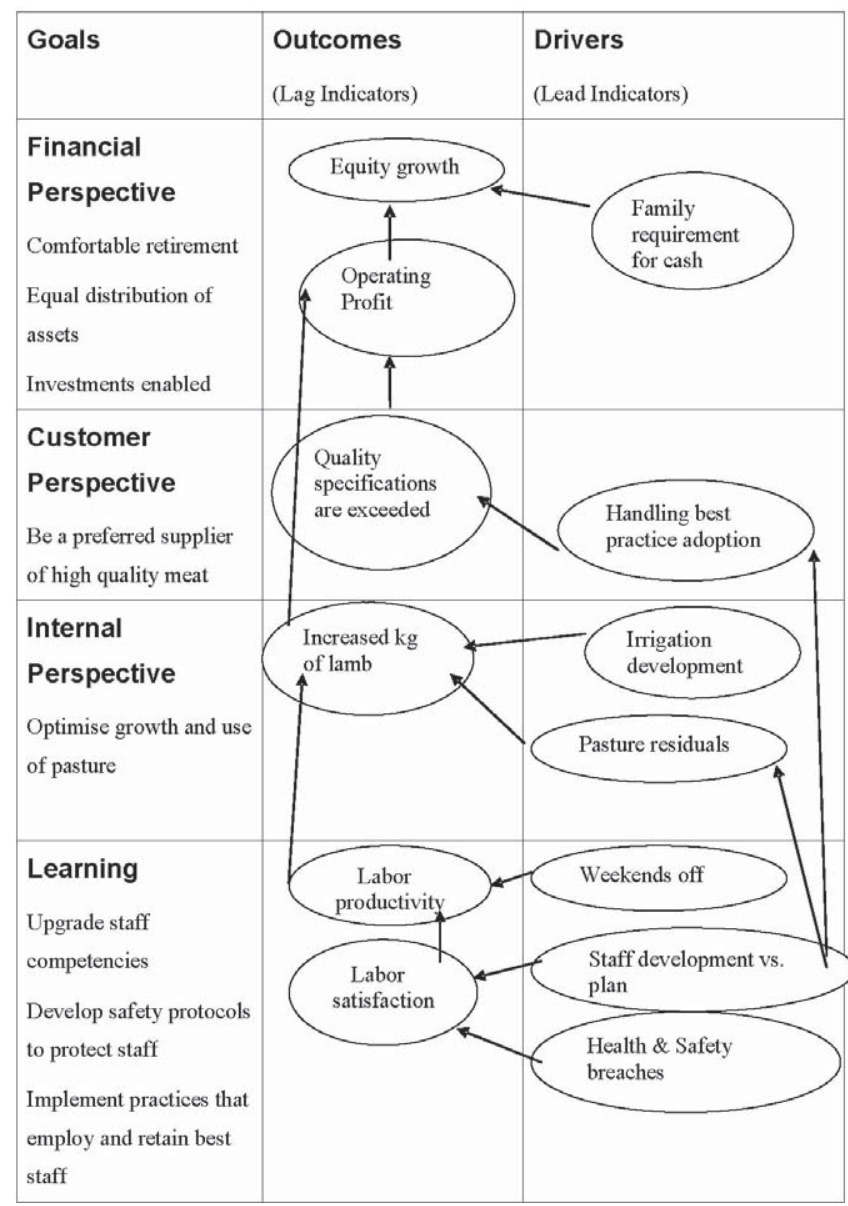

Figure 3. Balanced Scorecard for a pastoral farm business. ${ }^{28}$

has organization-wide implications. ${ }^{15}$ It requires systematic strategic planning activity and an holistic approach. Kaplan and Norton suggested the Balanced Scorecard be viewed as a template not a straitjacket so that it has flexibility and adaptive capacity. ${ }^{16}$ Knott suggests that flexibility and adaptive capacity is critical to its successful application in an organization. ${ }^{15}$

The Atkinson review on the role of the Balanced Scorecard in strategy implementation identifies some critical aspects to making it work: ${ }^{12}$

1. Begin with a full strategic appraisal and a clear articulation of the organization's strategic vision and objectives. This builds consensus and engenders learning.

2. Make explicit the cause and effect of a strategy. Convert strategic aims into tangible objectives and measures and identify where they interlink.

3. Implement the Balanced Scorecard participatively with measures identified and targets set cooperatively rather than imposed. This supports organizational learning and reflection and encourages interactive control through the testing of cause-and-effect relationships.

4. Encourage Balanced Scorecards at every level of an organization to enable middle-management engagement. Haapasalo et al., in their observation of Balanced Score- card in use in the energy sector, concur on the above and also add the necessity for each company to create its own metrics. If this is not done, the link to strategy can disappear and the connection to management is lost. The metrics must also evolve as the organization changes. They state there should be profound discussion over different perspectives; again the advice is to determine what is right for each company-do not use other company or industry lists. They state one of the most important aspects of implementing the Balanced Scorecard is the learning process inside the organization as it facilitates in-depth discussion about the business' vision, strategy, and critical success factors and translates them into specific measures and objectives in action. ${ }^{8}$

When applied to on-farm agribusinesses it has proven to provide an acceptable framework with which to capture the more holistic nature of farm systems and enable both financial and nonfinancial (including nonbusiness) goals to be managed. ${ }^{1,22}$ Shadbolt further suggests how, in a policy context, it can provide a framework to enable a specific plan, such as an environmental plan, to fit within the overall business. ${ }^{24}$

Figure 3 provides an example of a scorecard for a pastoral farm business in New Zealand. ${ }^{28}$ The simplicity of the scorecard should not be taken as being an indication of lack of in-depth discussion and debate on strategy and metrics, but instead as an illustration of how it can be a useful report that clarifies and operationalizes strategy. It illustrates the causeand-effect relationships and how they build from each level. The starting point is learning and growth. Without human capability and capacity strategy cannot be implemented. It then leads to the management of natural resources and production through which market needs are met. The result of meeting these needs is that financial targets are met and this, along with other nonfinancial outcomes, delivers to the lifestyle requirements of the family.

\section{Conclusions}

It is important to recognize that a strategy tool such as the Balanced Scorecard is likely to assist with part of the activity rather than provide a substitute for the capabilities and experience of the manager. It does not provide a blueprint, but can act as a guide to thinking and a starting point for structuring the activity. ${ }^{15}$ There is a risk that the tool or framework that a manager uses will channel or constrain thinking as it focuses and guides, in which case alternative tools or adaptation of the tool might be required to ensure robust strategy is crafted. Users of the Balanced Scorecard should keep this in mind; the tool is not a recipe for success but a means by which a business can assess its direction, craft strategy, and define success. Its application will vary from ranch to ranch according to the skills and motivation of the owners and managers. For some it might just guide thinking and debate. For others it will provide a framework that can enable planning greater detail on implementation and ongoing control.

The framework the Balanced Scorecard provides enables the components of strategy to be identified and the interac- 
tions between the components to be visualized. It forces goals to be linked to the vision and actions to be linked to goals. It enables ranch businesses to look beyond finance and production to include multiple perspectives. Ranchers must not only define how success is measured in the Balanced Scorecard but also what the drivers of positive change really are-what are the cause and effect relationships in the business. And, finally, to make best use of the Balanced Scorecard, keep it flexible, simple, and practical.

Author is Senior Lecturer in Farm and Agribusiness Management, Massey University, Palmerston North, New Zealand, N.M.Shadbolt@massey.ac.nz.

\section{References}

1. Shadbolt, N. M., and M. Rawlings. 2001. Successful benchmarking by balanced planning and identifying key performance indicators for goal attainment in dairy farming. Melbourne, Victoria, Australia: Dairy Research and Development Corporation (Australia). Project Code: MUNZ001. 238 p.

2. Duncan, W. J. 1999. Management: Ideas and actions. New York, NY: Oxford University Press. 226 p.

3. Harrison, E. F. 1999. The managerial decision making process. Boston, MA: Houghton Mifflin. 555 p.

4. Johnson, G., K. Scholes, and R. Whittington. 2005. Exploring corporate strategy: Text and cases. 7th ed. London, United Kingdom: Pearson Education Ltd. 1033 p.

5. Shadbolt, N. M., and A. Bywater. 2005. The dimensions of management. In: Farm management in New Zealand. N. M. Shadbolt and S. Martin S. [eds.]. Oxford University Press. 424 p.

6. Porth, S. J. 2003. Strategic management: A cross-functional approach. Upper Saddle River, NJ: Prentice Hall. 266 p.

7. Cuthbert, R. H., and T. R. R. Johnston. 1997. The strategic planning process of agricultural niche marketers: A case study approach. In: Proceedings of the 11th International Farm Management Congress; 1997. Calgary, Alberta, Canada: University of Calgary. p. 961-975.

8. Haapasalo, H., K. Ingalsuo, and T. Lenkkeri. 2006. Linking strategy into operational management. Benchmarking: An International Journal 13(6):701-717.

9. Doonan, B. M. 2001. Strategic planning in the dairy industry - the Tasmanian experience. Proceedings of the South Africa Large Herds Conference. Port Elizabeth, South Africa; 5-7 February 2001. p. 27-42.

10. GAsson, R. 1973. Goals and values of farmers. Journal of Agricultural Economics 24:521-537.

11. Gasson, R., and A. Errington. 1993. The farm family business. Wallingford, UK: CAB International. 300 p.

12. Atrinson, H. 2006. Strategy implementation: a role for the balanced scorecard? Management Decision 44(10):1441-1460.
13. Bungay, S., and M. Goold. 1991. Creating strategic control systems. Long range planning 24(3):32-39.

14. Kaplan, R. S., and D. P. Norton. 1992. Using the balanced scorecard as a strategic management system. Harvard Business Review 70(1):71-80.

15. Knotт, P. 2006. A typology of strategy tool applications. Management Decision 44(8):1090-1105.

16. Kaplan, R. S., and D. P. Norton. 1996. The balanced scorecard-measures that drive performance. Harvard Business Review 74(1):1-9.

17. Siввет, D. 1997. 75 years of management ideas and practices 1992-1997. Harvard Business Review 75(5):2-13.

18. Gifford, J. D. 2000. Small orange juice processor gets big results with the balanced scorecard. Balanced Scorecard Report 2(5):8-10.

19. Russell, R. 2003. The international perspective: balanced scorecard usage in Europe. Balanced Scorecard Report 5(3):13-14.

20. Creelman, J. 1998. Building and implementing a balanced scorecard-international best practice in strategy implementation. London, United Kingdom: Business Intelligence Ltd. $362 \mathrm{p}$.

21. Atkinson, A., And M. Epstein. 2000. Measure for measure: realizing the power of the balanced scorecard. CMA Management 74:23-28, September.

22. Shadbolt, N. M., N. Beeby, B. Brier, and J. W. G. GardNER. 2003. A Critique of the use of the balanced dcorecard in multi-enterprise family farm businesses. Proceedings of the 14th International Farm Management Congress; 10-15 August 2003; Perth, Australia. Part 1, p. 602-609.

23. Dunn, B. H., R. N. Gates, J. Davis, and A. Arzeno. 2006. Using the balanced scorecard for ranch planning and management: setting strategy and measuring performance. Brookings, SD: South Dakota State University. EC922. 30 p.

24. Shadbolt, N. M. 2004. Agri-environmental indicators put into perspective: their fit and relationship with other relevant farm business indicators. In: N. Fraser [ed.]. Farm management indicators and the environment. Proceedings of an OECD Expert Meeting; March 2004; Palmerston North, New Zealand.

25. Hepworth, P. 1998. Weighing it up - a literature review for the balanced scorecard. Journal of Management Development 17(8):559-563.

26. Kaplan, S. R., and D. P. Norton. 2000. The strategy-focused organization: How balanced scorecard companies thrive in the new business environment. Boston, MA: Harvard Business School Press. 400 p.

27. Andersson, P. 2002. Competence development program for the farmer with reference to life as well as business. Proceedings of the 13th International Farm Management Association Congress, 7-12 July 2002; Wageningen, The Netherlands.

28. Shadbolt, N., and S. Martin. 2005. Farm management in New Zealand. New York, NY: Oxford University Press. 119 p. 


\section{Understanding Learning Styles in Order to Meet Educational Objectives}

\section{By John E. Ford}

$\mathrm{P}$ robably no industry has perpetuated the myth of slow-to-change and reluctant-to-embrace new ideas and technologies than the agricultural sector. Within agriculture, ranching is the segment most perceived to be "set-in-its-ways." In part, this is because ranching families with long histories in beef production are committed to ranching not only as a livelihood but also as a way to preserve family heritage and traditions. Undoubtedly that very respect for tradition gives the perception that change is slow to occur in the ranching community where the retention of traditional practices are often viewed as outdated even when efficient and fully profitable.

Nonetheless, few businesses have made the advances witnessed in beef production over the past half century. Changes in operation methodologies, growth of feedlots and the feeding industry, and use of Expected Progeny Differences (EPDs) and DNA-based biotechnology provide compelling examples. These changes have not come easily. Of course, change often does not come easily in most established industries. History is littered with the past remains or memories of businesses that, for whatever reason, did not change or were slow to change in response to innovation, new markets, production differentiation and consumer desires, and more nimble and/or less risk averse competitors. For example, one should consider Montgomery Ward, the retail giant of the early to mid-20th century. This mail-order "department store" was a success by marketing a large selection of goods to rural America, yet was unable to respond to changing consumer demands or the pressure of its competitors as America became a more mobile urban populace. ${ }^{1}$

How does change come about? Change in business comes from a need, real or perceived. The need can be internal to a ranch and its operations, such as the desire to see increased

This article has been peer reviewed. calf weaning weights. Likewise, the need might arise from external pressures, such as consumer demands for a more uniform, consistent product. Regardless, addressing needs invariably initiates research, experimentation, education, and finally change or implementation. Although all of the aforementioned steps are important in realizing positive change in the ranch environment, education could very well be the key component. Changed practices must be understood from the technical, practical, and financial standpoint before successful incorporation into a production or management setting.

\section{The Role of Education in Ranching}

Education is more than an agent of change on the "production line." Education is essential for the development, maintenance, and growth of the value of human capital. Edward Prewitt cites research indicating that pay is not the most critical factor in employee satisfaction. ${ }^{2}$ Rather, the opportunity to learn and use new skills is much more important in attracting, retaining and motivating employees. Marilyn Mahugh states, "Continuous professional development is part of what makes up a rewarding work environment." (p. 2) Those businesses that remain competitive in today's quickly changing world are those entities that realize their workforce, in addition to their products or services, provide the competitive edge and financial success. Providing opportunities for employee learning, development, and growth contributes to improved individual and organizational performance.

Today, there are no shortages of learning opportunities for those involved in the ranching industry. The "information age" has broken down barriers from rural and remote settings such that isolation is no longer a hindrance to continuing education. Utilization of internet websites and subscriptions to industry publications bring information directly to the ranch, home, or office regardless of the zip code. State cooperative extension services, USDA Natural Resources Con- 
servation Service, universities, and community colleges provide educational opportunities in both a formal and informal setting. Industry-sponsored field days and short courses also can provide timely information on new technologies. Participation in trade and professional organizations allows for an exchange of ideas and information. However, attending or participating or enrolling an employee or managerial decision maker in one of the numerous educational opportunities does not guarantee that the learning and growth perspective of the ranch's management plan will be met.

What are the steps that a ranching enterprise should undertake to foster an atmosphere of learning that contributes to the well being of the ranch and personal and professional growth of its employees? Ranch management has to be committed to the "learning workplace" where continued education is the rule rather than the exception. Ranching is a time-consuming endeavor; however, lack of time is not an acceptable constraint to learning. Allowing employees release time for continuing education is essential. This does not mean that the doctor crew is to be sent to a field day when a load of fresh yearlings is scheduled to arrive. However, they should be encouraged to participate in an educational program after the last load of yearlings has been shipped. Cost should not be a constraint to developing an educational strategy. Funding, or at the least a sharing of training cost, reinforces that the ranch is committed to continuing education. ${ }^{4}$

The first step in formulating a professional development program should be inventorying the knowledge base of the ranch family and workforce. A successful continuing education program is developed after the ranch's strengths, weaknesses, and needs have been identified. The ranch manager must also realize that not all members of the ranch family learn in the same way. We all have different learning styles and the manager that recognizes this constraint can guide the employee to those learning tools and experiences that will best help the ranch meet its goals and enhance professional development. Understanding generational diversity and its implication on adult learning is of key importance.

\section{Generational Learning Styles}

A generation is a group of people who share the same place and time in history. Because of this shared space in time they have experiences in common and a similar view of the world and how things should be. ${ }^{5} \mathrm{~A}$ generation is considered to be approximately 20 years in length. Factors that influence and motivate one generation can be quite different from those that influence and motivate another generation. Today, there are four major generational groups that make up the workforce: Traditionalists are those 65 years and older; Baby Boomers are 46-64 years of age; members of Generation X were born between 1961 and 1981; and lastly Generation Y, sometimes referred to as "Nesters" or "Millenials," were born after 1982. Because the factors that influence and motivate each generation vary, a teaching style or delivery method that successfully conveys its message to a member of the Baby
Boom generation might be quite lost on a member of Generation $\mathrm{X}$. Understanding that generational learning patterns and educational needs differ allows ranch decision makers to develop effective educational strategies.

Traditionalists are loyal and hard working. Their view of the world was formed by events such as the Second World War and Korean War. They have great respect for authority and are detail-oriented. Traditionalists began their careers with the intention of remaining with the same employer until retirement. In their view, changing jobs carries a stigma. ${ }^{6}$ Even though this group and early Baby Boomers are the fastest-growing group of internet users, this generation learns better by interacting directly with people, not through impersonal media such as computers. ${ }^{6}$ Field days, extension educational meetings, and short courses that allow for social interaction in a relaxed atmosphere provide a learning environment that is most comfortable for this generation. Members of this pre-television generation can be widely read; therefore, printed materials that allow for additional review will aid or accelerate the learning process. Accordingly, outreach to this generation might best be met by providing printed material. Trade publications, extension publications, and professional journals are good educational tools for Traditionalists. It is likely that the ranch patriarchs are of this generation. Educational needs might focus around estate management and planning, information that will assist in transitioning the ranch to the next generation.

Baby Boomers were raised in an era of extreme optimism and progress. ${ }^{5}$ They grew up in a post-war, financially stable environment created by Traditionalists. Many are ambitious and driven. Baby Boomers want to succeed. They want to build stellar careers, and this generation considers a job change as a detour in their climb to the top. ${ }^{6}$ Boomers want to be in charge of their learning. They value learning experiences that provide a skill or knowledge that can be integrated into their everyday work. ${ }^{2}$ In other words, the subject matter being taught must have practical value. They enjoy social interaction and want a chance to show what they know. Baby Boomers like a structured approach to learning. Community college courses, extension short courses, field days, and symposia provide Baby Boomers with a structured setting and the opportunity for interaction. Members of this generation are in, or are assuming, managerial roles. Educational needs might center on capital acquisition management, financial planning, or other areas related to growing the ranching enterprise.

The average age of all US principal farm operators in 2002 was 55.3 years of age, with the average age for beef producers being 56.7 years. ${ }^{7}$ These data indicate that the majority of beef producers are Traditionalists or Baby Boomers and therefore many educational opportunities are designed to best engage their learning styles. However, educational programming designed to meet the needs of Traditionalists and Boomers will not necessarily meet the needs of Generation $\mathrm{X}$ and Generation $\mathrm{Y}$.

Members of Generation $X$ formed their view of the world during post-Vietnam and Watergate. ${ }^{5}$ They tend to be in- 
dependent and somewhat cynical. Generation $\mathrm{X}$ views job changing as necessary. ${ }^{6}$ Similar to Baby Boomers, they want information to be specific and geared to practical outcomes. Social interaction with others is not as necessary; they understand technology and expect that it be utilized. They prefer to work independently with self-directed projects. Internet, website, and distance learning provide the type of learning opportunities that best meet the needs of Generation X. Members of Generation X consider reading time consuming; therefore, information from printed material needs to be summarized into bulleted or annotated format.

The youngest members of the workforce, Generation Y, were born into a high-tech world and the use of technology is almost instinctual. This generation considers changing jobs routine. ${ }^{6}$ Learning experiences must be interactive and fast-paced. As students, Generation Y members require frequent and instantaneous feedback. This newest work force generation is adept at multi-tasking; however, many members lack people or socialization skills. Surprisingly, Generation $\mathrm{Y}$ members are readers and will take the time to re-enforce knowledge learned through another process. As would be expected, internet and website, interactive, and hands-on learning best suit members of Generation Y. However, short attention spans require that learning opportunities be supervised, structured, and fast-paced. This is the 30-second sound-bite generation geared to information uptake on the scale of a television commercial.

Due to their age, Generations $\mathrm{X}$ and $\mathrm{Y}$ are probably the most familiar with the day-to-day field operations of the ranch, and are looked to for production-related decisions, and are often expected to assist with labor. Educational needs focusing on increased production (forage, beef, and wildlife) or management tools that lead to an increase in production might best fit the learners and the ranch's overall needs.

\section{Educational Strategies for Ranches}

Regardless of the generation, adult learners retain what is relevant to them and what they need to be successful at their job. Adults are motivated to learn if they see where new knowledge can be applied. ${ }^{8}$ Placing the right member of the ranch staff in the right educational situation is the first step to a successful learning and growth strategy. Communication among coworkers is an important part of the learning and growth perspective. ${ }^{9}$ For the learning and growth perspective to be successful, ranch decision-makers must encourage a free flow of information between coworkers. According to business consultant Nancy Ahlrichs, continuous learning is not sufficient, because employees also must be engaged in continuous teaching. ${ }^{5}$ Communication between co-workers about knowledge obtained at a cooperative extension short course not only expands the knowledge base but helps reinforce knowledge learned. In addition to expanding the knowledge base, this communication or teaching helps employees cement the knowledge they have just acquired. Helping a member of the ranch team cement knowledge is as simple as asking them to demonstrate proper vaccination techniques learned at a Beef Quality Assurance program.

\section{Conclusions}

A ranch's learning and growth goals can be set and measured by the number of educational activities and programs attended or the number of practices implemented due to the acquisition of new knowledge. However, developing action items and goals that measure employee satisfaction and motivation in reality have a greater impact on the ranch's bottom line. Adult learning research suggests that the most successful professional development is that which is sustained over time. Setting a goal to implement a program to review yearly professional development and its impact on ranch practices sends the message that members of the ranch family are valued team members and workplace growth is an expectation. By doing so, continuous education becomes the normative practice, employee satisfaction level remains high, and the ranch has the most current and relevant information, insuring that it has the tools in place to remain a competitive enterprise.

Author is County Extension Agent-Agriculture, PO Box 1119, Kingsville, TX 78363, je-ford@tamu.edu.

\section{References}

1. Guy, S. 2000. End of line for Ward stores, Chicago institution is closing after 128 years; 37,000 lose jobs. Chicago Sun-Times p 33, December 29.

2. Prewitt, E. 1999. How to keep your company's star employee. In: P. Michelman, L. Gray, and A. Herrin [eds.]. Retaining your best people. Boston, MA: Harvard Business School Press. p 62-69.

3. Mahugh, M. 2004. The Ethic of Lifelong Learning. Stanford Nurse 24(2): 2.

4. McGrann, J. M., F. DeLans, and D. McCorkle. 1999. Farm and ranch personnel Management. Manhattan, KS: Kansas State University. 4 p.

5. Moore, B., And S. TAylor. 2004. Learning to work with generational diversity. Stanford Nurse 24(2): 3-5.

6. Gleeson, P. B. 2003. Managing and motivating the generations: Implications for the student and the employee. Texas Woman's University and Matrix Rehabilitation. Available at: http://www.uwsp.edu/education/facets/links_resources/4413. pdf. Accessed 6 March 2007.

7. Allen, R., And G. Harris. 2006. What we know about the demographics of U.S. farm operators. Agricultural Outlook Forum 2005. Available at: http://www.nass.usda.gov/census/ census02/otheranalysis/demographicpaper022505.txt. Accessed 6 March 2007.

8. Zемке, R., And S. Zемке. 1984. 30 things we know for sure about adult learners. Innovation Abstracts 6(8):1-4, March 9.

9. Kaplan, R. S., and D. P. Norton. 1996. Learning and growth perspective. In: H. Heimbouch [ed.]. The Balanced Scorecard. Boston, MA: Harvard Business School Press. p 126-146. 


\section{Natural Resources Perspective of the Balanced Scorecard: Balance and Boundaries}

\section{By Sean P. Kelly and Rob Ravenscroft}

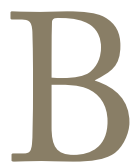

alance is defined as "a harmonious proportion of elements in a design." 1 (p. 45) Finding balance is difficult in any business. Finding balance within a ranch business can be extremely challenging. Several aspects of ranch must be brought into harmony to create a sustainable business. Some ranches might focus solely on cattle production and lose sight of the range and natural resources. The result can be poor range production following a drought. Some ranches might focus solely on the natural resources and cattle production and lose sight of the quality of life they are trying to achieve. The result might be that sons or daughters choose not to return to the ranch. Balancing livestock, rangeland resources, finances, and quality of life for a ranch that has a vision of sustainability and profitability is extremely important.

The Balanced Scorecard looks at a ranch from different perspectives with strategies and metrics for each perspective. Some examples of perspectives include: production, natural resources, financial, customers, and quality of life. The natural resources perspective is the foundation for all other perspectives of a ranch. The natural resources to a large extent also set the boundaries for each of the other perspectives on a ranch. These can include the soil, rangeland, wildlife, water, forage crops, and aesthetics. They also determine the number of cattle that can be stocked or the number of wildlife that can be sustained, as well as the amount of forage crops or hay that can be produced.

By determining the boundaries for the natural resources perspective, a ranch manager can unlock the potential and un-

This article has been peer reviewed. foreseen opportunities within other perspectives of the ranch business. For example, if a ranch manager determines that the ranch can support more livestock or wildlife due to increased rangeland production from proper stocking rates, this can generate more income and provide the opportunity for a son or daughter to return to the ranch. Or if a ranch manager determines there is potential for additional income from recreational activities, this decision can provide the opportunity for increased financial security and lower stress levels within the family. In any case, determining the bound-aries for the natural resources defines the limits of the ranch. However, the limits might be far beyond what was originally perceived, or they might be a fraction of what is currently being harvested.

This brings us back to the simple definition of balance: a harmonious proportion of elements in a design. For this discussion, think of the Balanced Scorecard as the "design" or plan for ranch management. The perspectives are the "elements" or essential components of the ranch business. Finding a harmonious proportion of each perspective is the challenge for every rancher today and for the future.

\section{Strategies and Metrics}

When determining strategies, a ranch manager usually is identifying and addressing needs for change. However, there are often features of the resource that should stay as they are. Whether for change or to encourage stability, strategies need to address the gaps between the present reality and the desired future defined in the vision. The following are some questions ranch managers might ask in order to develop strategies:

1) What can we control?

2) What do we want to keep? 
3) What don't we want to keep?

4) What do we need to change, or reach for?

5) What actions should we take?

These five questions can provide a powerful form of intervention for a ranch business. Asking and answering them causes management to think about their ranch at its very core. By going deeper and affecting the thinking and decision making of a ranch we are affecting the very structure of the ranch business. This can lead to the development of strategies with high leverage points that are long-lasting and self-sustaining for the ranch. ${ }^{2}$

When strategies are chosen, the next questions are:

1) What will indicate success?

2) What measuring tools can we use?

Each strategy will have metrics that can measure the success toward fulfilling each strategy and toward achieving the vision of the ranch. The metrics or indicators must be quantifiable, relevant to the operation, and easy to document. The metrics might be somewhat subjective; however, they should be both leading and lagging. Leading metrics are proactive and can trigger points for management action. Lagging metrics are historical and measure progress toward the strategies. ${ }^{3}$ The following are some examples of strategies and metrics (Table 1), but are not intended to be recommendations, because every ranching business will have its own unique strategies and metrics.

\section{Strategy 1: Flexible Stocking Rate That Equals Carrying Capacity Based on Current Growing Conditions}

Determining proper stocking rates and carrying capacity is the foundation for proper rangeland management. Stocking rates are a key leverage point that is entirely under a ranch manager's control. Regardless of the geographical location of the ranch, stocking rates that match the current carrying capacity of the rangeland should be a cornerstone for proper rangeland management. It's important to remember that carrying capacity is a variable figure and changes with growing conditions. A ranch manager should be aware of the carrying capacity of the ranch in both high and low precipitation years.

In order for the ranch manager to adjust stocking rates to match the carrying capacity, the manager has to be flexible with the stocking rates. Flexible stocking rates allow for rapid destocking in the event of a drought and rapid increase in stocking rates in wet years. Possibly changing to a $70 \%$ core cow herd and 30\% stocker operation will allow more flexible stocking rates. Also by having a mixture of classes of livestock, a ranch manager will have more marketing opportunities if stocking rates need to be adjusted. Networking and developing relationships with livestock order buyers or feedlots are other tools that can be utilized by ranch managers. Many livestock order buyers already have the vast network of connections with salebarns, feedlots, and other ranches if cattle need to be bought, sold, or moved quickly. They can also provide marketing advice in the event that cattle need
Table 1. Example strategies and corresponding metrics for the natural resources perspective of the Balanced Scorecard for a ranch

1. Flexible stocking rate that equals carrying capacity based on current growing conditions

- Maximum forage utilization $=60 \%$ except for "treatment" areas

- Cow BCS $=5$ at weaning

- Financial metrics $=$ positive

- Transects trend = positive

2. Drought management plan integrated into the overall ranch operation plan

- Implement when necessary

- Maximum forage utilization $=50 \%$

- Cow BCS $=5$ at weaning

- Transects trend = positive

- Was the drought plan successful?

3. Wildlife needs are part of grazing and investment plans

- Grazing, fire, chemical, and mechanical treatments applied as planned

- Prime grouse nesting areas ungrazed in May

- Bird and deer counts = goals

- Photo points and transects = trending toward goals

4. Maximize ability of watersheds to hold water

- Grazing is planned, executed, and adjusted to allow plants to recover from grazing

- Maximum forage utilization $=60 \%$

- Photo points show increasing riparian vegetation

- Photo points and transects show decreasing bare ground

5. Apply grazing, fire, chemical, or mechanical treatments to control brush or invasive species

- 3\% brush cover for targeted area

- Photo points show desired trend

- Maximum forage utilization $=60 \%$

- Increased stocking rates over time

- Bird and deer counts = goals

to be sold or bought quickly so the financial metrics of the ranch remain positive.

Monitoring the maximum forage utilization is a leading metric because it determines what stocking rates should be applied and will determine when stocking rates need to be adjusted. Forage utilization can be determined by ocular estimates, forage mapping, or by setting up exclosure cages. Ocular estimates should be used only if the manager has the required experience and knowledge of proper rangeland management. If a manager is not comfortable using ocular estimates, exclosure cages are a useful tool. A recording of 
the current stocking rate along with evaluating the health of the plant community inside and outside of the exclosure cage can help a manager determine the percent use of the rangeland. ${ }^{4}$ From these measurements a manager can then determine what adjustments need to be made to the stocking rates. Cow body condition score (BCS) is a lagging indicator because it will determine if the proper amount of nutritional forage was provided to the cow herd. If a manager does not provide an adequate amount of nutritional forage the BCS of the herd may fall to levels that will in turn hurt reproductive performance of the cowherd. ${ }^{5} \mathrm{~A}$ ranch manager must keep in mind that in some cases cow BCS can lag too far behind the condition of the rangeland. Overuse of the rangeland resource can happen before the nutritional requirements negatively affect a cow's BCS. Financial metrics are lagging indicators because they determine if the ranch made or lost money when stocking rates were adjusted by selling or buying cattle. In order for a ranch to be sustainable for the long term, financial metrics need to be positive. Rangeland transects determine the health and condition of the rangeland. Transects are lagging indicators because they indicate if the rangeland health is being negatively or positively impacted by the applied stocking rates.

The importance of including both leading and lagging indicators is clearly shown with Strategy 1 . The leading indicator tells us what stocking rates to use for the ranch. The lagging indicators indicate if the stocking rates were successful in maintaining or improving rangeland health, maintaining or improving cow BCS, and probably most importantly if we were profitable with the applied stocking rates, which leads to long-term sustainability.

\section{Strategy 2: Drought Management Plan Inte- grated Into the Overall Ranch Operation Plan}

On a majority of ranches across the United States, drought plays a major factor in ranch management. A ranch manager must understand that drought is cyclical and it's not a matter of if it's going to happen, but when it will happen. Having a successful drought management plan integrated into the overall management plan of the ranch, and more importantly, implementing it when necessary, will go a long way toward the sustainability and longevity of a ranch.

In order for a drought management plan to be successful it must have measures and triggers in place. Examples can include: identifying critical evaluation dates for amount of forage produced and moisture received, determining amount of soil moisture on key range sites at the beginning of the growing season, and specific stocking rate adjustments in terms of how many and how long. ${ }^{6} \mathrm{~A}$ ranch manager should be familiar with historical rainfall data on the ranch which will also aid in predicting an oncoming drought as well as how long the drought might last.

The first leading metric is to implement the plan when necessary. There are several reasons why a ranch manger may be reluctant to implement the drought plan. Financial con-

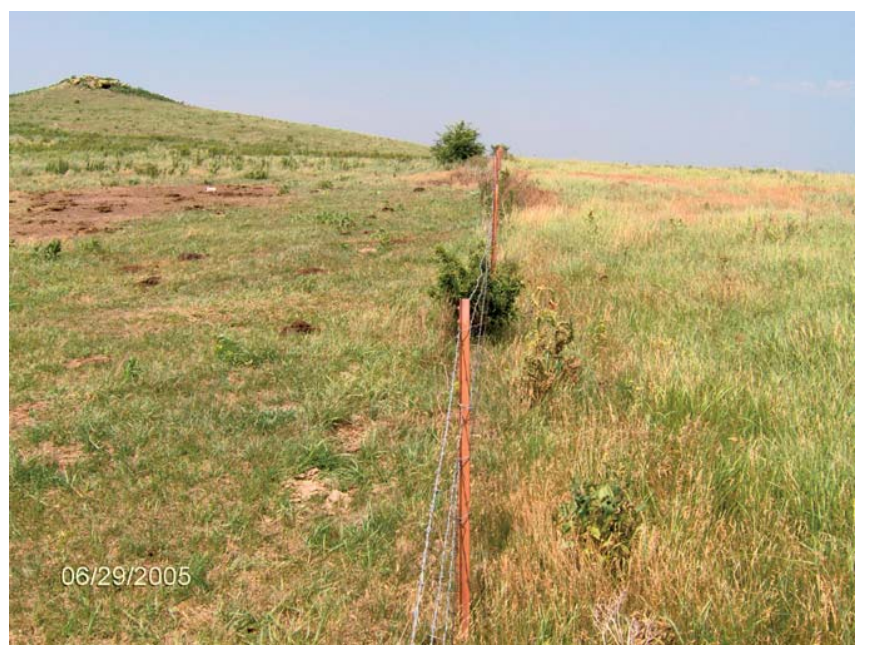

A fenceline contrast showing overgrazed rangeland and more healthy rangeland in Riley County, Kansas.

siderations, mental models, government policy, or the scale of the drought are a few examples. ${ }^{7}$ In order to minimize the hardships that may be encountered by the resources, finances, and the family during a drought, it's extremely important for the ranch manager to follow the plan, stay flexible, and don't second guess decisions.

The third leading metric is making sure the maximum forage utilization rate does not exceed $50 \%$. This metric is the same as the one listed in Strategy 1. Both leading and lagging metrics can overlap between strategies. Monitoring the maximum forage utilization gives us the proper stocking rates within the drought plan. Cow BCS of 5 at weaning and positive transect trends are both lagging indicators. They indicate if the drought management plan was successful in maintaining range condition and proper herd condition at weaning. The final metric could be determining if the overall drought plan was successful for the ranch. Adjustments can then be made to the drought plan if necessary.

\section{Strategy 3: Wildlife Needs Are Part of Grazing and Investment Plans}

Wildlife management is becoming a crucial component for ranch management of the 21st century. Whether it's for income from hunting or purely for aesthetic value, the needs of wildlife must be included in the overall grazing and investment plans. For the majority of ranches across the country, proper rangeland health and condition for wildlife will go hand in hand with proper grazing plans. ${ }^{8} \mathrm{~A}$ ranch manager must not forget the value that a healthy and sustainable wildlife population has on the general population not connected to ranching. Positive word-of-mouth from urban hunters or wildlife observers can go a long way toward improving the perception of grazing livestock and ranching in general.

The application of grazing, fire, chemical, and mechanical treatments as planned is a leading metric. One example might involve the removal of a percentage of cedar trees by either chemical or mechanical means to improve habitat for 


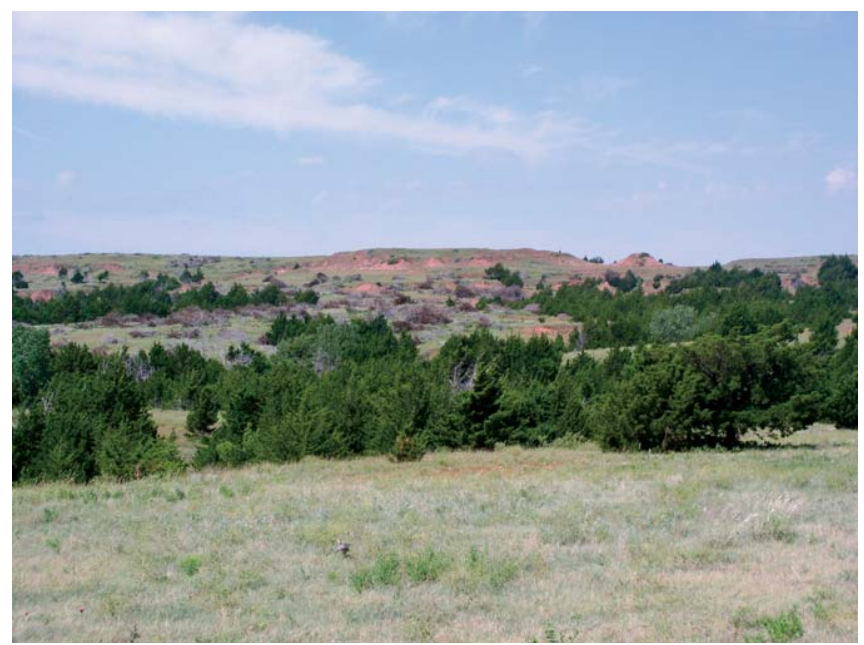

Mechanical treatment of cedar tree invasion in Comanche County, Kansas. A prescribed burn then follows the mechanical treatment to help prevent new seedlings from returning.

grassland bird species. Avoiding nesting areas for certain bird species at a particular time is also a leading metric. Being proactive with our grazing plans ensures proper nesting times for certain bird species. Assessing if bird and deer counts meet desired goals are both leading and lagging metrics. The counts set a goal for the amount of wildlife desired. The counts also determine if the grazing plans and various habitat treatments were successful in maintaining or increasing the amount of wildlife. Using photo points or transects are also lagging indicators that help us determine if the various wildlife management practices are maintaining or improving rangeland health.

\section{Strategy 4: Maximize Ability of Watersheds to Hold Water}

The cattle, wildlife, and the rangeland all need water for survival and sustainability. Maintaining a healthy and functioning water cycle on the ranch helps optimize the ability of watersheds to hold water on a ranch and go a long way toward sustaining healthy cattle, wildlife, and rangeland. If the water for livestock and wildlife is pumped from the ground, healthy watersheds that can hold water and allow precipitation to penetrate into the ground will help sustain or improve the water tables on the ranch as well. ${ }^{9}$

Developing grazing plans that provide adequate rest for the rangeland and provide adequate residual cover for maximizing the ability of watersheds to hold water is a leading metric. Proper stocking rates determined from the maximum grazing utilization is also a leading indicator. Proper stocking rates prevent overgrazing of the rangeland. Increased runoff and bare ground can result from overgrazing, which decreases the ability of watersheds to hold water on the ranch. ${ }^{9}$ Photo points of riparian areas or gullies are very effective lagging indicators that tell us if the grazing plans and stocking rates are improving or maintaining the ability of the watersheds to hold water.

\section{Resources for Rangeland Monitoring}

\section{Natural Resources Conservation Service \\ www.nrcs.usda.gov}

\section{Interpreting Indicators of Rangeland Health \\ www.blm.gov/nstc/library/techref.htm}

\section{Jornada Monitoring Manual}

http://usda-ars.nmsu.edu

The Grazing Manager Software

www.agren-inc.com/tgm/

\section{Strategy 5: Apply Grazing, Fire, Chemical, or Mechanical Treatments to Control Brush or Invasive Species}

Brush and invasive species can be a limiting factor in achieving desired rangeland production by competing with desirable forage species for moisture, light, and soil nutrients. A ranch manager must consider the economic benefits and limitations when developing a strategy for control of brush and invasive species. Balancing the expected value of implementing the treatments with the cost of implementing the treatments is essential for long-term sustainability. ${ }^{10}$

\section{Summary}

Range condition, wildlife counts, photo points, and grazing utilization are all metrics that can be used for each strategy if desired. They provide a good mixture of both leading and lagging indicators, which is essential for a successful Balanced Scorecard. ${ }^{3}$ However, a baseline of information or inventory is required before any monitoring can take place. The baseline measurements help a ranch manager determine the initial stocking rates and carrying capacity of the ranch. These measurements can be taken by a rancher or employees, or you may consider contracting with a range professional. Many natural resources services are provided by the USDA-Natural Resources Conservation Service.

When developing a monitoring program, make measurements as easy as possible and multipurpose. Set up transects or exclosure cages in areas where both range and wildlife improvements are objectives. The use of photo points is also a powerful monitoring tool for measuring long-term success toward the desired strategies. The use of computer software programs in conjunction with field measurements is an excellent tool for monitoring. "The Grazing Manager" software (TGM) developed by Dr Mort Kothmann of Texas A\&M University is a public domain software free to the public. It can be used to assist the ranch manager in monitoring and decision making regarding range improvement, livestock performance, management triggers, grazing and livestock records, and growing conditions. The Jornada Monitoring Manual developed by the USDA, Agricultural Research Service, Jornada Experimental Range is also an excellent 
tool that can be utilized by a ranch manager in developing a monitoring program.

The most important consideration in successfully meeting natural resource management goals is the ability to be flexible and adapt to resource conditions. Rangeland health and drought plans are priorities; a ranch manager must try and make other perspectives adapt if the ranch's vision includes long-term sustainability and profitability.

Authors are Graduate Fellow, King Ranch Institute for Ranch Management, Texas AEऽM University-Kingsville, Kingsville, TX 78363-8202 (Kelly); and Rancher and Rangeland Consultant, Lincoln, NE 68516, rravenscroft@neb.rr.com (Ravenscroft).

\section{References:}

1. Webster's New World Dictionary. 1995. New York, NY: Simon and Schuster. 694 p.

2. Goodman, M. 2002. Systems thinking: A language for learning and action. Hopkinton, MA: Innovation Associates Organizational Learning, Inc. 214 p.

3. Kaplan, R. S., and D. P. Norton. 1996. The balanced scorecard. Boston, MA: Harvard Business School Press. 323 p.
4. Natural Resources Conservation Service. 1997. National range and pasture handbook. Washington, DC: United States Department of Agriculture. 5. 520 p.

5. Pruitt, R. J., And P. A. Momont. 1988. Effects of body condition on reproductive performance of range beef cows. SD Beef Report. Brookings, SD: South Dakota State University. $80 \mathrm{p}$.

6. Reece, P. E, J. D. Alexander III, and J. R. Johnson. 1991. Drought management on range and pastureland: A handbook for Nebraska and South Dakota. EC 91-123. Lincoln, NE: University of Nebraska, Nebraska Cooperative Extension. 23 p. 7. Dunn, B. H., A. Smart, and R. Gates. 2005. Barriers to successful drought management: why do some ranchers fail to take action? Rangelands 27(2):13-16.

8. Sayre, N. F. 2001. The new ranch handbook: A guide to restoring western rangelands. Santa Fe, NM: The Quivira Coalition. 102 p.

9. Holechek, J. L., R. D. Pieper, and C. H. Herbel. 2001. Range management principles and practices. Upper Saddle River, NJ: Prentice Hall. 587 p.

10. Towne, G., and P. D. Ohlenbusch. 1992. Rangeland brush management. MF-1021. Manhattan, KS: Kansas State University, Cooperative Extension Service. 4 p. 


\section{Application of the} Balanced Scorecard to Realize Strategic Management
of Wildlife Resources

\section{By David R. Rios, Butch Thompson, and Mickey W. Hellickson}

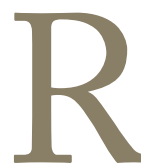

angelands are typically used to produce livestock and to provide habitat for wildlife. In some areas of the United States, it is becoming increasingly profitable for ranchers interested in diversifying their ranching operation to market the opportunity to harvest game species on their ranches through sport hunting. Nonconsumptive enterprises such as wildlife photography and bird watching are also enterprises used by some ranchers to diversify their operation. Commercial hunting enterprises are the most popular because they typically generate more revenue for the rancher. Sport hunting is a multibillion-dollar industry in the United States. Hunting-related expenditures in the United States equal $\$ 21$ billion annually. ${ }^{1} \mathrm{~A}$ great diversity of commercial hunting enterprises exists; day hunts, package hunts, and hunting leases are a few examples.

Commercial hunting enterprises represent one area where strategic management can be utilized to best fit the business enterprise with the environment on a sustainable, long-term basis. However, in the management of many businesses, there is often a disconnect between strategic planning and strategic management. ${ }^{2}$ The Balanced Scorecard is a tool currently available to ranchers to bridge the gap between strategic planning and strategic management of wildlife resources on their ranches (Table 1).

Strategic Planning requires a rancher to explore the following questions: ${ }^{3}$

- Where do we want to be? This question can be addressed by incorporating a shared vision of the future into the strategic plan.

- Where are we now? An evaluation of the strengths, weaknesses, opportunities, and threats of the business, com-

This article has been peer reviewed.
Table 1. Example strategies and corresponding metrics for the wildlife perspective of the Balanced Scorecard for a commercial hunting enterprise

1. Select high-quality customers

- Number of game violations

- Number of harvest mistakes

- Number of rules violations

- Adherence to or deviation from established harvest regulations

2. Develop and maintain long-term relationships with highquality customers

- Follow-up contact post-hunt

- Number of repeat customers

- Number of hunts with repeat customers

3. Develop and maintain an abundance of highly desirable game animals

- Number of trophy-class animals counted during annual preseason game surveys

- Gross Boone and Crockett scores of bucks harvested

4. Add value to the hunting lease through participation in wildlife management programs such as the Managed Lands Deer Permits (MLDP) program in Texas

- Annual browse survey

- Game survey

- Harvest data

monly referred to as SWOT analysis, can help a rancher understand the current position of the business.

- How can we get where we want to be? Gap analysis is a useful technique that can help to answer this question. In 
gap analysis, a comparison between the desired outcome and the expected outcome of the business is made.

- How can we make it work? Strategic options can be generated based on the gap analysis. These strategies should help to bridge the gap between the desired outcome of the business and the expected outcome of the business.

Strategic planning for the management of wildlife resources is commonplace on diversified ranching operations in southern Texas, but are the specific strategies outlined in the strategic plan actually being carried out? Are they truly helping the ranch close the gap between the current reality and the desired vision of the future? The Italian proverb, "It is not enough to aim, you must hit!" truly exemplifies the ambition of strategic management. A rancher must apply a persistent impetus to keep the strategic plan in motion, thus realizing strategic management. This is commonly referred to as a control function. ${ }^{3}$

Strategic management defines the logical methodology to create value for the owners of the business by fitting the business with the environment on a sustainable, long-term basis. ${ }^{3}$ Strategic business management has been applied to businesses from a wide variety of industries. In 1999 Agricultural Economists G. W. Brester and J. B. Penn explored strategic business management to address predicted fundamental changes to the structure of production agriculture. They predicted that the application of strategic business management concepts would be more important for farmers and ranchers during the coming decade than at any other time in the history of agriculture. Farmers and ranchers would have to adopt either a low-cost strategy or a differentiation strategy to survive in the modern age of market globalization, agricultural industrialization, trade liberalization, and ever-increasing human population. ${ }^{4}$ We now see successful farmers and ranchers gravitating toward either product differentiation or very low-cost production. Some producers differentiate their products through value-added programs such as organics and branded beef products, whereas others continue to produce undifferentiated commodity products by keeping production costs at an absolute minimum. Commercial hunting enterprises provide ranchers a third strategic option to address the aforementioned changes in production agriculture: a diversification strategy.

Strategic management involves the actual implementation and control of strategic planning. It requires monitoring and evaluation of the strategies outlined during strategic planning. It answers the question, "Have we succeeded?" The Balanced Scorecard is one approach that can be used as a control function in order to realize strategic management of wildlife resources. ${ }^{3}$

The Balanced Scorecard was developed for use in a general, large business environment, but it can just as easily be applied to diversified ranching operations. The Balanced Scorecard requires the manager to consider the future vision of the business from many perspectives simultaneously, thus providing insight to interactions between and among perspectives and the operation of the entire system. It was originally developed using 1) financial, 2) customer, 3) internal process, and 4) learning and growth perspectives. The original format of the Balanced Scorecard can be built upon by using additional or alternative perspectives as necessary. ${ }^{5}$ The wildlife perspective should be considered when applying strategic planning and management to commercial hunting enterprises. Critical strategies must be identified and implemented to help close the gap between the current reality and the future vision of the ranch when viewed from the wildlife perspective. These strategies must then be monitored and evaluated using a unique set of metrics. The following examples are offered after careful consideration by the authors and in the context of one alternative type of commercial hunting enterprise: hunting leases.

The example vision used for the purpose of this paper is " $T o$ graze cattle at a profit and optimize the profit of the hunting lease enterprise consistent with responsible wildlife and habitat management." We offer the following four example strategies to help close the gap between the current reality and the example vision of the ranch: 1) to select and develop high-quality lessees, 2) establish and continue to develop strong hunting lease agreements, 3) develop and maintain highly desirable hunting leases, and 4) add value to the hunting lease enterprise by participating in programs such as Texas Parks \& Wildlife Department's Managed Lands Deer Permits Program.

\section{Example Strategy and Metrics \#1-Select and Develop High-Quality Lessees}

People management is critical to wildlife management. This is especially true in a hunting lease enterprise where customers inherently wish to maximize the return on their investment. An overzealous group of hunters can decimate game populations and significantly reduce the value of a ranch as a hunting lease. Selective acceptance of hunting lessees is the foundation of this strategy. The rancher must select for lessees with interests that are consistent with, or at least complimentary to, the desired operation of the entire ranch. Lessee fitness can be determined by having prospective lessees complete a lease application, which can be used to conduct a background check to verify the fitness of prospective lessees. Information to collect on the lease application should include legal name, driver's license number, contact information, desired lease arrangement (i.e., corporate, multimember, outfitter, etc.), hunting lease history, and financial references.

Legal name and driver's license number can be used to investigate criminal history. Contact information enables the rancher to contact the prospective lessee in the future. Desired lease arrangement refers to the lessee's desired type of hunting lease. This is important information, because ranchers are typically biased toward or against certain hunting lease arrangements. Every rancher is an individual, and each ranching operation is unique. One rancher might prefer corporate leases, but another landowner might feel that multimember leases better fit the vision of their ranch. 
Hunting lease history includes ranch name, location, acreage, annual lease fee, dates of contract, specific reason lease was terminated, and ranch manager's contact information for all hunting leases previously held. This information can provide great insight to the type of prospective lessee you are dealing with, and allow you to examine the experiences that other ranchers have had with the prospective lessee. Customers in the hunting lease business typically develop accurate and definitive reputations.

Financial references are another great tool. These include bank references, business references, and financial statements. Bank references can provide insight into the prospective lessee's financial status and reputation, business references can provide insight into a prospective lessee's business reputation, and financial statements can confirm the solvency of a prospective corporate lessee.

Once all of this information has been considered and a quality group of lessees has been selected, it is important to continue to develop the lessees in order to work even closer to the vision of the hunting lease enterprise. Lessee development might include such things as an annual preseason meeting to discuss ranch rules, lease boundaries, harvest criteria, and the collection of harvest data in addition to off-season seminars to teach lessees skills such as accurately applying harvest criteria.

Metrics for the strategy of selecting and developing highquality lessees include the collection and consideration of data such as number of game violations, number of harvest mistakes, number of lease or rules violations, and adherence to or deviation from established harvest quotas.

\section{Example Strategy and Metrics \#2-Establish and Continue to Develop Strong Hunting Lease Agreements}

It is critical that high-quality hunting lessees are hunting the ranch under a strong hunting lease agreement. A strong hunting lease agreement allows the rancher to manage hunting lessees, thus managing the wildlife resource. The lease agreement should address lease duration, lease fee, payment/ lack of payment of lease fee, insurance requirements, harvest quotas, selective harvest criteria, lease violations, improvements, road maintenance, and waste disposal. Visit http:// www.naturalresources.umd.edu/Pages/Hunting_Lease.html to view a sample hunting lease agreement and additional information about the content of a hunting lease agreement.

A rancher really doesn't know the strength of his lease agreement until it is challenged or violated. This is when weaknesses in the contract are revealed. In the unfortunate event that a rancher signs a lease agreement with an undesirable lessee, a strong lease agreement will give the rancher the ability to effectively terminate the hunting lease agreement and remove the undesirable lessee from the ranch.

Two questions serve to measure the strength of a lease contract. When evaluating a hunting lease contract, the rancher should ask himself the following questions:
1) Have I been stuck with an undesirable lessee?

2) Has the lease agreement worked against the ranch in any way?

\section{Example Strategy and Metrics \#3- Develop and Maintain Highly Desirable Hunting Leases}

The rancher must develop and maintain highly desirable hunting leases, as the demand for exclusive hunting rights on his ranch will affect the revenue-generating potential of the hunting lease enterprise. Highly desirable hunting leases offer a quality recreational experience. ${ }^{6}$ This requires abundant, high-quality game, and the opportunity to harvest that game. White-tailed deer are the most popular game animal in Texas, and trophy-class animals are highly sought after. A rancher in southern Texas can develop and maintain highly desirable hunting leases by offering the opportunity to harvest trophy-class white-tailed deer. The quality of the trophy is as important a factor in hunting lease fees as the absolute number of animals on a ranch. ${ }^{7}$ Implementation of habitat manipulation, supplemental feeding, harvest quotas and selective harvest criteria are tactics commonly employed by ranchers in southern Texas to execute this strategy.

Game surveys and harvest records are excellent sources of data and can be used as metrics. As a leading indicator, the rancher could monitor the number of trophy-class animals counted during annual preseason game surveys. As a lagging indicator, he might look at gross Boone and Crockett scores of bucks harvested each season.

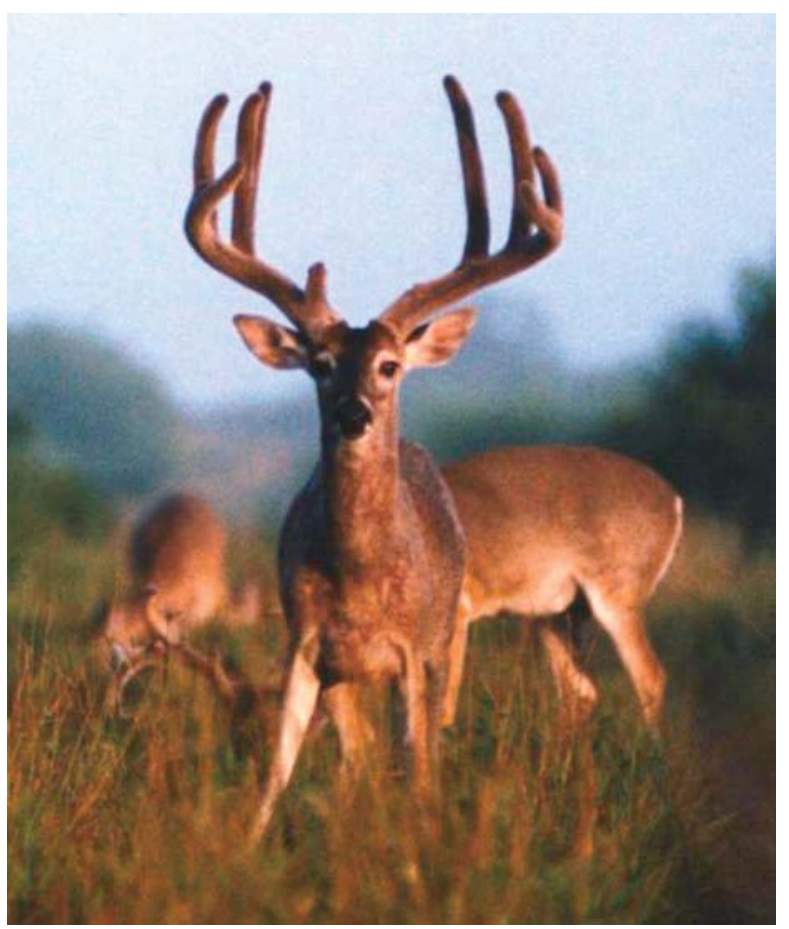

Photo by Mickey W. Hellickson 
Example Strategy and Metrics \#4-Add Value to the Hunting Lease Enterprise by Participating in Programs Such as Texas Parks and Wildlife Department's Managed Lands Deer Permits Program

In order to optimize lease fees, the rancher must make efforts to add value to the hunting lease enterprise. Ninety-eight percent of the land in Texas is privately owned, but the wildlife resource is publicly owned by the people of the state of Texas. Whitetailed deer are economically beneficial to ranchers in Texas, and help to keep large, contiguous tracts of habitat intact by allowing ranchers to generate additional revenue through commercial hunting enterprises. The incentive for conservation is strong when it is profitable to have wildlife on your ranch. ${ }^{1}$

Managing a public resource on private land is a complex endeavor, and Texas Parks and Wildlife Department (TPWD) has been innovative with their approach. One macrostrategy the agency has applied to the management of state-owned wildlife resources on private land is the Managed Lands Deer Permits (MLDP) Program. This incentivebased, habitat-focused program allows ranchers implementing a strategic wildlife management plan to have the state's most flexible seasons combined with increased harvest opportunities. Extended hunting seasons and increased harvest opportunities can add value to a hunting lease while helping to facilitate a rancher's wildlife management plan.

Participation in the MLDP program requires that a written wildlife management plan for the property be approved by a TPWD Biologist. There are three levels of MLDPs (1, 2 , and 3). Harvest flexibility and habitat management requirements increase by level of the MLDP.

The highest level MLDP (Level 3) requires the written wildlife management plan to include deer population data from the current year and 2 preceding years, as well as complete harvest data (age, weight, and antler dimensions) from the 2 preceding years. It must identify a minimum of 4 habitat management practices that are currently being conducted or will be conducted on the ranch. The rancher must accomplish at least 4 of the habitat management practices outlined in the wildlife management plan within 3 years of initial permit issuance. Each year a browse survey is conducted by a TPWD Biologist. The browse survey must indicate that either the habitat is being maintained in an acceptable condition, or the habitat is improving in condition. Otherwise the wildlife management plan will be reevaluated and the MLDP could be suspended.

The rancher benefits from these efforts by having hunting license tag requirements waived and by being allowed a hunting season extended by several months, thus facilitating the harvest goals outlined in the wildlife management plan and adding value to his hunting lease. Visit http://www.tpwd. state.tx.us/business/permits/ for more information about the Managed Lands Deer Permits Program.

By consulting with a state wildlife biologist to write a wildlife management plan, conducting game surveys, collecting harvest data, and conducting habitat improvements on their land, ranchers are able to acquire permits that allow them harvest flexibility and extended seasons for white-tailed deer, thus allowing the rancher to better manage wildlife habitat on his property while adding value to his hunting leases and allowing TPWD to manage a public resource on private land. The wildlife management plan outlines the tactics, and the annual browse survey combined with game surveys and harvest data are the metrics.

\section{Conclusions}

In businesses of all types, there can be a disconnect between strategic planning and strategic management. The Balanced Scorecard is a tool that can be used by ranchers to bridge the gap between strategic planning and strategic management of wildlife resources on their ranches. Table 1 outlines example strategies and metrics that can be applied to the wildlife perspective of a ranch with a commercial hunting enterprise. This basic structure of the Balanced Scorecard can be used to successfully guide and evaluate the wildlife perspective of a ranch in any state. Implementation of the Balanced Scorecard can lead to increased return on investment and more responsible management of wildlife resources by ensuring that management strategies are being implemented and by identifying ineffective management strategies. This allows valuable time and money to be spent on only the most effective strategies.

Authors are Graduate Fellow, King Ranch Institute for Ranch Management, Texas AE'M University—Kingsville, Kingsville, TX 78363-8202, david.r.rios@tamuk.edu (Rios); Resource Manager (Thompson) and Chief Wildlife Biologist (Hellickson), King Ranch, PO Box 1090, Kingsville, TX 78364-1090.

\section{References}

1. Chardonnet, Ph., B. des Clers, J. Fischer, R. Gerhold, F. Jori, ANd F. Lamarque. 2002. The value of wildlife. Revue scientifique et technique - Office International des Epozooties. 21:15-51.

2. Kaplan, S. R., and D. P. Norton. 1992. The balanced scorecard: measures that drive performance. Harvard Business Review 70(1):71-79.

3. Shadbolt, N., and S. Martin. 2005. Farm management in New Zealand. South Melbourne, Victoria 3205, Australia: Oxford University Press. 408 p.

4. Brester, G. W., and J. P. Penn. 1999. Strategic business management principles for the agricultural production sector in a changing global food system. Policy Issues Paper No. 11, November 1999. 11 p.

5. Kaplan, R. S., and D. P. Norton. 1996. The balanced scorecard: Translating strategy into action. Boston, MA: Harvard Business School Press. 322 p.

6. Gramann, J. H. 1986. Market analysis for hunting in Texas. Wildlife Management Handbook. 155 p.

7. BAEn, J. S. 1997. The growing importance and value implications of recreational hunting leases to agricultural investors. Journal of Real Estate Research 14:399-414. 


\section{Utilizing the Balanced Scorecard in Ranch Management: Cattle Production Systems Perspective}

\section{By H. H. "Trey" Patterson and Clinton Richardson}

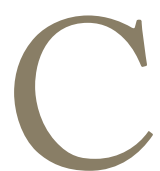

omplexity in the ranching business makes it difficult for mangers to ascertain whether applied strategies are successful in helping the business reach its goals. The time gap between cause and effect in biological systems can cause a lag in feedback that leads to frustration and hindered decision making. The Balanced Scorecard (BSC) gives managers a tool for strategy development and feedback for appropriate evaluation of long-term business success. ${ }^{1}$ The objective of this paper is to give an example of how to develop the livestock production perspective of the Balanced Scorecard by giving strategies for success and the associated metrics to measure success. Although strategies will vary by ranch, we will illustrate and explain some key strategies to consider in generating in developing cattle production systems.

The first step in developing a Balanced Scorecard is defining the vision for the business. A vision statement will be different for each ranch, but should contain aspects of profitability and ranch sustainability.

Long-term outcomes of profitable cattle production systems likely include:

1) Low overhead costs

2) Limited reliance on labor

3) Low reliance on harvested and purchased feed

4) Good productivity

5) High revenue per head

The strategies we discuss focus on achieving these outcomes from the perspective of livestock production as part of meeting the overall vision. A rancher needs to be aware that there is an inherent relationship between costs and revenues.

This article has been peer reviewed.
For example, if you do not have a system that is low cost (outcomes 1, 2, and 3 above), then you must have high production and revenue (outcomes 4 and 5). A rancher needs to work on both sides of the equation simultaneously. We have found, however, that in many ranch operations, the highest leverage lies in attacking the cost side of the equation.

\section{Constraints}

Every ranch system operates under a unique set of constraints. These constraints will have a profound effect on the strategy and metrics that might appear on a balanced scorecard. Some production constraints on a ranch might include context of cost, a stocking rate equal to carrying capacity, drought plan, labor, environment, market, and wildlife. Consideration of these constraints can help in managing the antagonisms that oftentimes exist between the production systems and the additional perspectives in the balanced scorecard. Appropriate production decisions can be made within the context of the entire system rather than focusing on each perspective separately. There should be clear relationships between the metrics of the production perspective and each of the other perspectives. Kaplan and Norton write that "the chain of cause-and-effect should pervade all four perspectives of the balanced scorecard." (p. 30)

\section{Strategic Planning}

Strategic planning is "...to achieve a sustainable long-term excellent fit for the farm business with its environment...." (p. 32) A review of the literature and experience has led the authors to select four strategies that will help achieve a longterm fit for a ranch. This fit is not only biological in nature but encompasses production and marketing. These four strategies are considered foundational to any ranching operation that deals with livestock production. 


\begin{tabular}{|l|l|}
\hline \multicolumn{2}{|l|}{$\begin{array}{l}\text { Table 1. Metabolizable energy requirements } \\
\text { of dry cows }\end{array}$} \\
\hline Breed cross & $\begin{array}{l}\text { Requirements, Kcal ME/kg } \\
\text { BW }^{\text {0.75 }}\end{array}$ \\
\hline Angus $\times$ Hereford & 130 \\
\hline Charolais $\times$ British & 129 \\
\hline Jersey $\times$ British & 145 \\
\hline Simmental $\times$ British & 160 \\
\hline
\end{tabular}

$\mathrm{ME}=$ metabolizable energy. $\mathrm{BW}=$ body weight.

\section{Strategy 1: Match Genetics to the Environment}

Bob Taylor said: "Profitable cattle are usually productive. Productive cattle are not always profitable." ${ }^{4}$ This is a concept that must be understood when making genetic selection decisions for the cowherd. The biological type of cattle in a production system must fit the system and environment in which they are asked to perform. Low weaning rates (or pounds weaned) per cow exposed leads to lower profitability. High expenditures to achieve good weaning rates often leads to lower profitability.

Requirements must be associated with biological type of cow, not just cow size. Milk production has a large impact on requirements, even when a cow is not lactating. Ferrell and Jenkins summarized the energy requirements of different breed crosses of dry cows on a metabolic body weight basis (Table 1). ${ }^{5}$ Simmental $\times$ British cross cattle had a higher energy requirement than Charolais $\times$ British cross per unit of metabolic bodyweight. Even if the two types of cows were the same size, the Simmental cross would have higher energy requirements. The reason is biological type of animal, including milk production, growth potential, etc. It is important to note that there are different biological types of cattle within breeds. For example, there are Angus cattle that have been selected to grow and milk more similarly to Simmental cattle than conventional Angus, and vice versa.

High maintenance cows have 1) high milk production, 2) high visceral organ weight, 3) high body lean mass, 4) low body fat, 5) high output, and 6) high input. The opposite is true for low maintenance cows. ${ }^{6}$ Jenkins illustrated this by supplying cows of different biological types varying levels of feed input (dry matter intake) over the course of a year. ${ }^{7}$ Larger, higher-output type cows had a greater weaning weight per cow exposed in a liberal feed situation than did a moderate biological type. However, when feed supply was restricted, the moderate biological type had a greater weaning wt/cow exposed than the larger type cow. In a liberal feed and/or low stress environment, heavier milking, larger cattle are more efficient; in a restricted feed or high stress environment, moderate milking and moderate sized cattle are more efficient. ${ }^{6}$ Note that the environment is not necessarily related to the part of the country. One Northern Great Plains

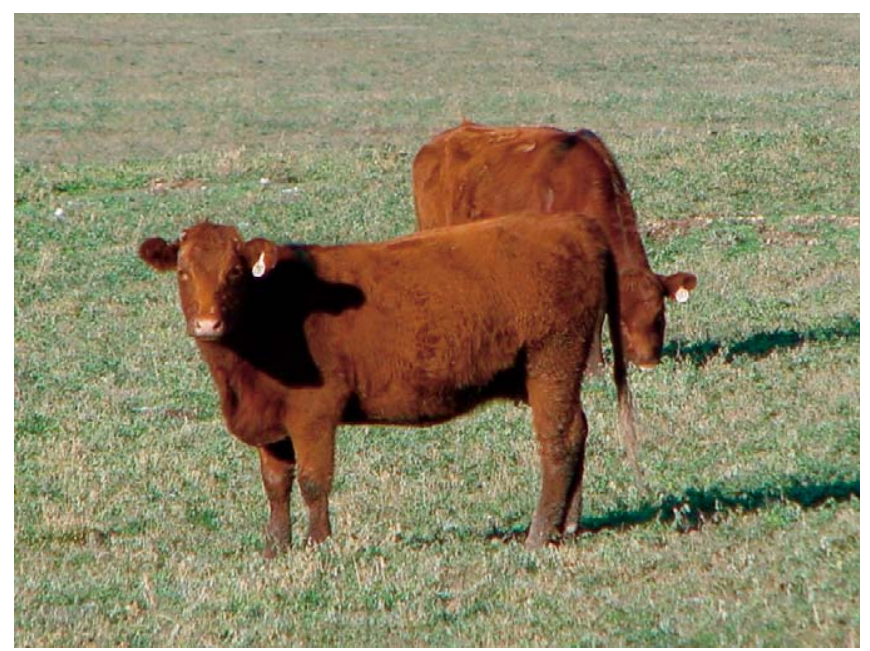

Heifers grazing farmground, Padlock Ranch, Dayton, Wyoming.

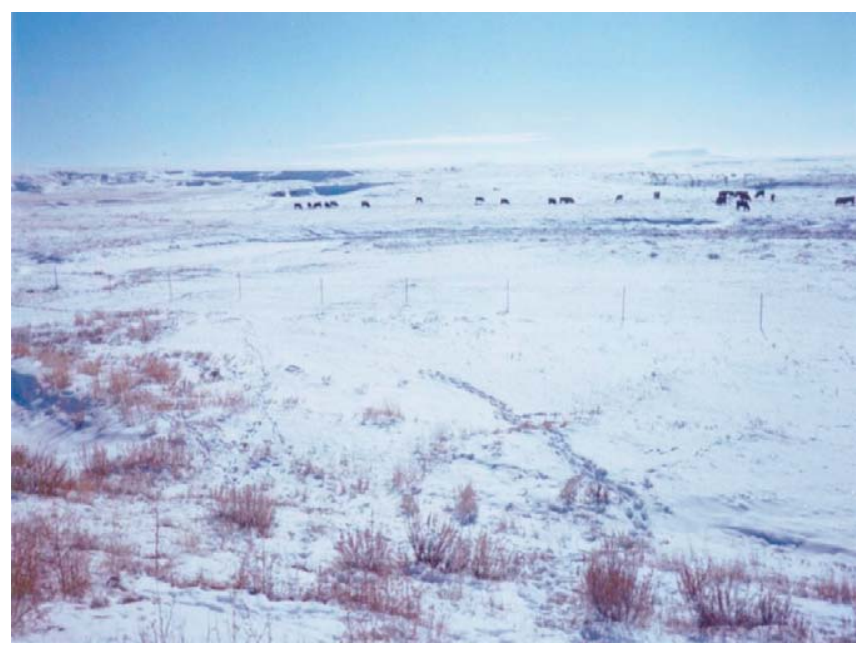

Cows grazing winter range in northern South Dakota.

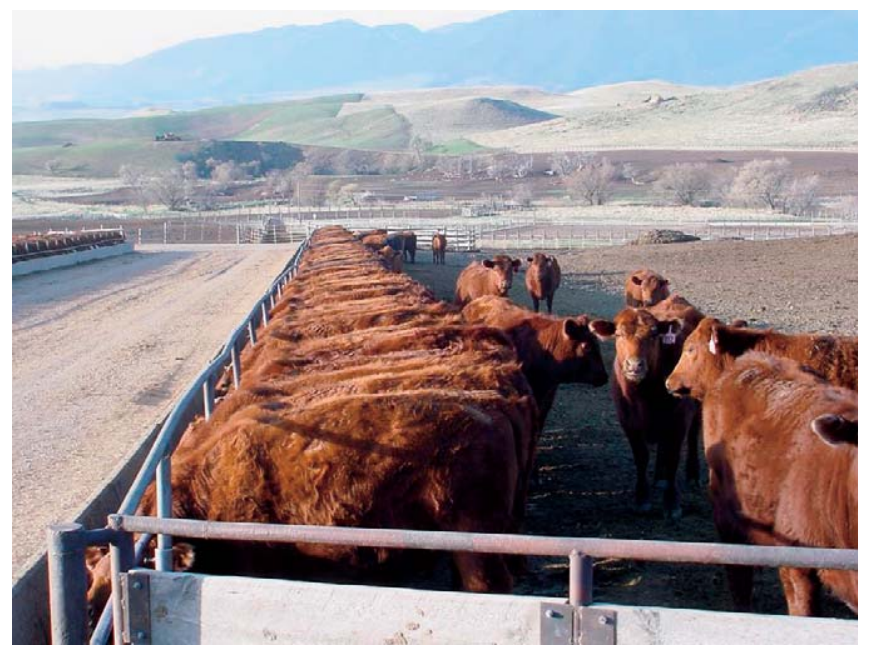

Heifers in feedlot, Padlock Ranch, Dayton, Wyoming.

rancher might strive to run cows on native range with no hay and limited supplement, whereas another might have the option to winter cows on crop aftermath and ethanol production by-products (at relatively low costs). 
Therefore, a rancher must look at the environment and system in which cows are running and evaluate the key metrics of performance in those systems. One key metric to evaluate is unit cost of production, or the cost to produce a pound of calf. You can lower unit cost of production by increasing output (pounds of calf weaned/cow exposed) or by lowering cost. If in most years unit cost of production does not allow for profit, then the biological type of cow or the system in which they are running must be re-evaluated. Examples of other key metrics to evaluate this strategy on a balanced scorecard are:

1) Pregnancy rate

2) Weaning weight/cow exposed

3) Cows bred in the first 21 days of the breeding season

4) Cow body condition score in at pregnancy testing

5) Harvested/purchased feed costs

\section{Strategy 2: Produce a Market-Targeted Animal} Producing a product that fits the particular market is important to any producer. Producers must decide "...which marketing method to use (direct negotiation with buyers, auction selling, terminal markets, forward contracts, etc.), where to sell, when to sell, and in some cases, what form of product to sell (heavy weights, light weights, at what quality grade, what frame, etc." (p. 1) It is important to understand that not all cattle will fit all markets and the type of production system used has a large impact on the marketing options. The strategies and metrics used in the BSC should be in line with the actual production potential of the herd. Therefore, a rancher needs to be able to predict how his cattle will perform. If this is unknown then one metric might be to enroll in a retained ownership alliance that generates the required information. Current production practices and genetics in the herd might preclude the qualification for branded programs. If the goal is to qualify for a particular branded program then adjustments need to be made in other aspects of the production system (i.e., genetics). The goals and metrics of this strategy can therefore have a synergistic relationship. We might choose the following metrics to measure success in the marketing strategy:

1) Market premiums received

2) Percent of cattle that qualify for a particular branded program

Each of these would be both lagging and leading indicators. The market premiums received would indicate how well our product fits the particular market. This strategy would tie into the customer service perspective of the scorecard because market premiums would also be an indicator of demand for our products.

\section{Strategy 3: Match Production System to the Environment}

The keys to matching the production system to the environment are: understanding body condition score (BCS) management, the lactation curve, and forage/feed nutrient supply.

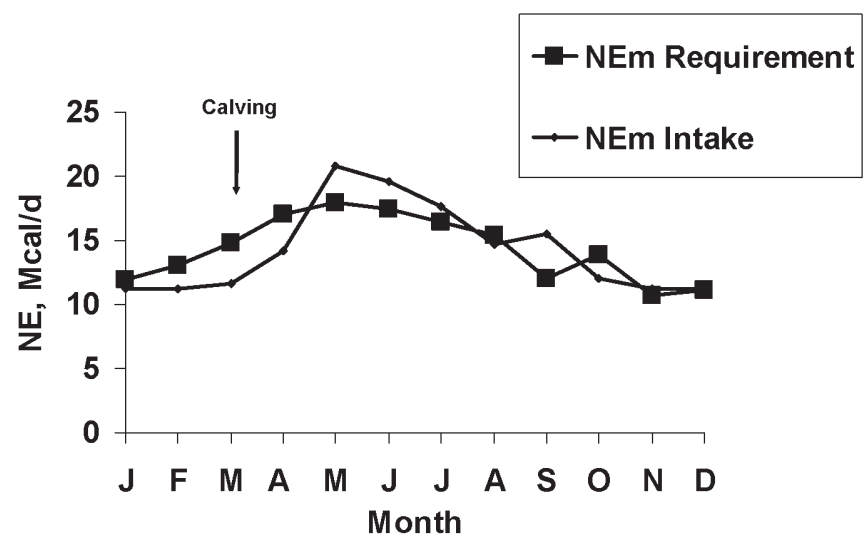

Figure 1. Net energy for maintenance (NEm) requirements and predicted NEm intake of a March-calving cow grazing rangeland in the Northern Great Plains with no supplemental feed (assume calf weaned in late October).

Richards and associates found that if cows calved at a BCS of 4 or less (1-9 scale), post partum interval (time from calving to first fertile estrus) was 12 days longer than if they calved at a body condition score of 4 or lower. ${ }^{9}$ Short concluded that a BCS at calving less than 5 in beef cattle would result in lower fertility unless an abundance of nutrients were present post-calving. ${ }^{10}$ Many have interpreted such data as meaning cows need to be in body condition of 5 or greater throughout the production year. Certainly, it is ideal to have cattle in moderate condition year-round, because there is less risk associated with varying environmental conditions, etc. However, cows can be thinner than a BCS 5 during the production year and still rebreed, given that body condition score at calving is indeed moderate and/or nutrient availability during and after calving is ample. Body condition score at calving needs to be looked at both as a leading and lagging indicator. For example, a low BCS one year might mean lower pregnancy rates during that year (lagging because it could be too late to respond), but it also might mean impaired reproduction in the following production year (leading indicator). Thin cows can become pregnant in year one of being thin at calving, but they might be bred later in the breeding season. ${ }^{11}$ If they are thin in a consecutive year, they might experience reproductive failure. We often emphasize $\mathrm{BCS}$ in the fall for spring-calving cows because it gives an indication of how much feed needs to be given during the winter to result in an adequate BCS at calving time. As we will discuss, this is dependent on the time of calving and the system in which the cattle are managed.

Forage nutrient supply from native grasses varies across locations, depending on temperature, moisture, and forage types. In the Northern Great Plains, the supply of nutrients from native rangeland begins to rise in April or May with spring growth of cool-season plants and usually peaks sometime in June. The period of high quality in June can be extended into early July as warm-season plants grow and produce nutrients. Certainly this pattern is different in southern 


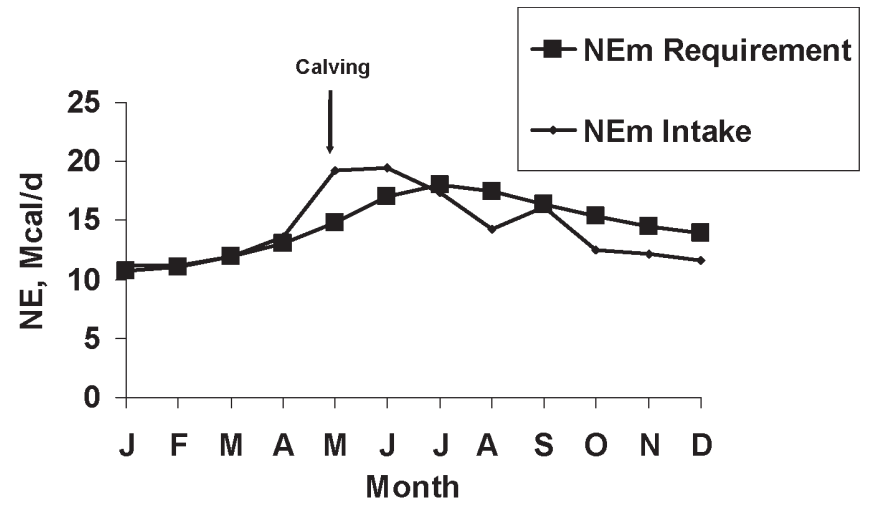

Figure 2. Net energy for maintenance (NEm) requirements and predicted NEm intake of a May-calving cow grazing rangeland in the Northern Great Plains with no supplemental feed (assume calf weaned in late November).

regions of the United States. Ranchers can consult local Extension or Experiment Stations for data relative to nutrient supply in a given area. It is important to note that nutrient supply can be manipulated to some degree by using annual forages, crops, and crop residues.

Working in the Sandhills of Nebraska, Adams and associates concluded that systems that have less reliance on harvested and purchased feeds have more potential to be profitable. ${ }^{12}$ Although not all-inclusive, this is a concept that holds true for most production systems. Therefore, it is important to match requirements with supply of nutrients from forages. Given a certain biological type of animal, the key to accomplishing this match is manipulating the timing of lactation, or time of calving and weaning.

Cattle requirements begin to increase during the second trimester of pregnancy and continue to increase until approximately 2 months after calving, or peak lactation. Requirements then decline gradually until weaning and pick back up with the next pregnancy. The timing in which calving occurs and lactation ends markedly affects the match between requirements and nutrient supply. Figure 1 shows the net energy for maintenance $(\mathrm{NEm})$ requirements and predicted intake (supply) of a March-calving cow using data typical of native rangeland in the Northern Great Plains. Note the mismatch between energy requirements and intake from January through April. Many ranchers feed significant amounts of harvested and purchased feeds during this period to avoid low body condition at calving. If the calving season is shifted to May (Fig. 2), note that requirements equal intake from January through April. In addition, energy intake is greater than requirements just prior to and after calving. The significance of this is that thin cows have an opportunity to put on condition prior to calving if they are too thin going into the spring. Certainly there is annual variation in nutrient intake, but the point is that a May-calving system results in the need for less harvested and purchased feedstuff in this scenario. The May-calving system can result in requirements being greater than nutrient intake during the fall of the year, which can cause cows to lose condition going into the winter. In some years this can be mediated through early weaning (data in Fig. 2 are with assumption that weaning would occur in late November), supplementation, or reliance on an excess of energy in the spring to make up for low condition.

Working in the Sandhills of Nebraska, Clark and associates conducted a 5-year study comparing March to June calving. Researchers reported that cows in the June calving season were fed an average of 227 pounds per head of hay each year compared to 3,947 pounds of hay per year for March-calving cows. The authors attributed the reduction in hay feeding to matching cow requirements to nutrient supply. Included in this system was the period of time before calving when intake was greater than requirements. Pregnancy and weaning rates were not different between March- and June-calving cows, but June-born calves were approximately 60 pounds lighter at weaning (same age) than the March-born calves. The market prices were higher for calves and cull cows when June-born calves were weaned in January than when March-born calves were weaned in October. The result was $\$ 37 /$ head advantage in revenue for June-born calves compared to March-born calves. ${ }^{13}$ Calving in the warmer conditions can also reduce labor needs associated with calving.

Time of weaning is another tool for managing lactation. Landblom and associates showed that weaning in August versus November improved cow body condition going into the winter and resulted in a $27 \%$ reduction in forage utilization from August to November. ${ }^{14}$

In developing a Balanced Scorecard for an operation, the environment, feed availability, and feed quality must be considered. In addition, many other factors are affected by decisions related to time of calving and weaning, including labor needs, marketing, range management, and others. That is where the Balanced Scorecard fits in. Metrics to consider in evaluating this strategy include:

1) Harvested/purchased feed costs

2) Days fed hay during the production year

3) Unit cost of production

4) Cow/man ratio

5) Body condition score at calving

\section{Strategy 4: Stocking Rate Includes Mix of Livestock Classes}

Running a mixture of livestock classes, which might include cow-calf pairs and stockers, can be an effective strategy for several reasons. First, current and future stocking rates can be adjusted based on available forage and precipitation. This adjustment allows stocking rate to be matched with the actual carrying capacity. ${ }^{15}$ Second, running a mixture of livestock classes provides flexibility in marketing. Yearlings or cull animals could be grazed and marketed to take advantage of market trends and can help to balance cash flows throughout the year.

Cull animals should not be ignored in the development of this strategy. As much as $16 \%$ of gross income on many 
Table 2. Example strategies and corresponding metrics for the livestock production perspective of the Balanced Scorecard for a ranch
1. Match genetics to the environment
- Pregnancy rate
- Weaning weight/cow exposed
- Cows bred in first 21 days of the breeding season
- Cow body condition score at pregnancy testing
- Harvested/purchased feed costs

2. Produce a market targeted animal

- Market premiums received

- Percent cattle which qualify for a particular branded program

3. Match production system to the environment

- Harvested/purchased feed costs

- Days fed hay during the production year

- Unit cost of production

- Cow/man ratio

- Body condition score at calving

4. Stocking rate includes a mix of livestock classes

- Percent pairs and percent yearlings

- Stocker gain/day

- Pregnancy rate

- Cull cow revenue

ranches comes from cull cows and bulls. ${ }^{16}$ Metrics to measure opportunities for adding value to cull cows and bulls could be included in the strategy. A proper mix of livestock classes would be a key strategy to the long-term success of the business. Each class should have specific metrics to measure success. These metrics might include:

1) Percent pairs and percent yearlings

2) Stocker gain/day

3) Pregnancy rate (cows)

4) Cull cow revenue

These metrics could be considered both leading and lagging indicators. The ability of a ranch to respond to drought and market trends in the future would be reflected in the percent pairs and percent yearlings metric. Stocker gains would be a lagging indicator of past performance. Pregnancy rate would be both a lagging and leading indicator of both past performance and could be used to predict future pounds of calf weaned and future revenues.

\section{Conclusions}

Success in the ranching industry can be measured by how well the management and work accomplished today helps to fulfill the vision of the future. The production perspective of the balanced scorecard helps ranchers to identify those processes "...critical for achieving customer and shareholder objectives." (p. 92) The purpose of this paper has been to provide an example of how a rancher might develop the livestock production perspective of the Balanced Scorecard. The fulfillment of the vision of the ranch is directly related to the effectiveness and efficiency of the production processes that occur on the ranch. The authors have identified four strategies and associated metrics that affect the future sustainability and profitability of a ranch. These strategies include match genetics to environment, produce a market targeted animal, match production systems to environment, and stocking rates includes a mix of livestock classes. Although these strategies and metrics are somewhat generic for the purposes of this paper, they should be considered foundational to any livestock production system on a ranch. A mixture of leading and lagging indicators (metrics) allows a rancher to be more proactive and less reactive in planning. For example, body condition score at calving or percent of calves qualifying for a branded program can be used to evaluate both past management decisions and predict outcomes expected in the future. Management adjustments can then be made to help close the gap between the vision and current reality.

Kaplan and Norton wrote: "In the Balanced Scorecard, the objectives and measures for the [internal-business-process perspective] are derived from explicit strategies to meet shareholder and targeted customer expectations. This sequential, top-down process will usually reveal entirely new business processes at which the organization must excel." ${ }^{2}$ (p. 93-94) The strategies and metrics developed in this paper were developed to meet both customer and shareholder expectations. The strategies and metrics will therefore flow upward through the customer and financial and lifestyle perspectives and ultimately to the vision of the ranch. In Table 2, the authors list recommended strategies and metrics for the livestock production perspective of the Balanced Scorecard.

Authors are Assistant to the CEO, Padlock Ranch, HC 64 Box 65 Ranchester, WY 82839, trey@padlockranch.com (Patterson); and Graduate Fellow, King Ranch Institute for Ranch Management, Texas AEM University-Kingsville, Kingsville, TX 78363-8202 (Richardson).

\section{References}

1. Kaplan, R. S., and D. P. Norton. January-February 1996. Using the balanced scorecard as a strategic management system. Harvard Business Review 74(1):1-11.

2. Kaplan, R. S., and D. P. Norton. 1996. The Balanced Scorecard. Boston, MA: Harvard Business School Press. 322 p.

3. Shadbolt, N., and S. Martin. Farm management in New Zealand. 2005. New York, NY: Oxford University Press. 408 p.

4. TAylor, R. A. 1994. Colorado State University. Personal Communication.

5. Ferrell, C. L., and T. G. Jenkins. 1984. Energy utilization by mature, nonpregnant, nonlactating cows of different breeds. Journal of Animal Science 58:234-243. 
6. Ritchie, H. D. 1995. The optimum cow-what criteria must she meet? In: Proceedings of the Beef Improvement Federation Annual Conference; 31 May-3 June; Sheridan, WY. p 126-141.

7. Jenkins, T. G. 1995. Performance of different biological types of cows under varying levels of feed availability. Washington State University Beef Information Day. Pullman, WA: Washington State University. 7p.

8. Rust, C. H., And D. Bailey. 1994. Beef marketing technology (Electronic). Beef Cattle Handbook. BCH-8460. p. 1

9. Richards, M. W., J. C. Spitzer, and M. B. Warner. 1986. Effect of varying levels of postpartum nutrition and body condition at calving on subsequent reproductive performance in beef cattle. Journal of Animal Science 62:300-306.

10. Short, R. E., R. A. Bellows, R. B. Staigmiller, J. G. BerarDinelli, And E. E. Custer. 1990. Physiological mechanisms controlling anestrus and infertility in postpartum beef cattle. Journal of Animal Science 68:799-816.

11. Pruitt, R. J., And P. A. Momont. 1988. Effects of body condition on reproductive performance of range beef cows. SD Beef Report. CATTLE 88-11. Brookings, SD: South Dakota State University.
12. Adams, D. C., R. T. Clark, S. A. Coady, J. B. Lamb, and M. K. Nielsen. 1994. Extended grazing systems for improving economic returns from Nebraska Sandhills cow/calf operations. Journal of Range Management 47:258-263.

13. Clark, R. T., D. C. Adams, G. Carriker, R. E. Sanberg, T. Milton, J. Musgrave, T. J. Klopfenstein, and G. P. LARDY. 1999. March vs. June calving systems: production and economic considerations. In: Proceedings of the University of Nebraska Gudmundsen Sandhills Laboratory Field Day, June 1999; Whitman, NE. 10 p.

14. Landblom, H., H. Patterson, P. Johnson, R. Gates, and S. PAisley. 2005. Effects of weaning date and retained ownership on cattle performance and forage disappearance in spring calving beef systems. Proceedings of the Western Section of the American Society of Animal Science 56:291-294.

15. Carpenter, B. B., And C. R. Hart. 1999. Livestock management during drought. College Station, TX: Texas Agriculture Extension Service. RLEM No. 2.4 p.

16. NCBA. 1999. Executive summary of the 1999 national market cow and bull quality audit. Englewood, CO: National Cattlemen's Beef Association. 15 p. 


\section{Branded Customer Service:} Implementing the Customer Perspective of the Balanced Scorecard to the Ranching Industry

\section{By Leslie G. Nunn, Troy Marshall, and "Donald" Donnell Brown}

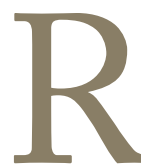

anch brands hold a rich and vivid place in American history, as well as a unique position in today's ranching industry. Commencing in the late 18th century, cattle brands were in many ways some of the first trademarks used in commerce. These brands were a mark of ownership, termed the ironclad signature, distinguishing one rancher's livestock from another. Many brands were simple; others were more descriptive and complex. For those familiar with them, most of these brands passively took on an entire legacy and contained an underlying story about the ranch they represented. As a result of this, the saying "riding for the brand" has a deep meaning to cattlemen. Riding for the brand signifies a way of life and a depth of character to which people in the ranching business aspire. Not surprisingly, many narratives, books, poems, and ballads have been written and told about brands.

As in times of old, ranch brands continue to portray a mental image of the ranch's history, its people, products, and services. However, unlike the ranches of old, ranches in the 21 st century are multifaceted and have an increasingly diverse customer base. Ranches today have an opportunity to take a proactive role when creating mental images by fashioning their ironclad signature to represent the ranch as they want their customers to perceive them. This means focusing the brand to represent the unique image, the public face, and the perceptions that come to mind when a customer thinks of a particular ranching business or sees its brand logo. The brand logo might not even be a hot iron brand, but could just be the name of the ranch. To the customer, the ranch's brand should represent a one-of-a-kind promise or a series of promises on which the ranch will deliver. They can in-

This article has been peer reviewed.

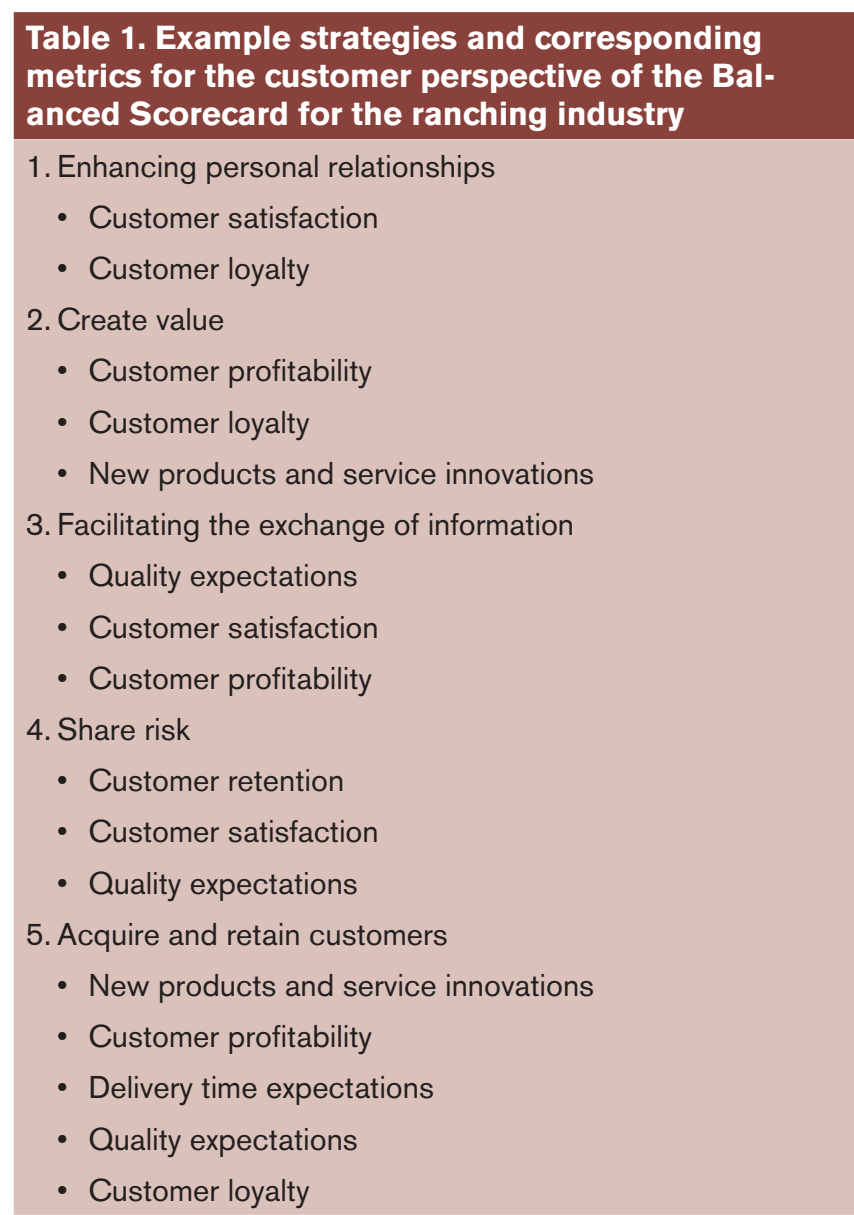

clude such things as performance expectations of livestock, their genetics, management, or services associated with ranch tourism and fee hunting operations. The brand should also symbolize the distinctive beliefs and values the ranch holds. 
Table 2: Example of customer service strategies with respective tactics that can be applied

to various ranch enterprises

\begin{tabular}{|l|l|l|l|l|}
\hline Strategies & Cow-calf & Seedstock & Hunting & Ranch tourism \\
\hline $\begin{array}{c}\text { Personal } \\
\text { relationships }\end{array}$ & $\begin{array}{c}\text { Learn customer's } \\
\text { family's names }\end{array}$ & $\begin{array}{c}\text { Host customer } \\
\text { appreciation } \\
\text { barbeque }\end{array}$ & $\begin{array}{c}\text { Learn hunters } \\
\text { preferred hunting } \\
\text { style }\end{array}$ & $\begin{array}{c}\text { Create data base of } \\
\text { repeat customers }\end{array}$ \\
\hline Create value & $\begin{array}{c}\text { Implement verified } \\
\text { health program }\end{array}$ & Performance tested & $\begin{array}{c}\text { Give framed } \\
\text { picture of hunt as } \\
\text { memorabilia }\end{array}$ & $\begin{array}{c}\text { Provide } \\
\text { complimentary } \\
\text { snacks in guest } \\
\text { rooms }\end{array}$ \\
\hline $\begin{array}{c}\text { Exchange } \\
\text { information }\end{array}$ & Provide carcass data & Provide catalog & Provide past harvest & Develop detailed \\
data & website & Offer one-shot \\
\hline $\begin{array}{c}\text { Share risk } \\
\text { guarantee }\end{array}$ & Join alliance & $\begin{array}{c}\text { Implement first-year } \\
\text { breeding guarantee }\end{array}$ & discounts for \\
program failures
\end{tabular}

If ranchers proactively work to develop their brand image, they will be branding their customer service.

Branded customer service is a tactful, organized maneuver ranchers can use to ensure that customer experiences are equal to the tangible promises associated with the product or service and representative of the ranch brand or name. ${ }^{1}$ Branded customer service can assist ranchers in reaching their ranch vision much more effectively than does generic customer service. When ranchers implement the customer service perspective of the Balanced Scorecard to their operation, they are branding their customer service and creating their figurative brand image. According to Kaplan and Norton, ${ }^{2}$ the customer perspective is integral in the ranch's ability to achieve long-term financial success. Without it, ranches will struggle to reach the ranch vision.

To help ranchers achieve a vision of a profitable, sustainable ranching operation, the following five examples are strategies that could be used on any ranch operation to brand customer service (Table 1). These strategies are 1) enhancing personal relationships, 2) creating value, 3) facilitating the exchange of information, 4) sharing risk, and 5) attracting and retaining customers. These five strategies easily can be applied to any segment of the production chain. They also can be used across all of the ranch's varying profit centers (see Table 2). Within each of these five strategies, there are several tactics that can be used to bolster each of the strategies. Furthermore, it is not adequate to have strategies unless there is some way of measuring the success of meeting the obligations tied to each strategy. Following the discussion of these strategies, several methods will be offered that can be used to measure the success of the customer perspective strategies.

\section{Strategy 1: Enhancing Personal Relationships}

Enhancing personal relationships with the business' customers is one of the most important strategies for the customer perspective of the Balanced Scorecard. It is important for various reasons. For example, it allows for ranchers to sincerely know and understand their customer's needs, issues, and the challenges they face. Most importantly, by building a personal relationship with a customer, the customer is able to feel as though they have something more to garner from the relationship with the ranch, other than the product or service being offered to them. To do this, the business must become "customer-centric." 3 This means treating the customer as though the world revolves around them. Focusing on these critical factors increases the likelihood that the customer will continue doing business with the ranch.

For ranchers with a generally small customer base, becoming customer-centric can be a simple task that does not require a lot of extra time; the ranchers need to know who their customers are. Branded customer service entails more than just knowing who they are; it involves getting to know as much about the customers as possible. Ranchers must be unique, but certainly genuine and sincere in this process. For example, ranchers should learn and remember where their customers are from; the ranch or business they represent; and the types of livestock in which they are interested, including genetics and preferred physical features. Ranchers can also probe for birth dates, anniversaries, family names, even the dog's name, hobbies, and customer preferences, such as black coffee versus coffee with cream and sugar. These are all small things that can go a long way to show the customer they are honestly cared about. A well-constructed personal relationship with a customer creates a relationship of trust and thus customer loyalty.

\section{Strategy 2: Creating Value}

Throughout the past decade, "value added" has become an industry buzz word. Ranchers and the beef industry have been striving to add value at all levels of the beef production 
chain, from improving genetics to providing prepared meals. Ranchers have also been adding value in other areas as well. For example, the King Ranch weans, halter breaks, and works on gentling their weanling horses before selling them. These are all extra benefits to the customers because they no longer have to perform these tasks themselves. Creating value is a critical strategy because it generates customer loyalty. Creating value means finding out what it is the customer truly values and drives them to remain loyal. ${ }^{2}$ Customers are more likely to repeat their business in the same place if they feel they are getting good value from the product or service. ${ }^{4} \mathrm{No}_{0}$ matter the segment, creating value in your product or service shifts generic customer service to branded customer service.

Cow-calf producers may wonder how they can add value to their cattle. John McNeill, from Texas A\&M, summarized it this way; "ranches need to know how their calf crop fits the needs of the beef industry and learn what creates value in the post-weaning phase of beef production." ${ }^{5}$ (p. 46) It might take some innovation on the manager's part, but there are ways this can be done. Some of the most common techniques being used today are improved verified health programs, age and source verification of commercial cattle (EID, or electronic identification system), genetic improvements for better growth and grade, and special offers or discounts.

Many seedstock producers create value by not only offering genetically superior bulls but also by offering bulls that are performance- and-fertility tested, ultrasounded, and rangeready. They also make special offers to reduce customer costs of delivery. Each of these items adds value to the product the customer is purchasing. Ranchers need to be innovative and develop some unique tactics that create value to the ranch's products or services. As in all businesses, it is the uniqueness that distinguishes one ranch from the other.

\section{Strategy 3: Facilitating the Exchange of Information}

Providing customers with a lot of information might be considered good customer service. On the other hand, facilitating the exchange of useful information is branded customer service. Because receiving information about the ranch could be one of the first contacts a customer has with the ranch, this strategy becomes one of the most effective ways to begin branding customer service. For example, if a ranch were to implement a website as a means for exchanging information with their customers, the first task would be to find out what information their customers need. The second task could be finding a competent web designer who understands how to develop a website that is easy to navigate as well as being aesthetically pleasing to the user. When a customer finds the information on the website to be professionally presented and useful, the ranch establishes credibility and makes a good first impression.

The way the information on the website is presented can indicate to the customer that the ranch cares about their customer's needs, which strengthens the first strategy of en- hancing personal relationships. Facilitating the exchange of information, no matter whether it is done via a website or by some other means, can be the first tool used to establish a relationship of trust and confidence. This is why it becomes crucial to use the tool correctly.

Country Natural Beef (CNB) provides an excellent example of how an industry alliance correctly uses the tool to exchange information with their customers through the use of their website. When scanning their website, it becomes immediately apparent that CNB is about more than selling beef. It is about effectively exchanging with their customers the information the customer must have to understand that CNB strives to provide healthy beef while maintaining healthy animals, healthy landscapes, healthy ranch families, healthy partners, and most importantly, healthy customers. The information and the way it is presented by CNB is unique and stands out to their customers. Their website is an excellent example of branding customer service through the exchange of information.

There is plenty of information that can be offered to customers, and there are many ways it can be made available. The information a ranch provides could encompass each of the ranch's varying enterprises, such as cattle, horses, hunting, and ranch vacations. The important point ranch managers need to decide is what information they need from their customer in order to make the product or deliver the service that is desired by the customer. Ranchers also need to know what information the customer needs or wants from the rancher so the customer is able to gain maximum results from the product or service. Finally, ranchers need to be able to turn all the information the operation generates into actionable knowledge.

\section{Strategy 4: Sharing Risk}

Sharing Risk can also be an important strategy to the customer perspective of the Balanced Scorecard. Sharing risk can be as simple as offering a guarantee to the customer that the product or service is what is promised or a refund will be granted. The most common example in the seedstock industry is the first-year breeding guarantee, where the bull is bought back by the seller if it did not perform as promised. Such guarantees will aid the customer in having a sense of security about what they are purchasing. As another example of sharing risk, Safeway Foods has teamed with Cargill Meat Solutions in producing Ranchers Reserve, a brand of beef that is guaranteed tender. Safeway guarantees their beef product to be tender and if it isn't, they refund the customer their money and then give them another package of equal or higher value to try the product again. Giving a refund for the undesired package would be generic customer service. Offering another package plus the refund is an example of branded customer service.

The following are some other examples of sharing risk. Many ranches that offer stallion services promise their customer a live foal by their stallion or the customer's money 
will be refunded. These same ranches also offer a sight-unseen purchase of the calves sired by one of their bulls so their customers do not have to worry about the risk of marketing those calves. Where hunting plays an integral part in a ranch's operations, hunters are often promised at least one shot at a trophy animal. It is up to the hunter whether they succeed in harvesting the animal. Guarantees must be honored, even if at times they might seem to be abused, or the sharing risk strategy will not be effective in implementing branded customer service.

\section{Strategy 5: Attracting and Retaining Customers}

In general most ranches want to grow, be profitable, and be sustainable. A key strategy for this vision is to attract and retain customers. Acquiring customers can't be like roping a calf at branding time, where one is heeled, dragged to the fire, branded, and then quickly released. So what do ranches need to do to attract and retain customers? As previously mentioned, to gain customer loyalty it must be demonstrated to the customer that they are more important than anything else. ${ }^{3}$ This is done through building a friendship firmly founded on trust, integrity, and passion. Furthermore, attracting and retaining also requires exceeding customer satisfaction and expectations. ${ }^{6}$ Accomplishing this task is how the ranch brands customer service and sets itself apart from all the rest.

The attracting and retaining customers strategy is greatly connected to each of the other four strategies we have discussed. Through effectively branding customer service by applying the four previously mentioned strategies, chances of attracting new customers and gaining their loyalty are increased. The first four strategies provide an avenue the customer can follow, which leads to a feeling of attachment to the ranch brand.

\section{Measuring Strategy Success}

Measuring progress and success of strategies is critical to the successful use of the Balanced Scorecard as a management tool. If it does not have measurements, it can be as worthless as a valuable tool that hangs in the shop and never gets used. Without measurements, the ranch will not be able to determine whether they are moving closer to obtaining the vision. Metrics help to recognize areas of improvement and also help to develop future strategic decisions.

Measurements within the customer perspective can be quite simple. The key is the focus on the fulfillment of each of the tactics used for each of the strategies. For example, a ranch might decide that implementing an EID system is an excellent way to create value in their cattle for their customers. Once the ranch has implemented the program, they must then measure whether or not it did indeed create value in their cattle. In other words, were the cattle worth more to the customer, and was the customer willing to pay more for the cattle, because of the implementation of the EID system? The measurement thus becomes the market premium received.
In addition to measuring the value brought to the ranch, ranchers might also want to know if their customer was able to benefit from EID implementation or any other strategy implemented to create value. One way for ranchers to know whether it created value for their customer or not, is to survey the customers and inquire about whether or not they found the EID system useful and if they would continue buying cattle for the sake of having the EIDs. To find out if a strategy created value for the customer could be the most important metric of all, because it could be a leading indicator for repeat business from the customer.

Another example of a strategic metric is to measure customer acquisition and customer retention. This is done by counting the number of new and repeat customers to the business. The strategy can then be considered successful when it is determined that the new and repeat customers have generated or will generate more business income.

When developing metrics, ranches should strive to create metrics with links between the strategies. For example, customer satisfaction should be important to measure and has a direct link to customer retention. Customer acquisition and retention are linked to business growth. These linkages tie the strategies together and are what make a good Balanced Scorecard. ${ }^{2}$ Other examples of metrics are also provided in Table 1.

\section{Conclusions}

Enhancing personal relationships, creating value, exchanging information, reducing risk, and acquiring and retaining customers are five customer service strategies that can be effective in realizing the accomplishments of a ranch's vision. However, they should only be used as a template in developing any ranch's customer perspective strategies. Ranchers should choose strategies that can most easily be applied to their operation.

Not every ranch will need five strategies; some might need less and some might need more. The objective is to have the most appropriate strategies to bridge the gap between the ranch's current situation and its vision of the future.

The cattle and ranching industry is moving from a traditional commodity market to an industry that also needs to provide intrinsic value to the customer. In order to do so ranches need to implement branded customer service, which is ranches doing more than mainstream generic customer service. In much the same way as their hot iron brand is unique, ranches need to discover something about their customer service strategies that sets them apart from all others. This makes the ranch's customer service exceptional from their customer's viewpoint. Branded customer service will then be a living representation of the ranch brand. ${ }^{1}$ Once it is, the ranch's customers will ride for the brand.

Authors are Graduate Fellow, King Ranch Institute for Ranch Management, Kingsville, TX 78363 (Nunn); Editor for Seed- 
stock Digest and seedstock producer, Burlington, CO 80807 , troy@seedstockdigest.com (Marshall); and RA Brown Ranches, Seedstock Division, Throckmorton, TX 76483 dbrown@ rabrownranch.com (Brown).

\section{References}

1. Barlow, J., and P. Stewart. 2006. Branded customer service: The new competitive edge. San Francisco, CA: Berrett-Koehler Publishers. 242 p.

2. Kaplan, S. R., and D. P. Norton. 1996. The balanced scorecard: Translating strategy into action. Boston, MA: Harvard Business School Press. 322 p.
3. Mitchell, J. 2003. Hug your customers: The proven way to personalize sales and achieve astounding results. New York, NY: Hyperion. 267 p.

4. Ford, L. 1998. Strategies that foster customer loyalty. In: R. Zemke and J. A. Woods [eds.]. Best practices in customer service. New York, NY: HRD Press. p 240-248.

5. McNeill, J. 2001. From the ranch to the feedlot: what works and what doesn't? Proceedings, The Range Beef Cow Symposium XVII. 11-13 December 2001; Casper, WY: University of Wyoming. $46 \mathrm{p}$.

6. Griffen, J. 1995. Customer loyalty: How to earn it, how to keep it. San Francisco, CA: Jossey-Bass Publishers. 228 p. 


\section{Financial Perspective of the Balanced Scorecard: Strategies for Profitability}

\section{By Craig A. Payne and Pete Talbott}

${ }^{6} \mathrm{D}$ rofitability measures the extent to which a business generates profits from the use of land, labor, management, and capital"1 (p. III-2) and its importance in ranching cannot be overemphasized. Profitability promotes owner satisfaction and it is essential for sustainability of the business. It also creates financial success, which supports not only the business, but also land stewardship and quality of life for those involved. It is not surprising then, that we commonly find a reference to profitability or profit in the vision statement of a business.

Assuming this is also part of the vision of the ranch for which we are creating the Balanced Scorecard, the financial perspective should contain strategies that increase profit and techniques for monitoring profitability in order to link the perspective to the vision. The following are examples of strategies and techniques the authors feel best accomplish this. Also included in the discussion are metrics that represent suggested ways of accomplishing each strategy (Table 1).

\section{Strategy 1: Establish Profit/Cost Centers}

In order for a ranch to thoroughly analyze its financial performance, it should organize its accounting system and management around profit and cost centers. A profit center is an area of the operation that receives income from off-ranch sources and the cost center is an area of the operation that only incurs costs and does not have a product for sale. The benefit of using profit and cost centers is the ranch can determine which segment of the operation generates the most profit and cash to pay for all the overheads (cost centers) that impact the different production units (profit centers).

This article has been peer reviewed.
Table 1. Example strategies and corresponding metrics for the financial perspective of the Balanced Scorecard for a ranch

1. Establish profit/cost centers

2. Establish a chart of accounts for management

3. Manage costs

- Budgeting

- Break-even analysis

- Cash flow projection

4. Manage/monitor debt

- Net present value (NPV) or internal rate of return (IRR)

- Debt-to-asset ratio

- Current ratio

5. Financial efficiency

- Return on assets

- Operating expense ratio

6. Measuring and monitoring profitability

- Return on assets

- Return on equity

- Net ranch income

- Trend analysis

- Benchmarking

To better understand the concept of profit and cost centers, it is helpful to use an example of a cow-calf ranch that also runs stockers. If the ranch sells calves (plus cull breeding 
animals) and stockers, then it has two profit centers, one for cows and one for stockers. Cost centers in the business might be equipment, general and administrative, and crops grown for the sole purpose of feeding (not for sale).

Profit centers include all the income associated with that center and all the costs that can be charged directly to that center. In the previous example, income from calf sales is included in the cow profit center. The cow profit center will also contain costs that can be directly expensed to it. Examples of this would be vaccine, supplements, and even the fuel that is used in the pickup specifically for the cows, not the stockers.

Cost centers include all expenses that are not directly associated with a specific profit center. Using an equipment cost center as an example, the cost of tires for the pickup would be expensed here because the tires will be used for all ranch activities, not just cows or stockers. The general and administrative cost center would take all the expenses that do not fall into one of the other cost centers. Examples of this would be accounting fees, insurance and supplies not easily allocated to a profit center.

During year-end preparation of the books, a percentage of each cost center is allocated to a profit center. If it is determined that $70 \%$ of the equipment expenses should be charged to cows and 30\% to stockers, then that allocation would be made. This is done with general and administration and any other cost centers, with all costs being allocated to a profit center(s).

\section{Strategy 2: Establish a Chart of Accounts for Management}

A complete list of how financial resources are to be handled in the business is essential and it is critical that it be done based on the needs of management and not for tax purposes. Examples of accounts would be: Assets, Liabilities, Owner's Equity, Revenues, and Expenses. For the Balanced Scorecard, the focus is on revenues and expenses. The chart of accounts should reflect how the business wants to track the financial activity of the established profit and cost centers.

Revenue accounts would list all the various income sources or classifications that are traceable when products are sold. Expense accounts would list all those areas of expenditures that are important to manage and analyze as it relates to either direct expenses to a profit center or a general expense for a cost (or support) center.

\section{Strategy 3: Manage Costs}

In its most basic form, profit is comprised of two components: revenues and costs (Profit $=$ Revenues - Costs). This means that profits can be increased by generating more revenue, by managing costs, or by using a combination of both. However, because ranching is typically a commodity business, it is generally easier to manage costs than it is to increase revenues. Therefore, managing costs is usually the preferred strategy. Using the budgeting process, performing break-even analysis, and managing cash flow are some effective ways of managing costs.

\section{Budgeting}

The budgeting process is the foundation of all business planning and it anticipates the financial outcome of the ranching operation by using probable expenditures and income. There are 2 distinct types of budget processes. One is historicaland the second is zero-based. Historical-based budgeting is the simplest as it takes the costs and incomes from the previous year and with a few minor adjustments becomes the next year's budget.

The preference of the authors is for zero-based with a few historical exceptions. By using zero-based budgeting, each line item on the budget begins with zero and the question(s) are asked, "What is really needed for the account?" By going through this process, all dollars must be accounted for and it's not just assumed that the same amount will be spent as last year.

Once the budget is prepared, monthly, quarterly, and annual comparisons to the actual expense or income items on the budget are made and analyzed. This reveals how the business is doing compared to the original plan. If there is a large discrepancy between budgeted and actual expenses, it is then important to understand why it occurred and to consider changes that need to be made in the future.

\section{Break-even Analysis}

The break-even cost is the cost of producing a unit of product at some point in the products value chain. Knowing the cost of producing a pound of weaned calf, a stocker at sale weight, a bull (for a seedstock producer) at sale time, or a ton of hay, is of the utmost importance. Knowing the exact cost on a per unit basis of the product sold or a product produced and used within the operation is critical for success. This information is useful for profit analysis of one or multiple profit centers.

Calculating the break-even is not difficult if you keep track of your costs and units of production associated with a particular product. This is done by taking the total cost and dividing it by the number of units produced during the cost time line. Calculating the cost of production per unit allows to you compare your costs to the potential market and your potential profit.

\section{Cash Flow Projection}

Projections of cash flow for the operation are critical for planning financing needs, or during times of excess cash, planning for debt repayment or investing. Many times ranchers make purchases based on tax implications and accelerated depreciation but fail to recognize how these purchases will impact future cash flow. Ignoring such factors can result in cash shortages, which reduces the ability of the operation to meet its financial obligations.

With cash-flow planning, projections are made about the timing and amount of cash inflows and outflows, and therefore cash availability can be estimated for the coming year. 
If the plan reveals cash shortages are likely, the rancher then needs to adjust next year's expenditures or borrowings to correct the shortage.

\section{Strategy 4: Managing/Monitoring Debt}

Debt is an acceptable and necessary source of capital for most ranches but it can become a problem when it is not managed properly or not monitored. In such cases, debt can become out of control and have a significant impact on the profitability of the ranch. Managing and monitoring debt are therefore important strategies.

\section{Managing Debt}

A common way to manage debt is to make sure that the investment for which the debt is incurred will provide a return that is greater than the cost of that debt. Although this seems like an elementary concept, it is often overlooked when making investment decisions.

The two methods commonly used to make this assessment are net present value (NPV) or internal rate of return (IRR). ${ }^{2}$ To describe NPV and IRR is beyond the scope of this paper but a rancher should employ one of these methods, using outside help, when making investment decisions for the operation.

\section{Monitoring Debt}

There are several ratios that can be used to monitor debt, but the two preferred here are the debt-to-asset ratio and current ratio. Debt-to-asset is a measure of financial position and expresses the proportion of the total farm assets that is owed to creditors. ${ }^{1}$ It is calculated by dividing total liabilities by total assets and a ratio of less than $30 \%$ is considered good.

The current ratio is an indication of the extent to which current farm assets, if liquidated, would cover current farm liabilities. ${ }^{1}$ In other words, it is the ability of the farm assets that will be turned into cash within 12 months to pay for the farm liabilities that will come due in that same period of time. This ratio is calculated by dividing current assets by current liabilities; a ratio above 1.5 is desirable.

\section{Strategy 5: Financial Efficiency}

The efficient use of resources is the cornerstone of successful ranching. Too often this concept is only applied to the use of rangelands or other natural resources. It is important that all assets of an operation be used efficiently for production, purchasing, pricing, financing, marketing decisions, and for generating revenues. ${ }^{1}$

The strategy of monitoring financial efficiency is included in the financial perspective so the rancher is aware of how efficiently the operation is being run. Although there are several ratios available for examining financial efficiency, the two presented here are: return on assets and operating expense ratio.

Return on assets (ROA) is a ratio that is an inclusive measure of efficiency. ${ }^{3}$ This ratio is preferred because it not only provides insight into the efficiency at which assets are used to produce net income from operations, but it is also an indication of how effective management is at deploying capital. ${ }^{4}$

Because ROA is a general measure of efficiency, those desiring greater detail can use the operational ratios, or more specifically the operating expense ratio, which measures the amount of gross revenue used to pay operating expenses. Although there are several operational ratios, the operating expense ratio is preferred because it provides information about a portion of the business (operating expenses) over which the rancher can exert immediate control. Some of the other operational ratios, such as depreciation and interest expense ratio, are important, yet they represent past investment decisions that are difficult to alter in the short term.

\section{Strategy 6: Measuring and Monitoring Profit- ability}

Up to this point the strategies have focused on increasing profitability. However, to determine if progress is being made, there needs to be a strategy in place for measuring and monitoring profitability. To measure profitability, return on assets (ROA), return on equity (ROE), and net ranch income (NRI) are preferred; for monitoring profitability, trend analysis and benchmarking are used.

\section{Measuring Profitability}

Return on assets, which has been discussed previously, is also a proven measurement of ranch profitability. ${ }^{3}$ This ratio compares Net Ranch Income to the base value of all ranch assets and is therefore an index of the net income against the value of assets employed to accomplish the production strategies that generate gross revenue. A healthy ratio would be greater than $5 \%$; however, striving for $10 \%$ or $15 \%$ is much better.

Return on Equity is the relationship of the equity or net worth of the ranching operation to the Net Ranch Income. This ratio is very helpful in comparing the profitability of ranch operations with other owned investments or potential investments. $\mathrm{ROE}$ is also very helpful in developing a trend line for the ongoing operation from year to year. Calculating this ratio is very similar to ROA in that you divide the net ranch income by the equity or balance sheet net worth.

Net Ranch Income is the calculation that remains after subtracting all expenses, including depreciation and gain or loss on the sale of capital assets, from gross revenues of the operation. This is done before income taxes. Because this does include noncash items such as depreciation, if cash-basis accounting is used, then accrual adjustments must also be incorporated into this calculation.

\section{Monitoring Profitability}

The financial measurements used so far have only provided information about the operation at a single point in time. Although this information is important, it is more valuable if it is monitored over time. This allows for the detection of trends, which gives a better indication of the financial direc- 
tion of the operation. The two methods chosen for monitoring internal financial trends are trend analysis and benchmarking.

Trend analysis is a simple process and only requires the rancher to have 5-10 years of financial data from which information can be collected. The information, which should include all of the metrics discussed so far, is displayed graphically to show the trends that are occurring within the operation.

Trend analysis not only shows how the operation has performed in the past, but it is also an indication of the future because a trend is expected to continue in the same direction until conditions change or management intervenes. Therefore, the real benefit of trend analysis is that it allows the rancher to see unfavorable trends and make necessary adjustments before they become detrimental to the operation.

Benchmarking is a process by which the rancher does a yearly financial performance comparison of the operation with similar operations. ${ }^{5}$ By doing so, it is determined how the operation is doing when compared to the industry standards. The rancher is then aware of where the inefficiencies are in the operation and adjustments can be made to improve financial performance.

Benchmark data for ranching can be collected from management consultants, extension services, industry associations, or universities. Many of the metrics that are discussed in this paper have benchmarks to which they can be compared. Although benchmarking is an extremely valuable management tool, it needs to be remembered that it is only useful when comparing "apples to apples." In other words, the comparison should be between operations of similar size and structure and the accounting methods used should be the same. The source from which the benchmark data are collected should be able to help determine the similarity of the operations.

\section{Conclusion}

A well-constructed balanced scorecard will have all strategies working together to accomplish a vision. Because profitability is assumed to exist in the vision statement for most ranches, the financial perspective includes strategies for achieving profitability and also strategies for analyzing the operation and strategies for measuring and monitoring the progress towards profitability. Although there might be others to consider, the ones presented here represent the most important and most comprehensive set of strategies for accomplishing the vision of profitability.

It is important to remember that this financial perspective (Table 1) was created for a ranch that has profitability as part of its vision. However, not all ranches will fall into this category. Some might be satisfied with merely breaking even, whereas others might choose to be profitable but only to a certain level. In such cases, the financial perspective will likely contain different strategies and metrics that are more suitable for achieving the particular vision.

Authors are Graduate Fellow, King Ranch Institute for Ranch Management, Texas AEัM University —Kingsville, Kingsville, TX 78363-8202 (Payne); and Consultant, Land E Livestock Advisory Service LLC, 17614 Tunnel Hill Rd., Lakeview, OR 97630,ptalbott@gooselake.com (Talbott).

\section{References}

1. Farm Financial Standards Council. 1997. Financial guidelines for agricultural producers: Recommendations of the Farm Financial Standards Council. Norwalk, CT: Financial Accounting Standards Board.

2. Gitman, L. J., and J. Madura. 2001. Capital budgeting techniques: certainty and risk. In: Introduction to finance. New York, NY: Addison Wesley. p 327-359.

3. Dunn, B. H. 2002. Measuring cow-calf profitability and financial efficiency. In: Proceedings of the Beef Improvement Federation, 34th Annual Research Symposium and Annual Meeting; 10-13 July 2002; Omaha, NE: Beef Improvement Federation. 218 p.

4. Miller, A., M. Boehlje, and C. Dobbins. 2001. Key financial performance measures for farm general managers. West Lafayette, IN: Purdue University Cooperative Extension Service Publication ID-243. 5 p.

5. McGrann, J. M., F. Abelló, and D. Richardson. 2003. Farm/ranch business financial analysis decision aid. College Station, TX: Texas Agricultural Extension Service and Texas A\&M University, Department of Agricultural Economics. 88 p. 


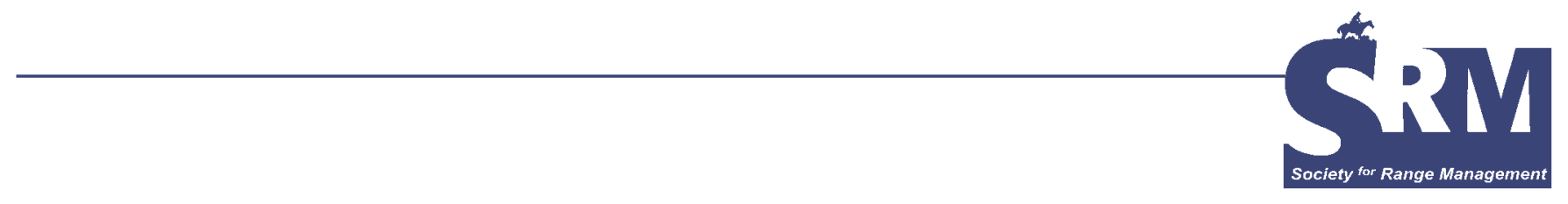

\title{
Low-Moisture Blocks: A Tool to Promote Uniform Utilization by Cattle?
}

\author{
Learn how to achieve uniform utilization across pastures that are partially burned.
}

\section{By Tanya M. Thrift, Tracy K. Brewer, and G. Robert Welling}

\section{Grazing Distribution Challenges Land Managers}

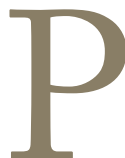

erhaps one of the most difficult tasks rangeland managers and ranchers face regarding cattle grazing is improving or influencing cattle distribution to promote grazing in under-utilized areas while minimizing overgrazing in other areas. Several landscapelevel factors, including slope, topography, distances to water and shade, and forage quality and availability influence where cattle graze. With these factors in mind, managers focus on improving cattle distribution through strategies that alter pasture attributes or strategies that capitalize on animal grazing behavior. ${ }^{1}$

Fire, whether prescribed or natural, alters pasture attributes, including vegetation growth patterns and forage quality, which can either positively or negatively influence cattle distribution across the altered landscape. Plant regrowth after fire is often more attractive to grazing animals than plants in unburned areas because of less dead plant material and higher palatability of new growth. Cattle often prefer areas altered by fire for up to 2 years postfire compared to unburned areas. ${ }^{2,3}$ Consequently, preferential grazing of burned areas can cause overutilization and can inhibit reestablishment of desirable vegetation. Research has demonstrated that strategic placement of low-moisture blocks (Fig. 1) is one tool that can

This article has been peer reviewed.

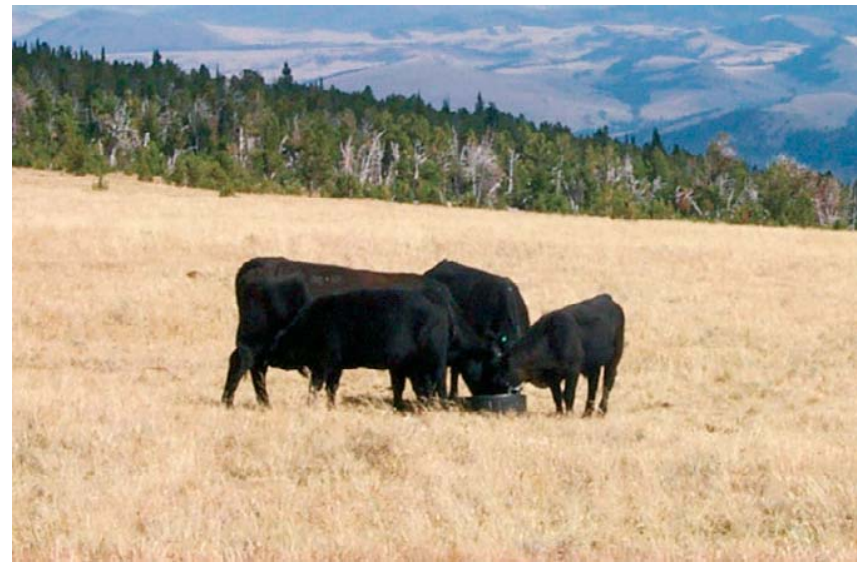

Figure 1. Cattle on summer range consuming low-moisture blocks.

encourage cattle to use areas that have been under-utilized, resulting in more even distribution on moderate terrain ${ }^{4}$ and more uniform utilization across pastures with varying topography and vegetation. ${ }^{5}$ Low-moisture blocks are a free-choice animal feed supplement, manufactured with a patented dehydration process that removes the water from molasses ingredients. Dry ingredients, that provide additional protein, energy, vitamins, and minerals, are then thoroughly combined with the dehydrated molasses for the completed supplement. In addition to influencing animal grazing behavior, these lowmoisture block supplements more accurately deliver nutrients to the targeted grazing animals. 


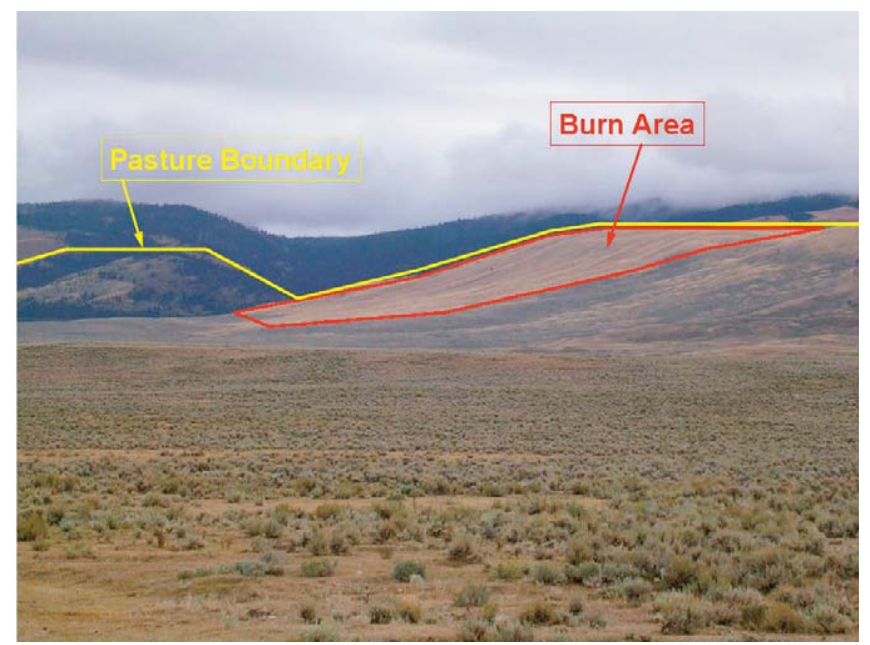

Figure 2. The 2,240-acre pasture in the Castle Mountains of central Montana that was partially burned in 2000.

To assess the influence that low-moisture blocks have on promoting more even levels of cattle utilization, both inside and outside of a burned area, low-moisture blocks were placed outside a burned area located within a 2,240acre pasture in the Castle Mountains of central Montana. The fire, which occurred in 2000, covered approximately 240 acres within an area of gently rolling sagebrush hills at lower elevations. The remainder of the pasture consisted of gently rolling sagebrush hills with steep, coniferous mountain slopes at higher elevations (Fig. 2). Adequate water developments and springs were available throughout the pasture. Average annual precipitation for the area between 1978 and 2001 was 13 inches, with 57\% falling from April through July. ${ }^{6}$

\section{Block Placement and Utilization Measurement Strategies}

Block placement sites were selected by ranch personnel within the unburned portion of the pasture to reduce the likelihood of cattle concentrating in the burned area during the grazing period. Each block placement site was about 7.5 acres and included areas that had historically been under utilized, as well as areas that typically received some use during the grazing period. Blocks were placed in pairs about 165 feet apart and the distance between each pair of blocks averaged 650 feet. Four pairs of blocks were used to accommodate the 200 cow-calf pairs present throughout the grazing period, resulting in 1 block for every 25 head of mature cattle. ${ }^{4}$ During the 8-week grazing period, from August 6 to September 30, 2002, blocks were successively placed at 3 different unburned sites. When the blocks at 1 site were completely consumed, new blocks were placed at a different site. On August 5, the day before cattle entered the pasture, blocks were placed at the first block placement site (Site A), which was farthest from the burned area (Map 1). Cattle were herded to the first block placement site to familiarize the animals with the blocks. Blocks were subsequently placed at the second block placement site (Site B), which was adjacent to and southwest of the first block placement site (Site A), on August 25, and at the third block placement site (Site C), which was closest to the burned area, on September 18. The cattle were removed from the pasture on September 30.

Forage utilization was characterized by collecting plant heights along transects located throughout block placement sites and also in key grazing areas both inside and outside of the burned area during 4 sampling periods. Height-weight forage curves were then used to determine forage utilization levels by converting plant height to percent utilization., Period 1 occurred prior to cattle turnout to account for any previous wildlife utilization that might have occurred. Periods 2 and 3 occurred immediately prior to placing blocks at sites $\mathrm{B}$ and $\mathrm{C}$, respectively, and Period 4 occurred after cattle were removed from the pasture. During each sampling period, plant height and the grazed/ungrazed status of 60 plants were recorded along a 1,040-foot transect. Transects were sampled on each block placement site both prior to and after the blocks were moved. Four transects were also completed within the burned area prior to grazing and after cattle were removed from the pasture to characterize grazing season utilization in the burned area.

\section{Impacts on Forage Utilization \\ Periods 1 and 2}

Utilization during Period 1, which occurred just prior to cattle grazing, was $<1 \%$ in both burned and unburned areas and was likely due to the observed presence of elk and mule deer. During Period 2, which occurred almost 3 weeks later, utilization data indicated that cattle were attracted to the areas around the blocks. The first block placement site (Site A) received $8 \%$ more utilization than unburned areas of the pasture and utilization on the site increased by almost 19\% between Periods 1 and 2. The rancher indicated that the portion of the pasture in this block placement site historically received very little use and that cattle were not observed in that area after blocks were moved.

\section{Periods 3 and 4}

Period 3 occurred on September 18, slightly more than 3 weeks after the second sampling period and 6 weeks after cattle were turned into the pasture. Utilization on the second block placement site (Site B), which was located on a ridge in the pasture, was approximately $20 \%$ during Period 3 . An increase from $11 \%$ to $20 \%$ utilization on this site between Periods 2 and 3 indicated that the blocks attracted and held the cattle on the ridge between sampling periods. Utilization levels on the block placement site were similar to the unburned key areas sampled (20\%), which suggests that both block placement and water developments on unburned key areas highly influenced cattle distribution patterns during Period 3. As with the previous sampling period, very few cattle were observed on the site after the blocks were moved.

The final sampling period occurred immediately after cattle were removed from the pasture. Percent utilization on 


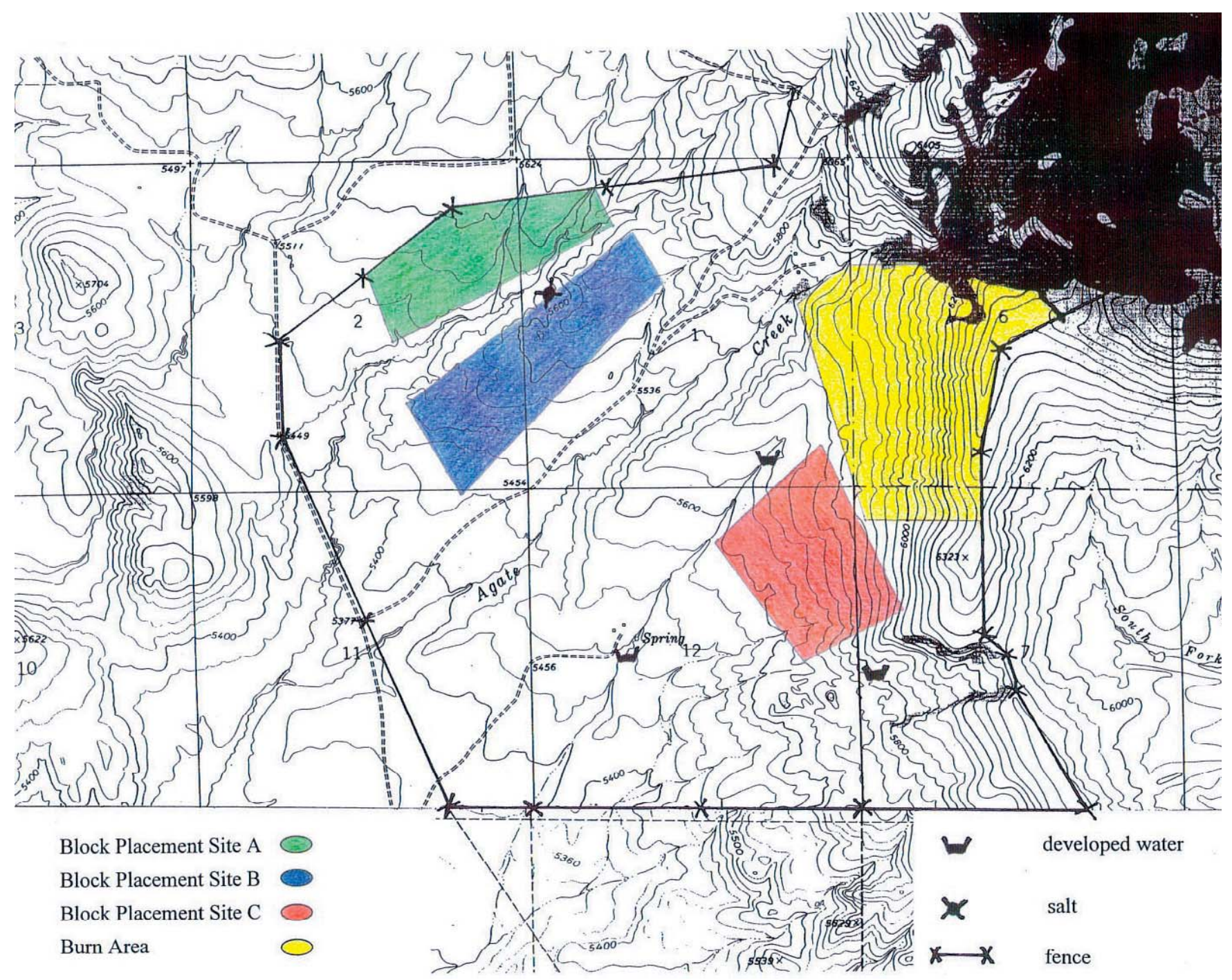

the final block placement site (Site C), which was closest to the burn, increased from $19 \%$ to $31 \%$ between Periods 3 and 4 and total utilization in this area was $<35 \%$ for the entire grazing season. The final block placement site had the most diverse and challenging terrain in the pasture and had typically not been used by cattle when adequate forage was available in other areas of the pasture.

\section{Uniform Grazing Distribution Is Achieved}

Overall, forage use across the entire 2,240-acre pasture was relatively light. At the end of each sampling period, utili-

Table 1. Average percent utilization on block placement sites before and after block placement

\begin{tabular}{|c|c|c|}
\hline & ------ \% Utilization ------- \\
\hline Block placement site & Before & After \\
\hline A & 0.0 & 19.2 \\
\hline B & 11.0 & 20.3 \\
\hline C & 19.3 & 30.7 \\
\hline
\end{tabular}

zation averaged 23\% across block placement sites (Table 1). Utilization on unburned key areas that were sampled away from block placement sites averaged 8 percentage points less than block placement sites throughout the experiment. Percent utilization in the burned area of the pasture was also $23 \%$ at the end of the grazing period, which mimics the level of use that occurred on block placement sites and exceeds the level of grazing that occurred on unburned key areas throughout the experiment.

These results indicate that low-moisture blocks attracted cattle away from the burned area to the unburned portion of the pasture, creating uniform utilization across the pasture. Utilization was relatively low across the pasture among burned and unburned sites and areas that did and did not have blocks present on them. Placement of low-moisture blocks, in conjunction with available water, discouraged cattle from concentrating on sensitive forage within the previously burned area, enhanced use of under-utilized forage in topographically challenging portions of the pasture, and, ultimately, encouraged more uniform use of available forage across the pasture. 
Authors are Range Technician, Bureau of Land Management, Dillon, MT59725, t_mackie_t@hotmail.com (Thrift); Assistant Research Professor (Brewer), Department of Animal and Range Sciences, Montana State University, Bozeman, MT 59717; and Research Support Manager (Welling), Ridley Block Operations, Vaughn, MT.

\section{References}

1. Bailey, D. W. 2004. Management strategies for optimal grazing distribution and use of arid rangelands. Journal of Animal Science 82(E. Supple.):E147-E153.

2. Willms, W., A. W. Bailey, and A. McLean. 1980. Effect of burning or clipping Agropyron spicatum in the autumn on the spring foraging behaviour of mule deer and cattle. Journal of Applied Ecology 17:69-84.

3. Willms, W., A. W. Bailey, A. McLean, and R. Tucker. 1980. The effects of fall grazing or burning bluebunch wheat- grass range on forage selection by deer and cattle in spring. Canadian Journal of Animal Science 60:113-122.

4. Bailey, D. W., and G. R. Welling. 1999. Modification of cattle grazing distribution with dehydrated molasses supplement. Journal of Range Management 52:575-582.

5. Bailey, D. W., G. R. Welling, and E. T. Miller. 2001. Cattle use on foothills rangeland near dehydrated molasses supplement. Journal of Range Management 54:338-347.

6. Western Regional Climate Center. 2002. White Sulphur Springs 2, Montana (248930). Available at: http://www.wrcc. dri.edu/. Accessed 28 February 2007.

7. U.S. Forest Service-Rocky Mountain Forest and Range Experiment Station. 1980. Utilization gauge: an instrument for measuring the utilization of grasses. Wheaton, IL:American Slide-Chart Corporation. 


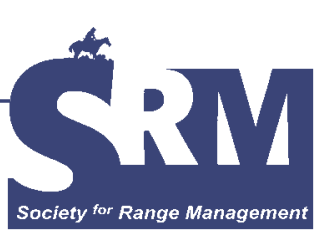

\section{How to Build Cost-Effective Skid- Sprayers for Prescribed Burning}

\section{By Nick Garza and Charles Taylor}

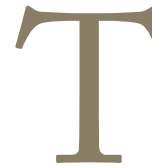

he decline of grassland and savanna ecosystems due to woody plant encroachment has led to an increase in restoration efforts largely focused on reintroducing an effective fire regime. However, reintroduction of fire into Texas ecosystems has not been easy, especially in the Edwards Plateau region, where fire has been suppressed since the development of the livestock industry. Implementation of an effective prescribed burning program requires rancher and landowner education and cooperation; it also requires prescribed fire training, sharing of proper equipment, reduced liability, and the ability of ranchers to gain experience on the fire line as well as writing burn plans and managing prescribed fires. Equally important in getting a sustainable fire program started is the ability to conduct prescribed burns under a wide range of environmental conditions (for example, conducting prescribed fire during burn bans). The formation of prescribed burn associations, such as the Edwards Plateau Prescribed Burn Association, has provided a framework for ranchers and other landowners to collectively manage all of these factors with the end result of a substantial increase in prescribed fire on Texas rangelands. ${ }^{1}$

\section{Proper Equipment}

With the increase in prescribed burning in general, and burning during the hot, dry growing season in particular, more efficient and cost-effective fire suppression equipment is a very critical component. Most ranchers have livestock sprayers; however, through years of prescribed burning experience, it is readily apparent that these machines were designed for purposes other than use on the fire line. What is needed is

This article has been peer reviewed. portable, light-weight, slip-in spray units that can be transferred from one truck to another at a moment's notice. There are many commercial models of slip-in spray rigs on the market that have been used by fire departments. These are well-made and efficient but tend to be costly. Commercially manufactured spray rigs can range from $\$ 3,000$ to $\$ 10,000$ and up for skid-mounted products that slide into a truck bed. On most prescribed burns, a minimum of 2 or more 150-200 gallon spray rigs are needed on site that can deliver 10-30 gallons per minute. These units must be portable and reliable. In addition to these units other on-site storage tanks, smaller sprayers for 4-wheelers, and backpack sprayers should be available. A good rule of thumb is that you can never have too much water at a fire.

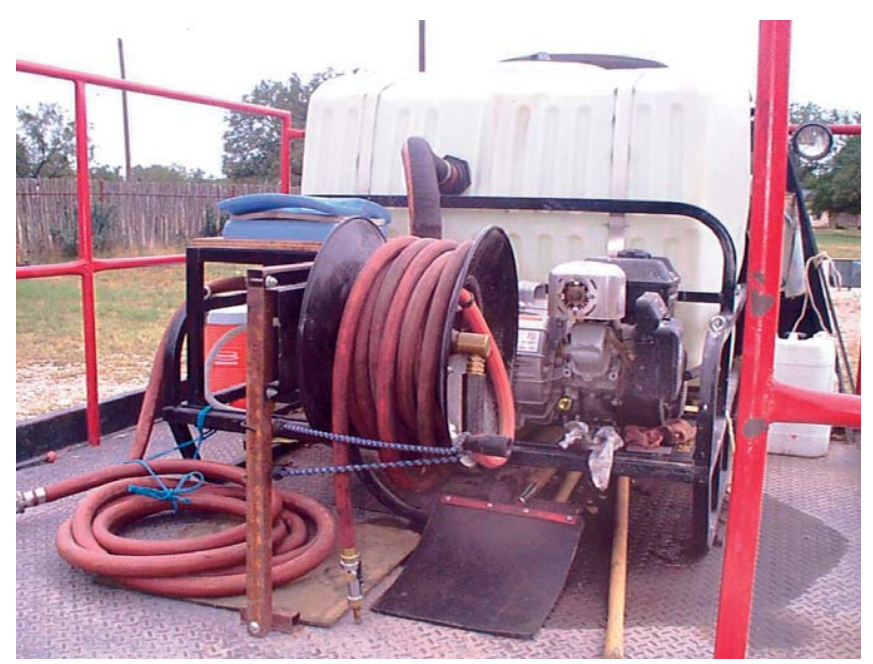

Figure 1. Slip-in unit showing 200-gallon tank, motor, pump, and hose. 
Table 1. Sprayer parts and prices

\begin{tabular}{|c|c|c|c|}
\hline Part & & Cost & Extension \\
\hline Poly tank & $200-230$ gallon & $\$ 250.00$ & $\$ 250.00$ \\
\hline Pump & 5.5 hp Briggs w/ 75 psi pump & $\$ 450.00$ & $\$ 450.00$ \\
\hline \multicolumn{4}{|l|}{ Fittings } \\
\hline & 2-inch nipple-close & $\$ 2.30$ & \\
\hline & 2-inch ball valve & $\$ 30.00$ & \\
\hline & 2-inch nipple-close & $\$ 2.30$ & \\
\hline & 2-inch Tee & $\$ 6.30$ & \\
\hline & ô Camlock $\times$ ô threads & $\$ 4.50$ & \\
\hline & 2-inch Camlock cap & $\$ 9.00$ & \\
\hline & 2-inch nipple-close & $\$ 2.30$ & \\
\hline & 2-inch union & $\$ 14.00$ & \\
\hline & 2-inch combination nipple & $\$ 2.50$ & \\
\hline & 2-inch $\&$ Camlock $\times$ hose barb & $\$ 9.00$ & \\
\hline & 2-inch ô Camlock $\times$ p pipe threads & $\$ 3.50$ & \\
\hline & 2-inch union & $\$ 14.00$ & \\
\hline & 2-inch street El & $\$ 6.00$ & \\
\hline & 2-inch to 1 -inch bushing & $\$ 2.00$ & \\
\hline & 1-inch nipple-close & $\$ 1.30$ & \\
\hline & 1-inch Tee & $\$ 4.00$ & \\
\hline & 1 -inch to $3 / 4$-inch bushing & $\$ 1.30$ & \\
\hline & 1 -inch ơ Camlock $\times$ ô pipe threads & $\$ 3.50$ & \\
\hline & 1 -inch Ball valve & $\$ 16.00$ & \\
\hline & 2-inch $\$$ Camlock $\times$ hose barb & $\$ 9.00$ & \\
\hline & 1 -inch $q$ Camlock $\times$ hose barb & $\$ 7.00$ & \\
\hline & 1 -inch combination nipple & $\$ 1.50$ & $\$ 151.30$ \\
\hline \multirow[t]{2}{*}{ Hose } & 20 feet of 1 -inch red utility hose & $\$ 30.00$ & \\
\hline & 22 feet of 2-inch suction hose & $\$ 20.00$ & $\$ 50.00$ \\
\hline Clamps & 3 worm drive hose clamps & $\$ 6.00$ & $\$ 6.00$ \\
\hline Nozzle & 1 -inch aluminum & $\$ 35.00$ & $\$ 35.00$ \\
\hline Skid & 1 -inch tubing, rods, grinding wheels & $\$ 110.00$ & $\$ 110.00$ \\
\hline $\begin{array}{l}\text { TOTAL } \\
\text { COST }\end{array}$ & & & $\$ 1,052.30$ \\
\hline
\end{tabular}

Pump stats: 1 -inch hose open flow $=55 \mathrm{gpm} ; 1$-inch nozzle heavy stream $=31 \mathrm{gpm} ; 1$-inch nozzle tight stream $=9 \mathrm{gpm}$; and spray distance $=53$ feet. 
We have been building portable spray rigs for use by the Edwards Plateau Prescribed Burning Association for several years and have developed a reasonably priced unit $(\$ 1,050)$ that provides adequate protection for most situations. These units are built from easily obtained parts and have proven to be portable, easy to operate, and reliable (Table 1). The level of complexity of these units varies depending upon the needs or desires of the builder but can be customized to serve several uses.

Figure 1 shows a design that incorporates only those parts necessary for spraying water and drafting to refill this tank or another tank. Water can be sprayed using a 1-inch outlet for higher volume or using a $3 / 4$-inch hose bib connection when smaller volumes are needed. The schematic shows the basic intake and discharge of water but does not take into account length of connections and relative position of each part because that will depend upon size of the water tank, skid dimensions, and level of complexity in plumbing design. With each increase in pump complexity, more space will be needed to fit additional parts into a limited amount of space.

Our experience has shown that a 5-6 hp engine with a moderate pressure centrifugal pump (70-80 psi with nozzle flow of 10-30 gpm) and high volume (80-150 gpm at open flow with 2-inch inlet and outlet) is relatively lightweight and provides enough pressure and volume to be an effective fire-suppression rig. These units are readily available, and when given proper care will last for years. Centrifugal pumps also have several advantages over other types of water pumps. These pumps are not affected by back pressure and thus, bypass lines are not necessary for pressure control. However, if water is not sprayed periodically after a few minutes, a build up of heat can occur which can eventually damage the pump. We solved this problem by adding a $1 / 2$-inch line with a ball valve from the tank to the discharge port. By opening this line slightly you provide water circulation without affecting water discharge significantly. Another simple solution would be to put the nozzle end into the tank and let water flow

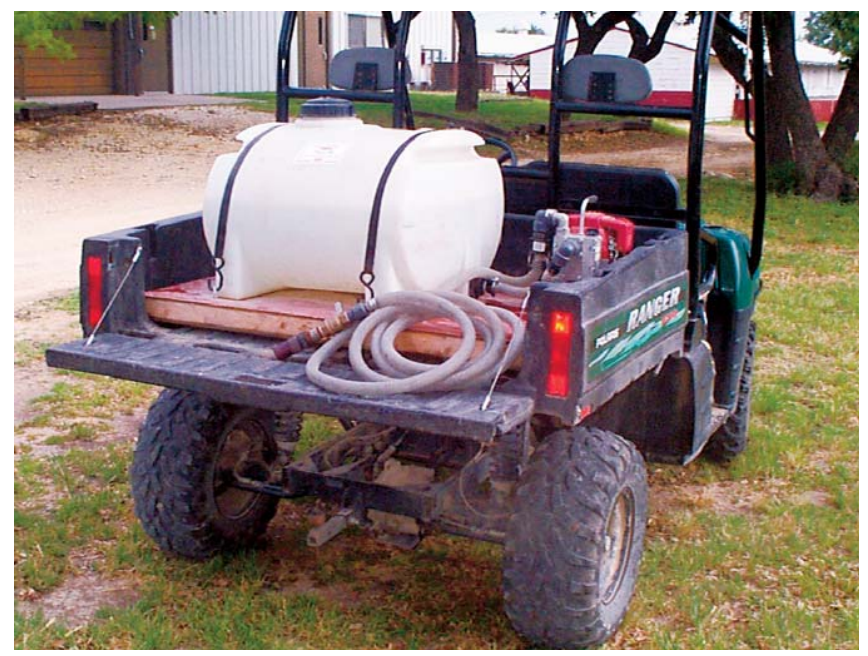

Figure 2. Polaris Ranger with 50-gallon tank and 1 1/2-hp engine. back to the tank when not spraying. Most centrifugal pumps can handle small solids ( $<1 / 8$ inch) as well, so fine-screen filters are not necessary; however, use relatively clean water and always use a $1 / 8$-inch strainer on the suction line. The cost and maintenance on centrifugal pumps is relatively low. Pumps with an attached 5-6 hp engine can be purchased for $\$ 500-\$ 600$ and free standing pumps can be attached by pulleys to many horizontal shaft engines.

Tank size depends upon size of the vehicle and amount of space available. Our original designs called for a 150-225 gallon tank. This provides a reasonable amount of water and can be carried by most full-sized pickups. Recently, many burn association members have been driving smaller trucks, jeeps, and small 4-wheel utility vehicles (eg, Polaris Rangers) which have less payload capacity, so we are building centrifugal sprayers with smaller tanks and smaller pumps and engines (Fig. 2).

Fittings originally used to plumb the units were galvanized, if weight was not a great issue, to reduce rust. However, many plastic or composite fittings are available that are able to withstand the pressures of a centrifugal pump. These fittings are lighter and easier to put together than galvanized parts and are often less expensive. The use of "Cam Action" or "Quick Couple" connections make assembly and disassembly much easier as well.

Most pumps in the horsepower range we use come standard with 2-inch intake and discharge ports (Fig. 3). Our standard assembly uses 2-inch fittings and hoses for all intake plumbing. We reduce discharge lines to $1 \mathrm{inch}$ or $3 / 4$ inch for ease of use. There are variable flow 1-inch nozzles that can put out 10-30 gallons per minute, which is adequate for most situations. Reducing the fitting size on the intake side reduces maximum water flow on the discharge side.

Other important considerations:

1) Preconstructed skid-frames can be purchased for different prices (average price is approximately $\$ 800$ ) or they can be self-constructed for much less. The main concern is will the skid-frame fit in the bed of your truck (between wheel wells and over a goose neck hitch), and will your truck handle the load. We suggest a skid-frame that can fit in almost any truck so it can be transferred easily.

2) Tanks can be plastic, fiberglass, or metal in any size. We use plastic because it is lighter and costs less. Prices range from about $\$ 150$ and up for the $150+$ gallon tanks.

3) Plumbing is usually kept as simple as possible. We like to include at least one fitting to allow drafting to refill the tank quickly. The best fittings are galvanized or aluminum because they are strong and do not rust. We also have used poly and nylon fittings. These work well when connected to flexible connections but sometimes do not hold up if they are used in a position where there is movement or vibration. We have developed systems that can draft water, transfer water, spray with a 1 -inch line, a garden hose, or inject soap into the system. 


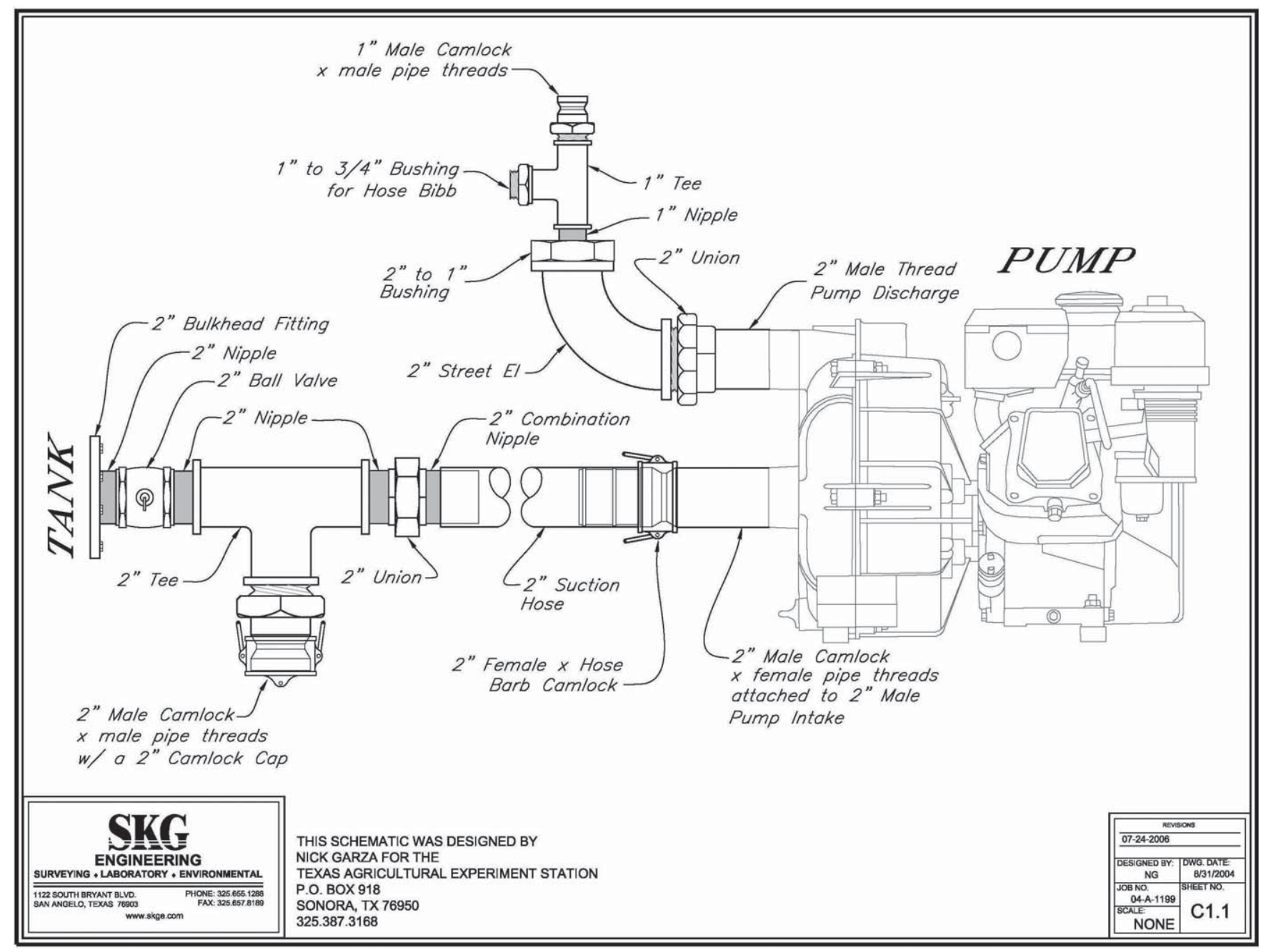

Figure 3. Schematic design of slip-in spray unit.

4) Use a 2-inch bulkhead fitting in the tank and mount the pump in a position to connect the 2 -inch intake to the 2 -inch hole in the tank. If you are not interested in being able to draft from a reservoir, then hook directly from tank to pump. If you want to draft, then connect a 2-inch $T$ and a ball valve in between the pump and tank so you have a connection and a cutoff to stop the flow of water from the tank. A 2-inch male cam lock and a 2-inch cap is all that is needed to close this connection. The ball valve is open when spraying water and closed when drafting.

5) Fifteen to 20 feet of suction hose should be adequate for drafting. A strainer should be attached to the end of the hose to prevent the passage of solids greater than $1 / 8$ inch in diameter.

6) We like to use approximately 20 to 30 feet of 1 -inch red utility hose which does not need to be rated for high pressure. We prefer this length because hoses of greater length increase the probability of the hoses being tangled, run over, and in the way. Also, we prefer the operator to stay in the back of the truck as much as possible and not be lugging a fire hose any great distance from the truck. Use whatever kind of nozzle is preferred, but remember that volume is always going to be determined by the smallest opening on the line.

Authors are Senior Research Associate, nickg@sonoratx.net (Garza) and Professor (Taylor), Texas Agricultural Experiment Station, Texas AEऽM University System, Sonora, TX 76950.

\section{Reference}

1. TAYlor, C. A., JR. 2005. Prescribed burning cooperatives: empowering and equipping ranchers to manage rangelands. Rangelands. 27:18-23. 


\section{SiM}

\section{Rapid Assessment}

Methodology for Proactive

Rangeland Management

\section{By Christopher D. Allison, Jerry L. Holechek, Terrell T. Baker, Jon C. Boren, Nicholas K. Ashcroft, and John M. Fowler}

here is an increasing need for rangeland monitoring methodologies that provide rapid assessment of grazing conditions, with reasonable cost and labor requirements. Controversies and problems regarding livestock grazing management decisions on public lands have been on the rise during the past 15 years. Agencies managing public rangelands, primarily the Forest Service and Bureau of Land Management, are under increased pressure to be more proactive in their management decisions and to base these decisions on reliable quantitative data. These pressures have come from an affluent rapidly growing human population that demands high-quality recreation, aesthetic

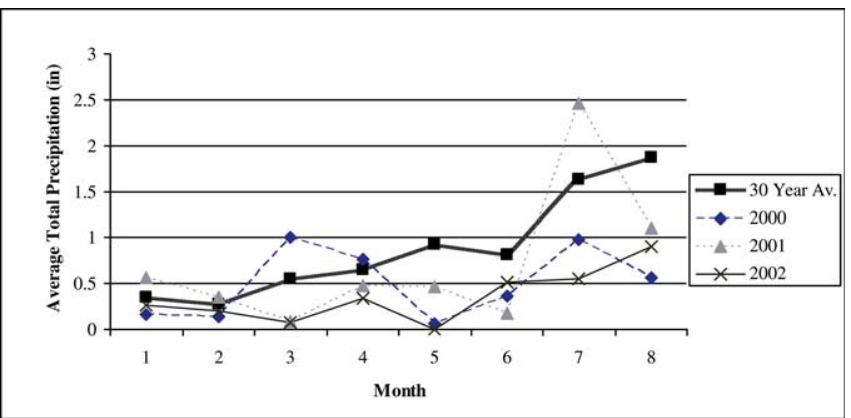

Figure 1. Total monthly precipitation (January-August) relative to 30year average for 2000, 2001, 2002 at the Abiquiu Dam, New Mexico, Station from the Western Regional Climate Center. While not site specific, Abiquiu Dam is centrally located to provide an index of precipitation on allotments surveyed during 2002.

This article has been peer reviewed. appearance, and abundant wildlife populations from public rangelands. Drought, enforcement of the National Environmental Policy Act, and the desire by ranchers to better manage their rangelands have further increased the need for quick, practical, low-cost, and rapid assessment methods for grazing management decisions.

In the late spring of 2002, rangelands throughout New Mexico were in the third year of severe drought (Fig. 1). In July, ranchers and agency personnel were facing important decisions regarding forage availability, carrying capacity, and length of grazing season on Forest Service lands near Santa

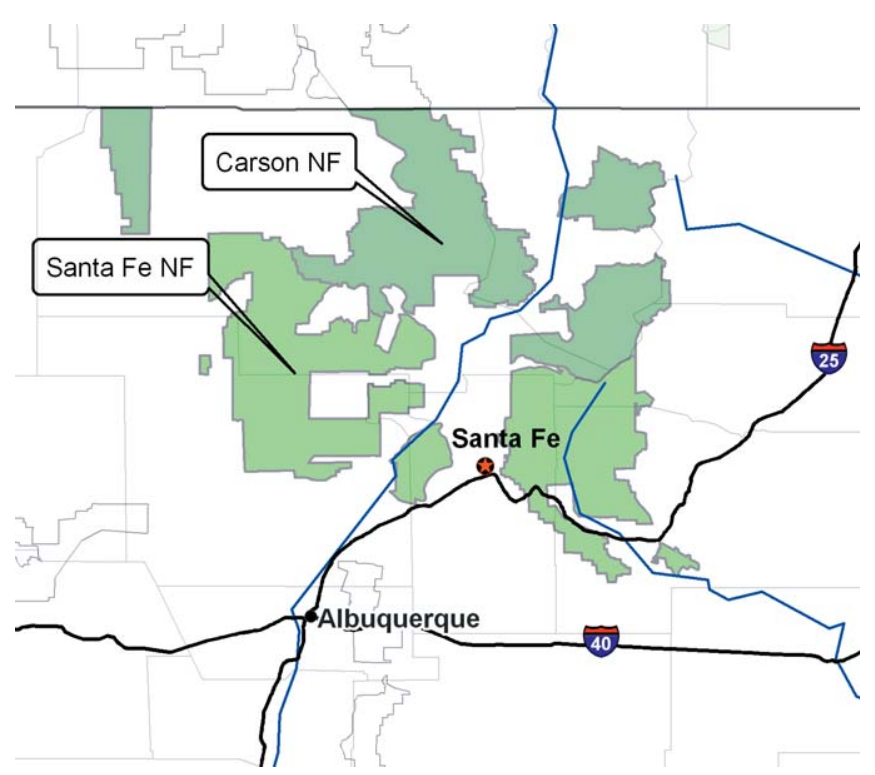

Figure 2. Map of the Santa Fe National Forest in New Mexico. 
Fe, New Mexico (Fig. 2). Forest Service range personnel and grazing permittees contacted the Range Improvement Task Force at New Mexico State University. They requested that surveys be conducted to provide the basis for decisions regarding grazing duration and intensity on allotments comprising nearly 586,000 acres on the Santa Fe National Forest. These surveys involved 116 families on 25 different allotments and had to be completed in a matter of weeks. Seven teams (3 or 4 range science technicians each) were assembled to accomplish this mission. Prior to implementation of these surveys, the authors of this article met to decide what soil and vegetation characteristics should be evaluated to effectively assess range condition and grazing suitability in a short period of time. It was decided that the key area approach, coupled with any historical range transect that existed, would be used for surveys on each allotment. Cover, species composition, residual forage biomass, grass stubble heights, and photographs were used to characterize vegetation status. Pellet group counts served as an index of wild and domestic ungulate use. In order to assess potential plant growth, depth of soil moisture was evaluated at each site. In the remainder of this article, we discuss our specific rapid assessment procedures and their outcomes. We believe the approach we used has practical application for rangelands in other parts of the western United States and different parts of the world.

\section{Rapid Assessment Methodology}

Our rapid assessment methodology depended on proper selection of key areas. Key areas are an essential part of any sound rangeland monitoring program. ${ }^{1,2}$ The key area is a portion of a range unit that, because of its location, grazing or browsing value, and/or use, serves as an indicative sample of forage production, trend, or degree of seasonal use. We used the following criteria and guidelines in our selection of key areas for monitoring on the Santa Fe National Forest.

Key areas were typically between one-quarter and 1 mile from water sources, on slopes less than $15 \%$, on soils in satisfactory condition, and greater than 5 acres in size. Historic agency transect and cluster locations were evaluated for their potential as current monitoring sites. However, just because they were once historic key areas did not qualify them as current key areas. Water, fence, and road locations may have changed livestock distribution to make the historic sites poor locations for current monitoring efforts. These sites were evaluated individually and changed when deemed necessary.

There are no universal guidelines to determine the number of key areas to be monitored on a particular allotment or ranch. Differences in ranch size, pasture size, and site heterogeneity all combine to make such strict guidelines impossible. We attempted to install at least 1 key area for each range site or vegetation type on each allotment. However, in a few cases this was not possible because of time constraints, access, or other considerations. A total of $77 \mathrm{key}$ areas and sites were sampled across all 25 allotments. Key areas were marked on a topographic or allotment map.

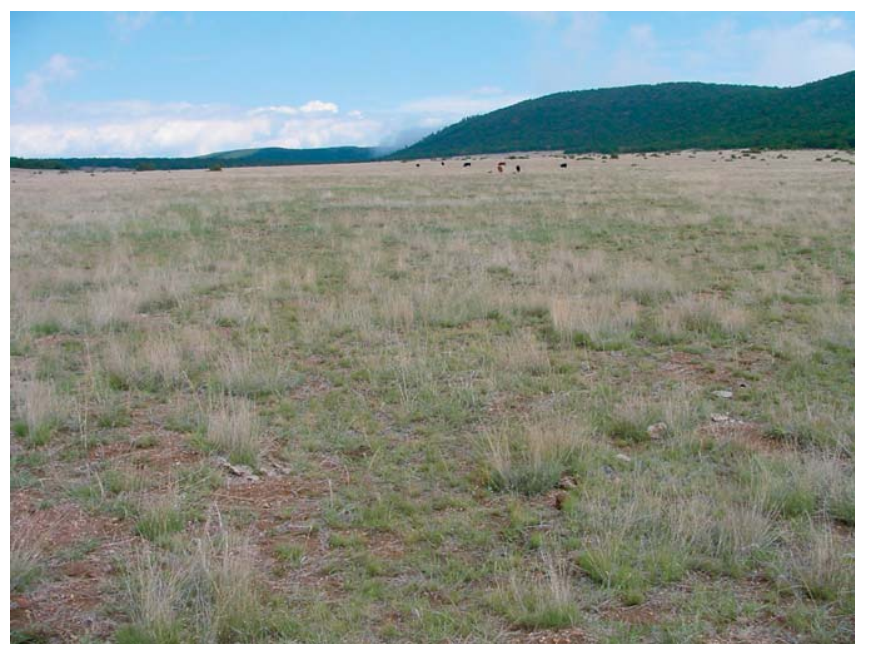

Figure 3. Sample key area used for rapid assessment methodology used on Santa Fe and Carson National Forests in the late spring of 2002. Erasable marker board with site labels are not included to maintain privacy.

We recognize that, ideally, monitoring should be conducted in autumn to determine net forage supply after the growing season. When possible, monitoring should also be conducted before spring green-up, when forage standing crop is at minimum. However, we designed the rapid assessment methodology to be used to provide quantitative information for adaptive management purposes at any time during the grazing season.

\section{Photo Points}

We used photo points to provide a visual qualitative record to support quantitative site data. We believe that 2 photographs should be taken at each monitoring site: 1 landscape-level photo point and 1 ground-level photo point. The landscape photo provided a panoramic view of the monitoring site (Fig. 3 ) and can be marked with a steel t-post. Approximately 15 feet away from the t-post, we propped up an erasable marker board so it could easily be seen in the photograph. Pasture name, photo point number, and date were recorded on the board. We also recorded the direction the photo was taken. We tried to include in the photograph some landmark, such as a rock outcrop or hill, so the same photo location could be used each visit. Technicians should have the previous year's photograph with them to more readily duplicate the photo. If no landmarks are apparent, we take a compass reading. We recorded the photo point site on a USGS topographic map or aerial photograph for future reference and recorded the GPS coordinate. We placed the ground-level photo point at least 10 feet away from the steel $t$-post in a location that is representative of the vegetation composition and ground cover.

\section{Determination of Cover and Species Composition}

We used the step-point method for determining plant cover and species composition. ${ }^{3}$ We like this method because of its simplicity and reliability. It involves making observations along a transect at specified intervals using a pin or tip of the 
Table 1. Critical stubble-height minimums for different categories of New Mexico forage grasses

\begin{tabular}{|c|c|c|c|c|}
\hline $\begin{array}{l}\text { Extra short } \\
3 / 4 \text { inches }\end{array}$ & $\begin{array}{l}\text { Short } \\
1.5 \text { inches }\end{array}$ & $\begin{array}{l}\text { Short-mid } \\
2.5 \text { inches }\end{array}$ & $\begin{array}{l}\text { Mid } \\
4.0 \text { inches }\end{array}$ & $\begin{array}{l}\text { Tall } \\
8.0 \text { inches }\end{array}$ \\
\hline $\begin{array}{l}\text { Muhlenbergia } \\
\text { torreyi }\end{array}$ & $\begin{array}{l}\text { Bouteloua } \\
\text { aristoides }\end{array}$ & $\begin{array}{l}\text { Agropyron cris- } \\
\text { tatum }\end{array}$ & Aristida arizonica & Andropogon spp. \\
\hline Bouteloua gracillis & $\begin{array}{l}\text { Bouteloua } \\
\text { gracillis }\end{array}$ & Agropyron smithii & Blepharoneuron tricholepis & $\begin{array}{l}\text { Sporobolus } \\
\text { airoides }\end{array}$ \\
\hline \multirow[t]{19}{*}{ Hilaria belangeri } & $\begin{array}{l}\text { Bouteloua } \\
\text { hirsuta }\end{array}$ & Aristida & Bouteloua curtipendula & $\begin{array}{l}\text { Sporobolus } \\
\text { wrightii }\end{array}$ \\
\hline & $\begin{array}{l}\text { Bromus tec- } \\
\text { torum }\end{array}$ & Aristida pansa & Bromus inermis & $\begin{array}{l}\text { Mulenbergia } \\
\text { emersleyii }\end{array}$ \\
\hline & \multirow[t]{17}{*}{ Carex spp. } & Aristida purpurea & Dactylus glomeratus & $\begin{array}{l}\text { Muhlenbergia } \\
\text { rigens }\end{array}$ \\
\hline & & $\begin{array}{l}\text { Bouteloua eri- } \\
\text { opoda }\end{array}$ & Danthonia intermedia & $\begin{array}{l}\text { Sorghastrum } \\
\text { nutans }\end{array}$ \\
\hline & & Hilaria jamesii & Danthonia parryi & \\
\hline & & Juncus spp. & Deschampsia caespitosa & \\
\hline & & Koeleria cristata & Elymus elmoides & \\
\hline & & $\begin{array}{l}\text { Koeleria macran- } \\
\text { tha }\end{array}$ & Elymus smithii & \\
\hline & & Lycurus phleoides & Festuca arizonica & \\
\hline & & $\begin{array}{l}\text { Muhlenbergia } \\
\text { spp. }\end{array}$ & Festuca thurberi & \\
\hline & & M. montanus & Muhlenbergia virescens & \\
\hline & & Poa fendleriana & Oryzopsis hymenoides & \\
\hline & & Poa pratensis & Phleum pratense & \\
\hline & & $\begin{array}{l}\text { Lycopodium } \\
\text { selago L. }\end{array}$ & Sitanion hystrix & \\
\hline & & Festuca ovina L. & Sporobolus cryptandrus & \\
\hline & & $\begin{array}{l}\text { Muhlenbergia } \\
\text { wrightii }\end{array}$ & Stipa spp. & \\
\hline & & $\begin{array}{l}\text { Agrostis hooveri } \\
\text { Swallen }\end{array}$ & Agropyron intermedium & \\
\hline & & $\begin{array}{l}\text { Bouteloua eri- } \\
\text { opoda }\end{array}$ & Dactylis glomerata L. & \\
\hline & & & Schazachyrium scoparium & \\
\hline
\end{tabular}

Note: Use abbreviations for recording on data sheets. The first 2 letters of both genus and species is used (ie, Muto for Muhlenbergia torreyi). Source: Holechek and Galt (2004).

boot to record "hits." Total cover, cover of individual species, and species composition were derived from the record of hits.

The initial starting point and direction of the step-point transect should be randomly determined (eg, randomly selecting a bearing between 1 and 360 degrees or simply using the minute hand of a wristwatch to determine the transect direction). However, we also used professional judgment to ensure that the transect did not intercept inappropriate areas (ie, roads, salting areas, etc.) and that it was representative of the entire key area.

To determine cover, observation points were made at paced (approximately 5 foot) intervals. Each step-point transect 
had a total of 100 basal hits. At each basal hit, we recorded the cover type that bisected a pin or tip of the boot. We used 4 cover type categories, including litter, bare ground, rock, and vegetation. The basal hits were then recorded on the data sheet. If the basal hit was on live vegetation, then the species was identified and recorded on the data sheet. If the basal hit was not on live vegetation, then the nearest plant species was identified and recorded. A summary of the plant species present and relative composition based on 100 observations was provided for each transect.

\section{Residual Forage Biomass}

In order to determine residual forage biomass, we clipped a total of 5, 6- by 24-inch quadrats along the step-point intersect transect. The 5 sampling points were at the 20 th, 40 th, 60th, 80th, and 100th observation points along the transect. All palatable herbaceous forage plants (includes both grasses and forbs) within the 6- by 24-inch quadrat were clipped to ground level and placed into a paper bag. Experience and the site-specific foraging habits of livestock on the allotment determined which forage species we clipped. Clipping more than 5 frames per transect would be desirable. However, we recognize that increasing the intensity may dissuade range managers from collecting data or severely reduce the number of sites visited. Either of these results is undesirable, so we recommend that interpretation and analyses of data should take the small number of clipped samples into consideration.

Samples were then placed in an oven for 24 hours at approximately $60^{\circ} \mathrm{C}$. This is important in order to standardize weights because percent plant moisture can account for a significant portion of the plant's weight and may vary drastically from one day to the next. Samples were then weighed to the nearest $0.01 \mathrm{~g}$. A conversion factor of 96 (for a 6- by 24-inch sampling frame) was used to convert grams to pounds per acre.

We consider residual forage biomass important for avoiding harm to soil, vegetation, livestock, and wildlife. Across the western United States, on most sites, a minimum of between 100 and 200 pounds per acre of residual foraging matter is needed to sustain these values. ${ }^{1,4}$

\section{Determination of Grazing Intensity}

Because of its simplicity, reliability, and wide acceptance, we used stubble height of herbaceous forage grasses to assess grazing intensity. 5 We took stubble height measurements while evaluating basal cover using the step-point method. We implemented the stubble height method as follows. If the basal hit is on a grass species, the stubble height (average leaf length of majority of leaf blades) was measured using a ruler and recorded on a data sheet. However, if the basal hit was not a grass species, then the stubble height of the nearest grass species was determined and recorded on the data sheet. Mean stubble heights by species were then compared to stubble height guidelines developed for New Mexico rangelands (Table 1)., ${ }^{5,6}$ These guidelines describe the mini- mum advisable stubble height for continued livestock grazing. They are not intended for use as management targets but are thresholds below which grazing is detrimental to plants, livestock productivity, and site stability. ${ }^{5,6}$ Leaf length should be measured by pulling leaves up (not by measuring in place) and estimating the average height (not longest or shortest) of the majority of leaf lengths. This approach standardizes the measurement and eliminates variability associated with weather conditions (ie, moisture, wind, etc.).

Our stubble height measurements were not converted to percent utilization. Similarly, frequency of use (ie, comparing number of grazed vs ungrazed plants) was not used to determine utilization or to measure range condition. As always, we stress that our purpose was not to determine grazing use but rather to avoid excessive defoliation that could cause long-term harm to grass plants.

\section{Soil Moisture Depth}

In order to make relative comparisons regarding potential plant growth between pastures or allotments, the depth of soil moisture was recorded at each monitoring location by digging a soil pit. A soil core was first removed using a spade or shovel. The depth was then recorded at which the moist and dry soil meet. Qualitative descriptions of soil moisture availability were then recorded (ie, wet to 3 inches, moist 3-6 inches, dry 6-12 inches). This information can be used to estimate the adequacy of soil moisture for plant growth.

\section{Index of Wild and Domestic Ungulate Use}

Pellet-group counts for elk, deer, and cattle were made within a belt transect. The belt transect was 6 feet on each side of the existing step-point transect (approximately 500 feet) used for vegetation sampling and was delineated while walking using a 6-foot carpenter ruler.

A minimum of 15 pellets of the same size, shape, and age were considered to be a group for elk and deer. At least 50\% of the elk and deer pellets in a group had to occur within the belt transect boundary to be counted. The same 50\% standard applied to cattle fecal groups. The number of cattle fecal piles also were counted within the belt transects. Each cow pie constituted 1 defecation event.

This particular pellet group method was not used to make density estimates for wild or domestic ungulates. However, this method provided a relative index of use by elk, deer, and cattle. It also provided an approximation of animal trends over time and a rough assessment of which animals were responsible for observed use. Because the defecation rate between elk (average 13 pellet groups per day) ${ }^{7-9}$ and cattle (average 9 groups per day) $)^{10,11}$ are not the same, they must first be standardized before any comparison can be made.

\section{Data Interpretation and Decision Making}

After data collection in the field, quantitative information was computerized and summarized for each allotment by Range Improvement Task Force personnel. Each allotment 


\begin{tabular}{|c|c|c|}
\hline $\begin{array}{l}\text { Information } \\
\text { category }\end{array}$ & $\begin{array}{l}\text { Types of } \\
\text { measurements }\end{array}$ & $\begin{array}{l}\text { Managerial } \\
\text { applications }\end{array}$ \\
\hline & Plant cover & Soil stability, watershed health, rangeland \\
\hline Vegetation & Species composition & Ecological condition, stocking rate, grazing \\
\hline \multirow[t]{2}{*}{ Assessment } & Residual forage biomass & Use/intensity \\
\hline & Grass stubble heights & \\
\hline Soil assessment & Soil pit/core & Available soil moisture \\
\hline Wildlife assessment & Pellet-group counts & Relative index or visitation of elk, deer, and cattle use \\
\hline Visual assessment & Photographs & $\begin{array}{l}\text { Aesthetic quality, watershed health, rangeland condi- } \\
\text { tion, grazing use }\end{array}$ \\
\hline
\end{tabular}

was then reviewed by the Range Improvement Task Force range specialists and placed in categories of 1) suitable for continued grazing, 2) unsuitable for continued grazing, and 3) grazing status required further review. Santa Fe National Forest range personnel were then contacted for review of information. A joint meeting was held between the Range Improvement Task Force and Forest Service range personnel for formal decision making. It was decided to conduct additional monitoring on allotments where uncertainty and disagreement existed over management actions. Permittees were kept apprised of progress in both monitoring and decision making.

\section{Survey Results}

Our rapid assessment of 25 grazing allotments on the Santa Fe National Forest in July 2002 found that 17 allotments had adequate forage to support full numbers of permitted livestock. These allotments were characterized by adequate amounts of forage standing crop (over 400 pounds per acre) and grass heights well above threshold levels. Depth of soil moisture indicated dry conditions on most of these allotments. Eight of these 17 allotments were selected for further reevaluation in September 2002. This was primarily due to standing forage levels only slightly above threshold values and/or lack of soil moisture. Continued livestock grazing with a reduction in numbers was recommended for 5 allotments. Overall, these allotments had grass stubble heights and/or forage standing crop at or near threshold forage levels. Soil moisture levels were generally low on these allotments. Follow-up monitoring was conducted on these allotments and revealed properly balanced forage supply and demand. We believe that our initial recommendations were appropriate.

No livestock grazing was recommended on 3 allotments. Key features of these allotments were grass stubble heights below threshold levels and inadequate standing forage crop. These 3 allotments all had wet soils. Average number of cattle fecal groups was $56 \%$ higher for allotments placed in "the unsuitable for continued grazing" category compared to those placed in the "suitable for continued grazing" category. Average elk and deer fecal groups were similar between allotment categories, although considerable variation occurred for elk within each category.

\section{Management Implications}

The rapid assessment methodology we developed and applied in our surveys on the Santa Fe National Forest in the late spring of 2002 enabled an integrated team of range professionals to make timely and critical grazing management decisions based on quantitative information on 25 allotments with severe drought. Our approach integrated a variety of well-proven monitoring methodologies into a practical framework. With the rapid assessment methodology, suspension of grazing occurred on only 3 allotments, whereas without the assessment, suspension was imminent on all 25 allotments. We believe the assessment helped to avoid resource degradation and sustain ranching enterprises in a multiple use context. The rapid assessment methodology has been employed since 2002 on several of the same allotments and has provided valuable baseline information for these subsequent efforts. In fact, the rapid assessment methodology has been requested on numerous occasions throughout the northern New Mexico region since 2002 and adopted as a collaborative approach to joint agency-permittee monitoring efforts. A list of the variables sampled using the rapid assessment procedure is provided in Table 2. However, the flexibility associated with the rapid assessment methodology also allows for increasing sampling intensity and the integration of other quantitative sampling methods depending on the monitoring goals and objectives. Therefore, we believe our approach and procedures have practical application on rangelands throughout the world.

Authors are Extension Range Specialist (Allison); Professor of Range Science, holecheck@nmsu.edu (Holechek); Extension Riparian Management Specialist (Baker); Extension Wildlife Spe- 
cialist (Boren); Economic Development Specialist (Ashcroft); and Coordinator of the Range Improvement Task Force (Fowler), New Mexico State University, Las Cruces, NM 88003. This article was supported by the New Mexico Agricultural Experiment Station, the Range Improvement Task Force, and the New Mexico Cooperative Extension Service.

\section{References}

1. Stoddart, L. A., A. D. Smith, and T. W. Box. 1975. Range management. 3rd ed. New York, NY: McGraw-Hill.

2. Holechek, J. L., R. D. Pieper, and C. H. Herbel. 2004. Range management: Principles and practices. 5th ed. Upper Saddle River, NJ: Pearson/Prentice Hall.

3. Evans, R. A., And R. M. Love. 1957. The step-point method of sampling - a practical tool. Journal of Range Management 10:208-212.

4. Stoddart, L. A., and A. D. Smith. 1943. Range management. New York, NY: McGraw-Hill.
5. Holecheк, J. L., and J. D. Galt. 2000. Grazing intensity guidelines. Rangelands 22(3):11-14.

6. Holecheк, J. L., And D. Galt. 2004. More on stubble height guidelines. Rangelands 26(4):3-7.

7. Eberhardt, L., and R. C. Van Etten. 1956. Evaluation of the pellet group count as a deer census method. Journal of Wildlife Management 20:70-74.

8. Rogers, G., O. Julander, and W. L. Robinette. 1958. Pellet-group counts for deer census and range-use index. Journal of Wildlife Management 22:193-199.

9. Sмiтн, A. D. 1964. Defecation rates of mule deer. Journal of Wildife Management 28:435-444.

10. Johnston-Wallace, D. B., and W. K. Kennedy. 1944. Grazing management practices and their relation to the behavior and grazing habits of cattle. Journal of Agricultural Science 34:190-197.

11. Wagnon, K. O. 1963. Behavior of beef cows on California range. California Agr. Exp. Sta. Bull. 799 pp. 


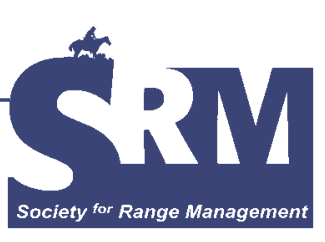

\section{Wish Upon a Satellite: Applying GPS to Rangeland Management}

By A. L. Hancock, E. K. Strand, and K. L. Launchbaugh

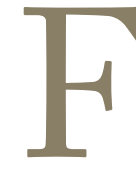

or years resource managers have used paper maps to document the location of important natural and human-imposed features. It is hard to find a desk, wall, or dashboard of a working range professional that is not adorned with some sort of map. Maps depict ownership boundaries, pasture fences, stream courses, and topographic features. The locations of monitoring plots, study sites, and range improvements are often stored on maps. Global Positioning Systems (GPS) now bring documenting spatial rangeland features to a new level of precision and accuracy. However, GPS systems come with a plethora of features and limitations that can cause confusion and frustration and make one long for the good old days of paper maps and compasses. In this manuscript we hope to dispel misconceptions and improve working knowledge of how GPS can be applied to rangeland management.

\section{Uses of GPS in Rangeland Management}

Range scientists adopted GPS technology shortly after it became available to aid in locating field plots, tracking wildlife and domestic livestock, and in recording known locations of invasive or rare species populations (Fig. 1). Rangeland managers and ranchers are now using GPS technology to accomplish many of their day-to-day tasks, including marking locations of range improvements, trend plots, green-line

This article has been peer reviewed.

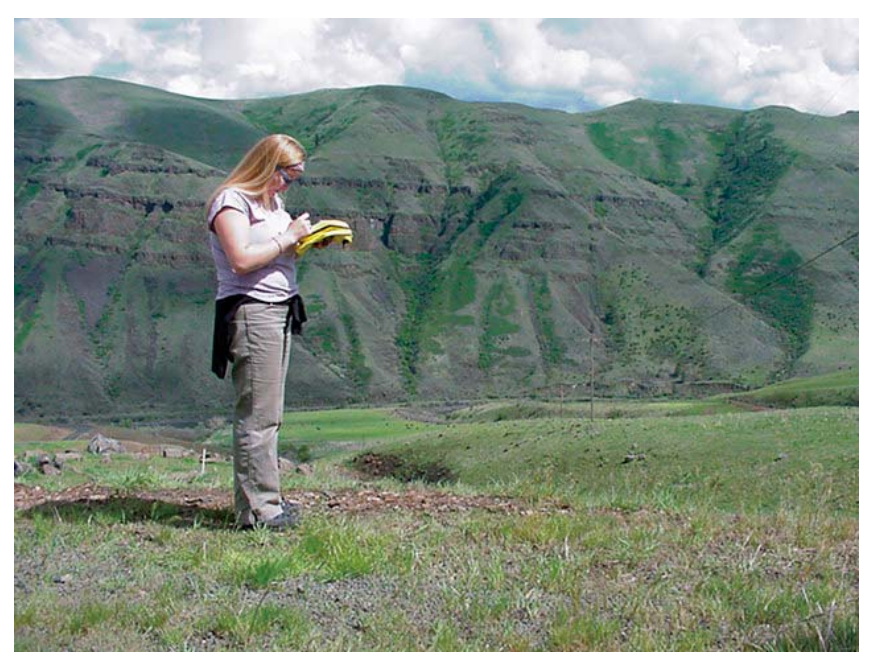

Figure 1. Today's rangeland specialists use GPS to document the location of many rangeland features including invasive plants, wildlife habitat, and range improvements.

surveys, and repeat photopoints. Historically, written directions on maps often marked monitoring points, with written directions or sketches on how to locate the plot. In most cases, legal coordinates (Township, Range, Section) were the only description of plot locations. The imprecise and sketchy locations led to thousands of hours spent simply trying to relocate monitoring plots. Even with a basic GPS unit, resource managers can now easily record or find a previous plot location within about 50 feet $(15 \mathrm{~m})$. 


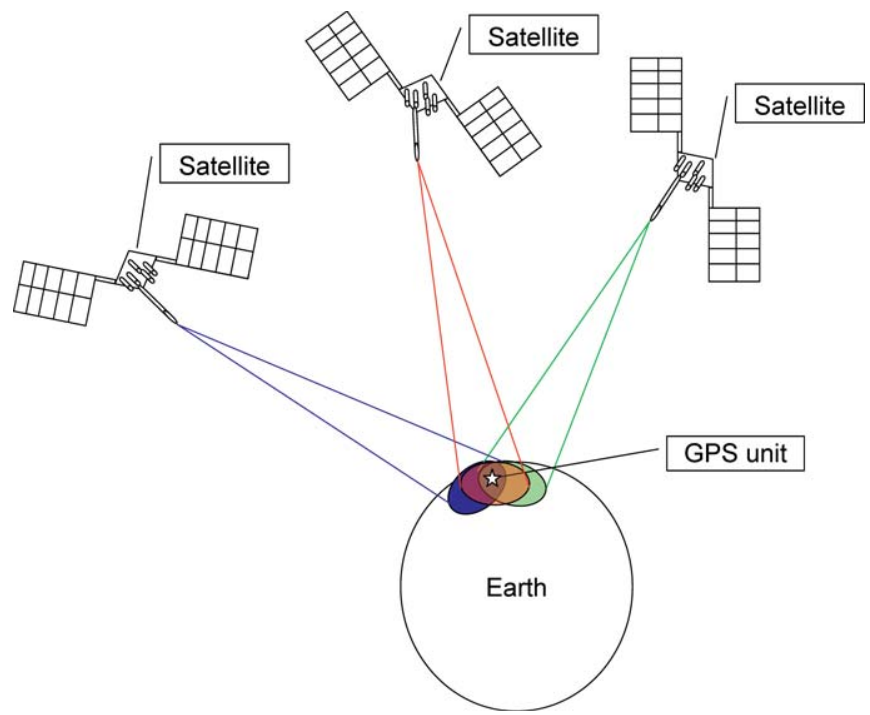

Figure 2. Global Positioning Systems (GPS) calculate their location based on a distance from at least 3 satellites through a process called "trilateration."

Locations and conditions of rangeland improvements, such as water tanks, fences, or creek crossings, can be collected and documented with GPS technologies and are an important part of the inventory of rangeland resource management tools. Some GPS units include the ability to add a description, or attribute, of specific locations such as the condition of a range improvement. Many invasive plants management programs include GPS tools to record the location of weeds, document management actions applied, and note the results achieved.

Information gained by GPS can also be linked to Geographic Information Systems (GIS) which are software programs designed to capture, display, analyze, retrieve, and store spatial information. Points and lines collected with a GPS unit can be displayed on maps created in a GIS. Sophisticated maps can also be created from layers such as slope, aspect, vegetation type, utilization level, and condition relative to streams and watering spots.

\section{What Is GPS and How Does It Work?}

The Global Positioning System (GPS) is a constellation of satellites orbiting the earth that constantly transmit signals of precise locations. The GPS in use today is called Navigation System with Timing and Ranging (NAVSTAR) and includes more than 24 solar-powered satellites. GPS units use a process called trilateration to accurately pinpoint locations on the earth's surface based on their distance from satellites of known location. Simply put, trilateration involves making measurements from intersecting circles of distance from satellites (Fig. 2). For example, if a GPS receiver was 11,000 miles from 1 satellite, there would be a finite number of places on the earth's surface (in the shape of a circle) where the location could be. If the same GPS receiver was 12,000 miles from a second satellite, the receiver could narrow down the location by the overlap from the 2 circles. The same would be true for a third and fourth satellite. In this manner, the more satellites a receiver can detect, the more accurate the position; GPS receivers require at least 3-4 satellites to $\log$ data points.

\section{How Accurate Is GPS?}

There are generally 3 grades of GPS units: recreational, mapping, and surveying. Most of the recreational grade units are marketed as being accurate from 20 to 50 feet (7-15 $\mathrm{m})$, but can incur higher inaccuracies. The mapping grade units are commonly accurate to 3 to 16 feet (1-5 m), and the survey grade units are usually accurate to less than 4 inches $(1-10 \mathrm{~cm})$, called "sub-foot" accuracy. Generally, the more accurate the unit is, the higher the cost. Most recreational grade units cost between $\$ 100-\$ 900$, whereas mapping grade units cost between $\$ 1,500-\$ 7,000$, and survey units generally cost upward to $\$ 45,000$. The accuracy of a location displayed on a GPS unit depends on several features related to the type and hardware of the unit itself, including the type of antenna, the number of channels the unit can receive, and the ability to differentially correct the location.

Antennas. A GPS unit receives signals from either an internal or an external antenna. Most of the recreational grade units employ internal antennas. Internal antennas, although not as accurate, are much more convenient. The mapping grade units generally come equipped with internal antennas, but have the option of an external antenna. The survey grade units generally have an external antenna. The advantage of an external antenna is that it allows a user to place the antenna where it can best acquire a satellite signal. For example, if a user was driving down a road, an external antenna could be placed on the outside of the vehicle for better reception.

Channels. The number of channels a unit has can affect a unit's accuracy. Most units of all grades currently have between 12-16 parallel channels. This means that these units can track 12-16 satellites simultaneously. Although a unit only needs 3 or 4 satellites to locate a position, the more satellites it can acquire, the more accurately it can narrow down its precise location.

Satellite Locations. The relative position of the satellites on the horizon affects the accuracy of the signal. If a satellite being tracked by a GPS unit is lower than $10^{\circ}-15^{\circ}$ on the horizon, it should be considered unusable. Because satellites are in a continuous orbit, and are constantly changing their location, acquiring a good satellite signal can be difficult or nearly impossible at certain times of the day. Some GPS units are capable of rejecting signals from satellites with poor position relative to their horizons. Mapping and survey grade units generally include software packages that calculate times on user specified dates when an adequate number of satellites will be available, which is useful in planning field activities that require GPS. One example is Trimble's "Pathfinder Office" (http://www.trimble.com/pathfinderoffice. shtml). These tools are useful in planning GPS acquisition to 
assure that 4 or more satellites will be available at the desired place and time of GPS data collection.

PDOP. "Position Dilution of Precision" is the expression of the effect that satellite positions has on GPS accuracy. It is difficult to acquire a precise location when satellites are clustered together in the GPS receiver's horizon because all the satellites are broadcasting similar location signals; thus, the circles of signal will overlap each other considerably. When the satellites are spread out over the sky, the precise location will be easier to acquire. In general, the lower the PDOP is, the more accurate the location. Commonly, a threshold PDOP of 6 is recommended, above which locations estimates are rejected because of potentially large inaccuracies. Mapping and survey grade units usually report PDOP, whereas recreational units usually do not.

WAAS and Other Differential Corrections. The process of applying corrections to data locations is called "differential correction" GPS or DGPS. Through DGPS the signal is corrected for atmospheric conditions, satellite orbit problems, and satellite clock drift. Most units of all grades allow for "real-time" differential correction, in which the current location displayed on a GPS receiver is adjusted based on the error of a simultaneous GPS reading at a base station of known location. One of the most common correction systems is the "Wide Area Augmentation System" (WAAS). Sometimes, however, a unit is too far away from a base station to receive a correction signal. When this happens, the data must be adjusted back in the office to obtain better accuracy. Most mapping and survey grade units allow for this "postprocessing," but recreational units generally do not. Base-station files for postprocessing can be accessed via the internet (http://www.fs.fed.us/database/gps/welcome.htm). The ability to postprocess data is one of the major price differences between recreational grade and mapping and survey grade units.

How do Environmental Conditions Affect GPS Accuracy?

The signal quality that reaches a GPS unit is affected by atmospheric and topographic conditions. Atmospheric gases, particularly water vapor, slow the speed of the signal, resulting in inaccurate estimations of position. Canyons, draws, or steep basins can inhibit the unit's ability to detect satellites that are lower on the horizon. Dense canopy covers in forests also distort the satellite signal and will cause some recreational grade units to produce errors over 165 feet $(50 \mathrm{~m})$. The errors in accuracy resulting from terrain and vegetation are called "multipath signals." That is, the satellite signal can be reflected off of inanimate objects such as trees, rocks, buildings, water bodies, the ground, etc. and then be picked up by a GPS unit, which results in significant distortion of the original signal. Some advanced mapping units and all survey grade units use a technology that is capable of filtering multipath signals and are more accurate under adverse conditions. Multipath filtering technology largely contributes to the accuracy and price differences between recreational grade units and mapping and survey grade units.

\section{What Kind of Display and Memory is Needed?}

Information on GPS units can be displayed either in color or grayscale. The recreational grade handheld units tend to come in grayscale, although most newer ones have optional color screens, but at an increased cost and reduced battery life. Most of the mapping and survey grade units come with full color screens that can easily be read in any light. The use of GPS units in rangeland settings generally requires screens that can be easily read in full sunlight. Because some GPS units can even display full topographic coverage of the area, screen readability is an important feature. Screen readability varies greatly from unit to unit, so make sure to try a unit in full sunlight before purchasing it.

The amount of memory on a GPS unit determines how much data, including maps, the unit can store. Many basic recreational units do not come with any capabilities to upload maps. These units have a predetermined amount of memory based on the number of waypoints and tracks they are programmed to handle. Intermediate and advanced recreational grade units include varying amount of memory for adding maps and storing data. Mapping and survey grade units have a virtually unlimited memory capacity because they can accept memory cards, so a user is limited only by the number of memory cards available. Units with more memory can upload and store more complicated data. For example, aerial photographs are commonly used with mapping quality units; however, photographs are extremely large files, too big for most recreational grade units. The memory capacity of a unit will affect its price but not the accuracy.

\section{Field GPS Settings and Data Management}

Data logging. Most units of all grades currently include data logging capabilities. This means that they are able to record positions, tracks, or routes. These data can then be stored in the unit or downloaded into a computer. An individual position recorded in the unit is called a waypoint, whereas a route is a collection of waypoints that define an intended path of travel. A track $\log$ is a collection of waypoints taken while the user is moving. Units vary considerably in the number of waypoints, routes, and track logs they can store. Most recreational grade units can store up to 500 waypoints, and between 20-50 routes. The survey and mapping grade units have a capacity that is only limited by their memory storage.

Data Dictionaries. Data dictionaries describe locations in a database and can be very useful in the field when a user wants to add descriptive information or attributes to object locations. For example, if a user is mapping locations of weed infestations, a data dictionary could include the date, species, phenology, infestation size, previous treatments, terrain, or the surrounding plant community. The information recorded in the data dictionary can be directly transferred from the GPS unit to a computer, avoiding the arduous task of entering field data 


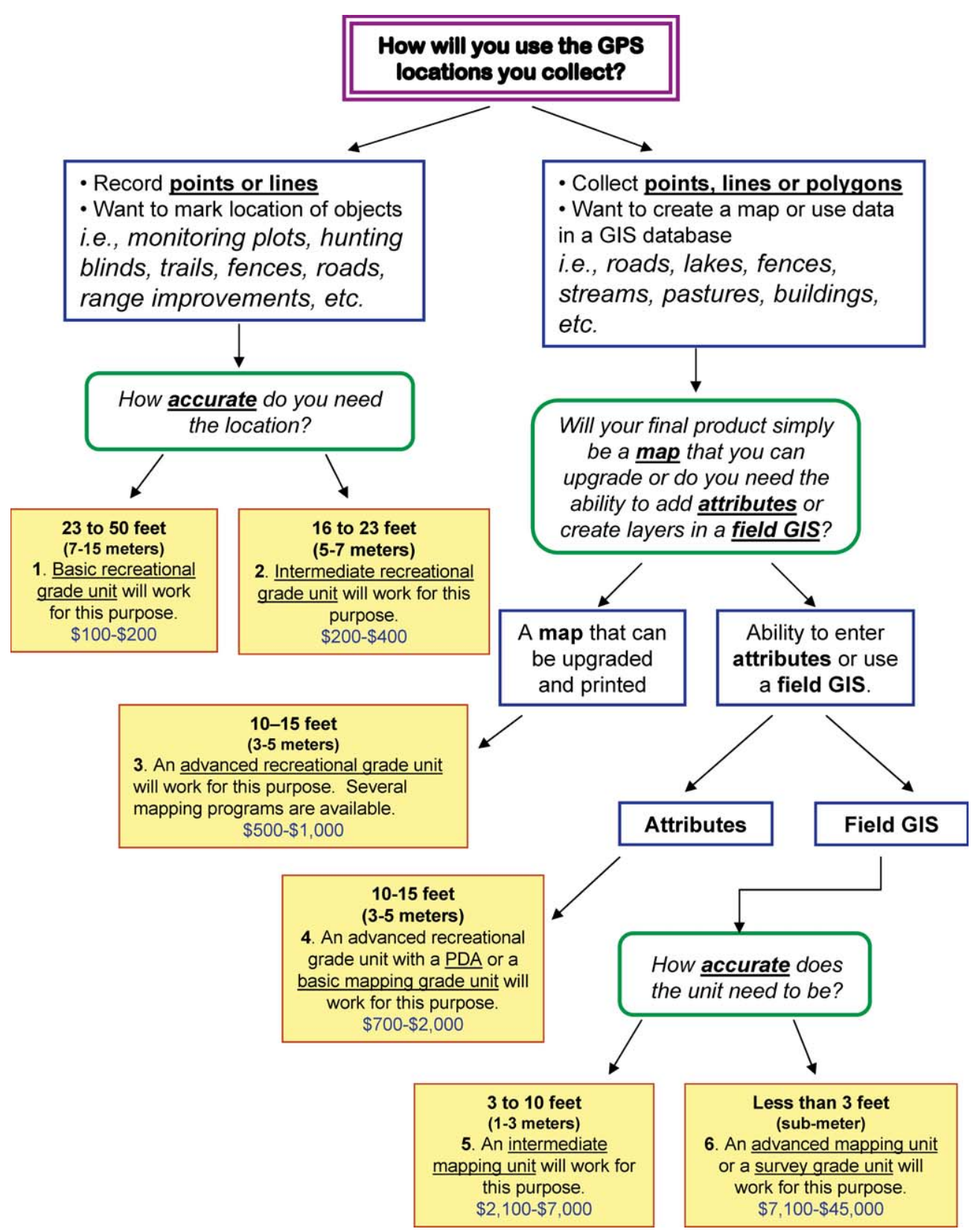

Figure 3. The selection of a GPS unit is based on accuracy needs, intended uses of data, and cost.

into the computer. Recreational grade GPS units generally do not have data dictionary capabilities unless they are connected to a palm computer or personal digital assistant (PDA).

Grids and Datums. GPS users must master the concept of grids and datums and understand how they apply to their fieldwork. A grid is a set of horizontal and vertical lines on a map that help determine absolute location on the earth; for example, latitude and longitude represent a grid system that builds a true relationship between map locations and those that correspond to on-the-ground points. There are several different grids or coordinate systems in use, and most GPS units can be set to report locations in a specified grid. The two most commonly used grids are Latitude and Longitude (lat/long) and Universal Transverse Mercator (UTM) pro- jection. Lat/long is a grid that is based on the measurement of angles from a reference line; the equator is the reference line for latitude and the Greenwich Meridian is the reference for longitude. UTM is a metric grid that divides the earth into 60 6-degree-wide zones. The advantage of using a metric grid such as UTM is that the location coordinates reported by the GPS unit directly relate to a distance on the ground. For example, if you move 100 meters to the north, the northing UTM coordinate has increased by 100 . On the other hand, most maps are displayed with a latitude/longitude grid, and setting the GPS unit to report latitude/longitude is convenient. Although it is possible to convert data between different grids, you must know the grid in which the location was originally collected. 
A datum is a geographic reference system of parameters and control points that accurately defines the three-dimensional shape of the earth. There are many different datums in use today, but the most common in North America are North American Datum 1927 (NAD 27), North American Datum 1983 (NAD 83), and World Geodetic System 1984 (WGS 84). Using the WGS 84 or NAD 83 datum generally results in slightly more accurate locations than older datums. Most of the older topographic maps produced by the United States Geological Survey (USGS) and the United States Forest Service (USFS) used NAD 27. It is important to know and correctly set the coordinate system and datum of the GPS unit. Not knowing the datum in which a point was collected can result in errors of up to a mile when trying to relocate a point using a different datum.

If you plan to incorporate GPS data in a Geographic Information System (GIS), it is advantageous to set the GPS unit to collect data in the same grid and datum that are used in the GIS. At minimum, it is important to note the datum in which you collected location data so that points can be reprojected and data can be shared.

\section{Relationship Between GPS and GIS}

GPS data can be used by itself - but many times it is integrated with a GIS program. GIS programs are capable of storing the spatial data collected by a GPS unit and displaying it as part of a map. The map can be tailored to an individual's preference, adding or removing layers of data as needed for a particular application. "Layers" represent a group of data that is categorized and displayed together. For example, a group of waypoints that make up a route, such as a road, might be displayed together in a layer. Another layer might be all the stock tanks on a ranch.

Field GIS. There are many different types of GIS programs and some have field-ready versions that can be incorporated into a GPS unit allowing data to be added and viewed in the field. Most mapping and survey grade units are able to handle a variety of field GIS programs. Some of the recreational grade units can be attached to a PDA to support such field GIS programs as ArcPad (http://www.esri.com). The use of a field GIS program reduces the need for significant data manipulation after returning from the field. In other words, the user can see exactly how the field data they are collecting fit with the other data used in a GIS.

Desktop GIS. GIS programs allow data from different sources to be combined. For example, data taken in the field with a GPS unit can be combined with topographic features, soils, and watershed characteristics. Many organizations such as federal land management agencies, states, and others host websites with spatial data available for download. For example, the Natural Resources Conservation Service has soil surveys available for download free (http://soildatamart.nrcs. usda.gov). A land manager could download a soil map of a parcel of land, use a GPS unit to record the location of fencelines, and then combine the two layers with a GIS program to determine the soil types within each pasture.
Aerial photographs are also commonly used with a GPS unit and incorporated into GIS data. There are many ways in which GPS data can be utilized within a GIS program, and it is important to recognize that although the two technologies can be used separate from one another, they can be used in combination to produce powerful analyses and maps.

\section{Which GPS Unit Is Best for Me?}

There are many different types and brands of GPS units available. Which ones work best for land managers? Which ones are most cost-effective? The answer to these questions depends on what needs to be accomplished with the unit. It also depends on the terrain and canopy cover in which the unit will be used and the user's accuracy needs. The decision tree in Figure 3 is designed to help rangeland managers decide what kind of unit may suit their needs best.

\section{Basic recreational unit}

Generally these units are meant for the occasional user that does not need highly accurate positions. They tend to be very rugged and user-friendly, but cannot download data from a website or upload data to a computer. Usually, these units have a long battery life and use batteries that can easily be replaced in the field. Most of the screens are either monochrome or grayscale, but tend to be fairly small. The units are lightweight, and can easily be carried in a backpack.

\section{Intermediate recreational unit}

These units have more features than the basic units, and take a little longer to learn how to use. Data collected with these units can be transferred to a computer and most will accept uploaded maps. Some of these units have color screens. The accuracy is generally better than the basic units, although they use the same types of technologies. These units are slightly larger than the basic units, but are rugged in construction. Most use $2 \mathrm{AA}$ batteries like the basic units, but the more expensive models can use rechargeable lithium ion (Li-ion) batteries that are expensive and can be difficult to obtain and/or replace.

\section{Advanced recreational unit}

These units generally have color screens and come loaded with several maps. They also have the ability to accept maps uploaded by the user. Like the intermediate units, some of the advanced units use $2 \mathrm{AA}$ batteries; others use a Li-ion battery. These units typically have other functions besides collection of location information; for example, they might have an electronic compass, barometric altimeter, or other features. These units typically either have a large memory
Side note: Some advanced recreational units can be attached to a personal digital assistant (PDA) or palm computer and are capable of adding attributes to features. They are also usually capable of handling a field version of a GIS program. 
capacity (> 100 megabytes) or are able to accept secure digital (SD) cards for data storage. These units have a shorter battery life due to the multiple functions and the color screen. The resolution of the screen (number of pixels) varies widely in this class of unit, but the screens tend to be larger than the previous two classes. Most of these units are rugged enough to be taken in the field, and the weights are generally comparable to the intermediate units.

\section{Basic mapping unit}

Basic mapping units are usually field computers or PDAs made more rugged for field use. They tend to be fairly accurate (comparable to the intermediate or advanced recreational unit), but lack some of the sophisticated technologies such as multipath signal rejection. Mapping units generally run a compact, field version of Microsoft Windows ${ }^{\circledR}$ and are capable of supporting field GIS programs. A user can create data dictionaries and add attributes to data points, with memory usually dictated only by the number and size of memory cards available to a user. These types of units are generally not as rugged or small as some of the recreational units and have large, full-color displays that reduce battery life. These units typically come with a rechargeable nickel metal hydride $(\mathrm{NiMH})$ or a Li-ion battery. Although the batteries are not meant to be changed in the field, most have the option of $12 \mathrm{~V}$ vehicle charging cables. The biggest difference between these types of units and the recreational units is the ability to process the data after it is collected, allowing for correction of inaccuracies incurred in field data collection.

\section{Intermediate mapping unit}

These units are very similar to the basic mapping units, but have a higher accuracy and are more field rugged. They are fully capable of running field GIS programs, and many have the ability to transfer data via a wireless network. These units are equipped with rechargeable batteries that last 5-8 hours.

\section{Advanced mapping unit/survey grade unit}

Even though there are significant differences between an advanced mapping unit and a survey grade unit, the authors group them here together for simplicity. These units have all the functions of the intermediate mapping units plus sophisticated technologies that allow for sub-foot accuracies. These units generally are not as rugged as some of the other units and weigh considerably more. They are also dependent on external antennae that require the use of cables and connectors. A user must be within a certain range of a base station for the technologies that allow for sub-foot accuracy to work. Cost can be prohibitive for these units.

\section{Summary}

The future is bright for the use of GPS in land management. As technology progresses, the cost of GPS units will undoubtedly come down and accuracy will increase. Currently, basic recreational grade units can be purchased for $\$ 100$ or less, making GPS technology very affordable. With a little experience, it would be easy to carry a GPS unit while out checking range resources, and record the location of important items such as poisonous plants, weed infestations, salt locations, broken fences, or wildlife sightings. The potential uses of GPS in land management are limited only by the user's imagination and the satellites in the sky!

Authors are Range and Natural Resource Specialist, Central Grasslands Research Extension Center, 4824 48th Ave SE, Streeter, ND 58483, amanda.hancock@ndsu.edu (Hancock), and Research Scientist (Strand) and Associate Professor (Launchbaugh), Department of Rangeland Ecology and Management, University of Idaho, ID 83844.

\section{For Further Reference}

Frair, J. L., S. E. Neilsen, E. H. Merrill, S. R. Lele, M. S. Boyce, R. H. M. Munro, G. B. Steinhouse, and H. L. BEYER. 2004. Removing GPS collar bias in habitat selection studies. Journal of Applied Ecology 41:201-212.

Gansкорт, D. 2001. Manipulating cattle distribution with salt and water in large arid-land pastures: a GPS/GIS assessment. $A p$ plied Animal Behavior Science 73:251-262.

Johnson, C. J., K. L. Parker, D. C. Heard, and M. P. GillINGHAM. 2002. Movement parameters of ungulates and scale specific responses. Journal of Animal Ecology 71:225-235.

Johnson, C. E., And C. C. BARton. 2004. Where in the world are my field plots? Using GPS effectively in environmental field studies. Frontiers in Ecology and Environment 2:475-482.

Witte, T. H., And A. M. Wilson. 2005. Accuracy of WAASenabled GPS for determination of position and speed over ground. Journal of Biomechanics 38:1717-1722. 


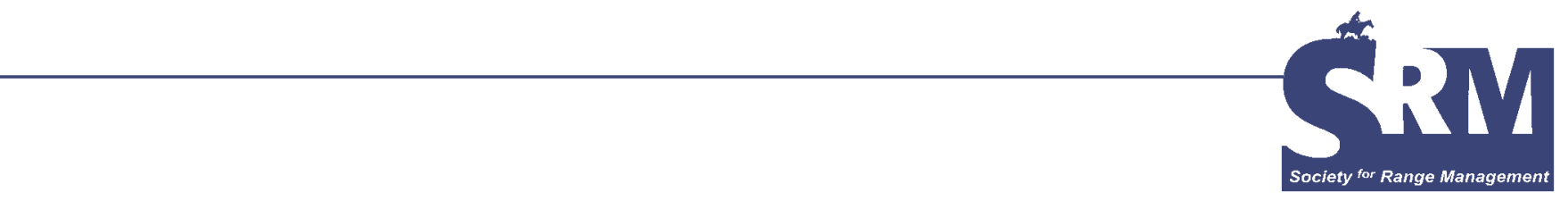

\section{Mobile Solar Water Pumping}

\section{Providing Off-Site Watering as an Aid to Livestock Distribution and Improved Riparian Condition}

\section{By Kenneth Primrose and Gary Delaney}

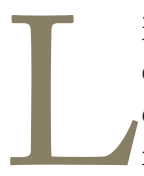

ivestock are attracted to riparian areas because of easy access to water, limited slope, shade, thermal cover, and a high quantity and quality of forage relative to the adjacent uplands. Supplemental offstream water can improve livestock distribution by luring the livestock away from the riparian areas.

The availability of off-stream water can also improve gain on livestock. A study at the Hall Ranch, Union, Oregon, showed that cows with access to off-stream water and trace mineral weighed more than those without off-stream water. ${ }^{1}$

A mobile solar pumping unit was developed to pump water to an off-stream watering site. The pumping system is able to pump from various water sources with variable lift requirements to supplement existing water sources.

\section{Pumping System}

A mobile pumping unit uses solar panels for a power source. The solar panels were mounted on a 16 -foot $\times 6$-foot 8 -inch flatbed trailer for moving from location to location. To prevent damage to the electrical connections on the panels, a wooden frame is used to support the panels when the unit is in transit. It is sufficiently sturdy to tolerate rough roads.

The pumping system consists of four 75-watt solar panels, a submersible pump with a helical rotor, 100 feet of black plastic pipe, and 2 water troughs. Each of the solar panels produces 4.41 amps at 17 volts. The solar panels should have a life of at least 20 years and the submersible pump should pump for at least 15 years.

The current mobile solar unit does not have batteries or a tracker but it is suggested that if one were to construct a similar unit, batteries and a tracker might be desirable.

This article has been peer reviewed.
The submersible pump was a Grundfos ${ }^{\circledR}$ with a helical rotor. The helical rotor is a shaft bent in a spiral which is placed inside of a Butna ${ }^{\circledR}$ rubber sleeve which is smooth.

The shaft screws the water out of the pump. Helical rotors produce a smooth and even flow and are easy to frostproof. The pump can tolerate a degree of sand in the water but excessive sand will scratch the smooth surface of the Butna ${ }^{\circledR}$ rubber.

Two 10-foot aluminum troughs and 60 feet of steel gate panels were also placed on the trailer. Panels were placed around the trailer to protect the solar unit from livestock.

\section{Performance Evaluation}

The mobile solar pumping unit was used for two grazing seasons on the Rockpile Allotment and the Windy Pt. Allotment. Both allotments are in the Grant County, Oregon.

The Rockpile Allotment is located 13 miles south of Dayville, Oregon, in the South Fork John Day River drainage. The pasture consists of steep, adjacent uplands with east-facing slopes along the South Fork John Day River. Elevations in the pasture ranged from 3,000 feet along the South Fork John Day River to 4,200 feet at the western boundary of the pasture.

The majority of the South Fork John Day River is fenced. Grass species along the South Fork John Day River include bluebunch wheatgrass, basin wildrye, and bluegrasses. Herbaceous species include lupines and yarrow. Trees and shrubs include wild rose, snowberry, juniper, and ponderosa pine.

On the dryer upland sites, bluebunch wheatgrass is the dominant forage species. Other grass species include Idaho fescue, Sandberg's bluegrass, bottlebrush squirreltail, and needlegrasses. Forbs include yarrow, buckwheat, lupine, and phlox. Shrub species include bitterbrush, basin big sagebrush, low sagebrush, and rabbitbrush. Junipers at various density 


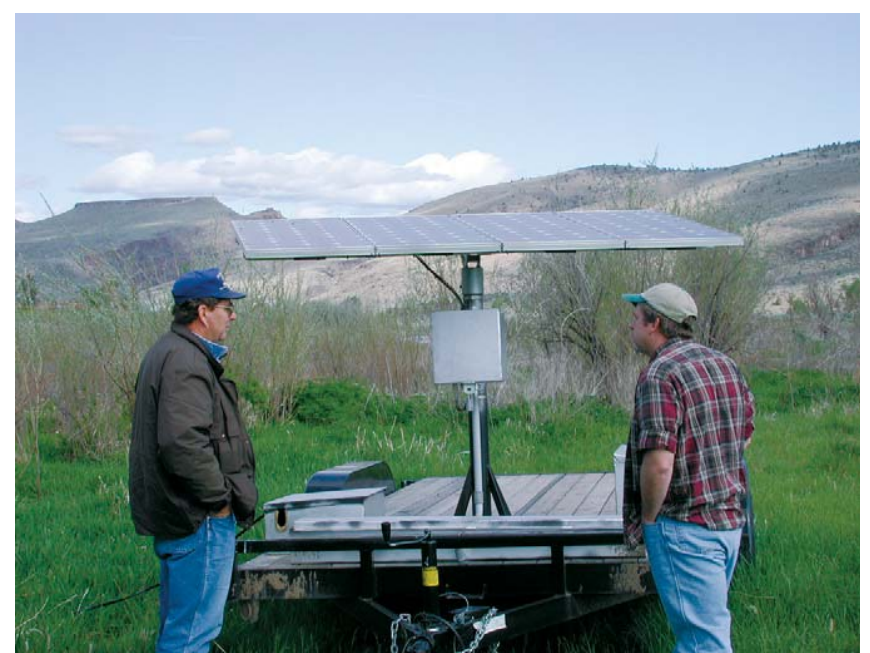

Ken Primrose (BLM) and Ed Teel (NRCS) discuss the solar power unit.

are found throughout the pasture. Cheatgrass or downy brome is common throughout all sites.

Windy Point Allotment, Pasture 7A, is located approximately 4 miles northwest of Dayville, Oregon. Elevation in the pasture ranges from 2,120 feet at the southern boundary to 2,720 feet at the northern boundary. The majority of the acreage in the pasture is public land.

The pasture is a juniper/sagebrush/grass vegetation type with a mixture of herbaceous vegetation, including bluebunch wheatgrass, needle and thread, bluegrass, bottlebrush squirreltail, basin wildrye, and several forbs with primarily cheatgrass at the lower elevations along the John Day River.

The mobile solar unit was used in four pastures during the 2004 and 2005 grazing season.

The watering system minimized the time that the livestock spent in the riparian area. Streambank trampling and damage was negligible. Repeated observations by the livestock owner and the authors consistently indicated that the pump unit accomplished the objective of luring the livestock away from the riparian areas. The system provided enough water

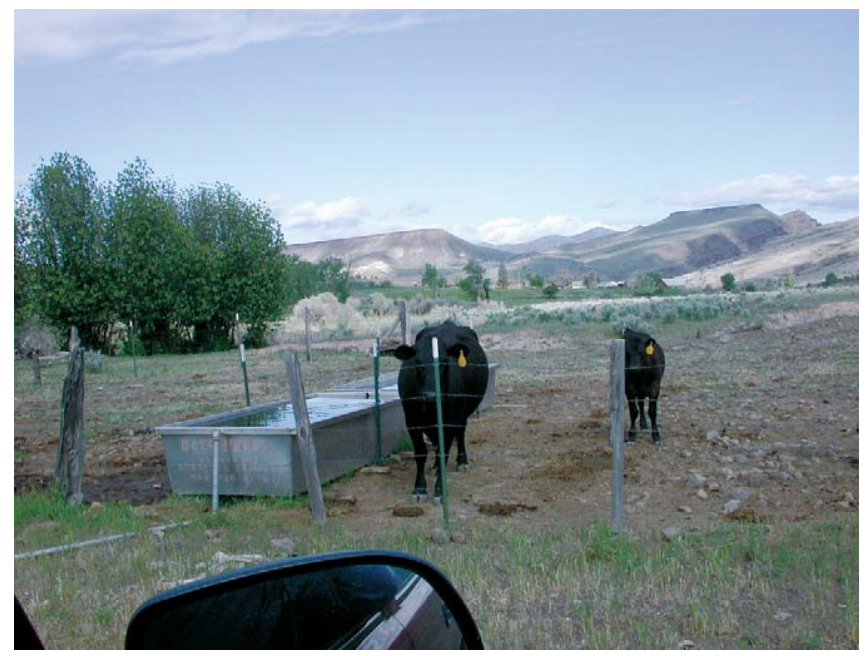

Cattle at off-stream water troughs. even on cloudy days to meet the requirements for livestock. Livestock in small social groups of 10 to 12 head trailed to the watering troughs to drink, then trailed back out to graze. The livestock did not "camp" at the watering trough.

During the 2005 grazing season the pump quit pumping water to the watering troughs. The surface of the Butna ${ }^{\circledR}$ sleeve in the helical rotor became too rough because of excessive sand being suctioned into the helical rotor. If the surface of the Butna ${ }^{\circledR}$ sleeve in the helical rotor becomes too rough, the motor goes into overload and the pump will not start.

When the unit was moved from pasture to pasture, the problem with the excessive sand could have been prevented by placing the submersible pump in a silting well such as a culvert. By utilizing a silting well, which requires a minimum of 12 inches of water for the pump to start, excessive sand would not be suctioned into the helical rotor of the pump.

Perforations cut at the top of the culvert should be at least 6 inches higher than the submersible pump. A metal support could be welded to the inside of the culvert to hold the submersible pump in an upright position to allow the pump to function more efficiently.

It is believed that a centrifugal rotor submersible pump would be a more efficient pump for this application because it can tolerate more sand in the pump and is designed for low head flows.

The helical rotor pump is designed for use in wells and high head flows and has a lower tolerance for sand than the centrifugal rotor pump. It has a higher efficiency and can lift water higher elevations than the centrifugal rotor pump.

\section{Table 1. Actual cost of mobile solar pumping unit}

\begin{tabular}{|l|l|l|}
\hline Component & $\begin{array}{l}\text { Cost per } \\
\text { component }\end{array}$ & Total cost \\
\hline Grundfos pump & $\$ 1,400.00$ & $\$ 1,400.00$ \\
\hline Pole mount & $\$ 230.00$ & $\$ 230.00$ \\
\hline $\begin{array}{l}\text { Four 75-watt solar } \\
\text { panels }\end{array}$ & $\begin{array}{l}\$ 349 \text { per } \\
\text { panel }\end{array}$ & $\$ 1,396.00$ \\
\hline $\begin{array}{l}\text { Other components for } \\
\text { the solar system (wir- } \\
\text { ing, pump controller, } \\
\text { float switch, shipping) }\end{array}$ & - & $\$ 748.10$ \\
\hline $\begin{array}{l}\text { Trailer (16 feet long } \times \\
6 \text { feet 8 inches wide) }\end{array}$ & $\$ 1,695.00$ & $\$ 1,695.00$ \\
\hline \begin{tabular}{l}
6 Panels (10-foot) \\
\hline $\begin{array}{l}\text { Two 10-foot aluminum } \\
\text { troughs }\end{array}$
\end{tabular} & $\$ 84.00$ each & $\$ 504.00$ \\
\hline $\begin{array}{l}\text { Miscellaneous (fab- } \\
\text { rication of boxes on } \\
\text { trailer, etc.) }\end{array}$ & $\$ 200.00$ & $\$ 690.00$ \\
\hline Totals & $\$ 200.00$ \\
\hline
\end{tabular}


All necessary components and costs for the mobile solar pumping unit are shown in Table 1.

\section{Conclusions}

The mobile solar unit demonstrated that solar units successfully can be used to pump water to an off-stream watering site and such units are tolerant of being transported over rough roads. The unit was capable of filling our off-site watering troughs directly from the stream. Use of the mobile solar pumping unit and off-site watering troughs resulted in decreased riparian impact and improved cattle distribution.

Excessive sand in the pump could be a problem if the pump is placed on the bottom of a water source (stream, etc.) and/or by a sudden discharge of sediment in a stream by a storm. By placing the pump in a silting well, excessive sand should not accumulate in the pump.

Authors are Rangeland Management Specialist, Bureau of Land Management, Prineville District, Prineville, OR 97754, kwprose@my180.net (Primrose), and Oregon State University, Grant County Extension Agent, Canyon City, OR 97820 (Delaney).

\section{Reference}

1. DelCurto, T., M. Porath, C. T. Parsons, and J. A. Morrison. 2005. Management strategies for sustainable beef cattle grazing on forested rangelands in the Pacific Northwest. Rangeland Ecology and Management 52:119-127. 


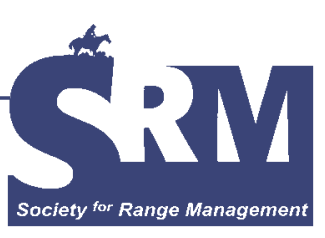

\section{National Animal Identification and the Elephant in the Room}

By Rhonda Skaggs and Terry Crawford

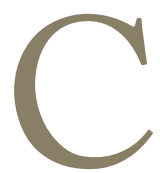

urrent interest in individual animal identification arises from a confluence of events: foot-andmouth disease outbreaks in Great Britain, bovine spongiform encephalopathy appearing in Canada and the United States, and the waning influence of older animal identification programs (such as for brucellosis and scrapies eradication). The goal of the planned National Animal Identification System (NAIS) is rapid tracing of animals during an outbreak situation. According to the US Department of Agriculture Animal and Plant Health Inspection Service (USDA-APHIS), the NAIS would help limit the scope and expense of disease outbreaks, reduce negative impacts on domestic and foreign markets, and support ongoing disease eradication efforts.

The current NAIS includes voluntary identification of both individual animals and premises. ${ }^{1}$ A premise is defined in the NAIS as "an identifiable physical location that represents a unique and describable geographic entity where activity affecting the health and/or traceability of animals may occur." According to the NAIS Draft Program Standards, a premise can be a farm, a ranch, another production unit, markets, packing plants, quarantine facilities, ports of entry, veterinary clinics, exhibitions, and so on. The USDA has stated that it is maintaining a technology-neutral position with regard to the technologies that will be used to identify individual animals (or group lots) in the NAIS. However, radio-frequency identification (RFID) ear tags are endorsed for use by the NAIS Cattle Working Group as the "most practical technology" for implementing NAIS in the US cattle industry.

This article has been peer reviewed.

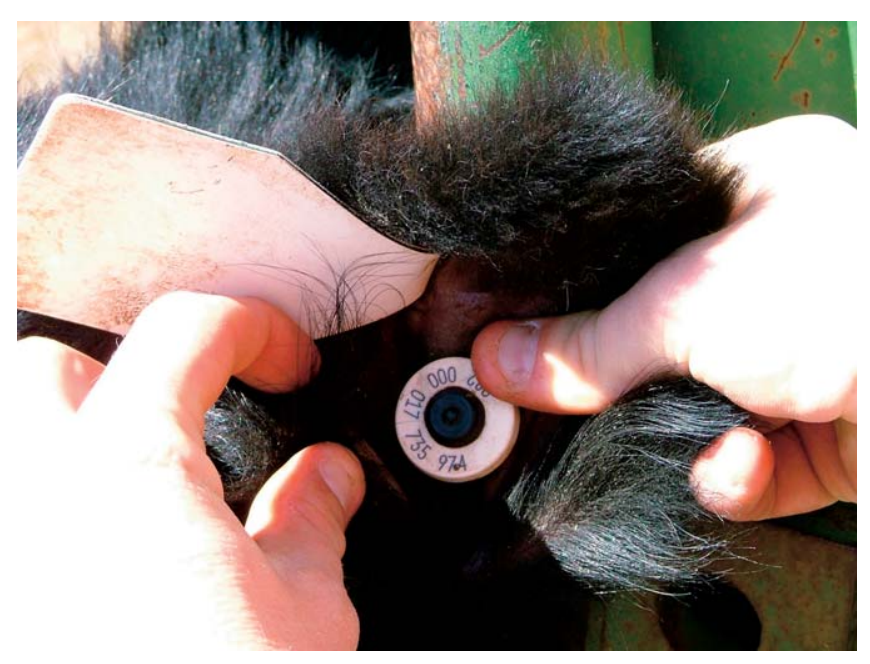

An RFID ear tag. Photo by Shad Cox.

A mandatory NAIS is likely to accelerate pressure for structural change in the US beef/cattle industry to fewer and larger production units, as has happened in the US dairy industry. However, it is our contention that NAIS and its proponents have yet to confront the "elephant in the room" that consists of the deeply ingrained sociocultural aspects of cowcalf production and traditional small-scale lifestyle agriculture in the United States. Advocates of NAIS appear to have an intentionally narrow view of the structure, characteristics, and objectives of a significant portion of the nation's beef cow-calf industry. The objective of this article is to provide insight into the nature of the elephant. This is accomplished using our own and other published data and research. 


\section{Structure and Nature of the US Cow-Calf Pro- duction Sector}

Nationally, almost $80 \%$ of US beef cow-calf operations have fewer than 50 mother cows. ${ }^{2}$ These cattle operations account for $30 \%$ of all reproducing beef cows and heifers. Cattle operations with 50 or more female animals are $20 \%$ of farms with beef calves and heifers that had calved, and they account for almost $70 \%$ of total beef cow and heifer numbers. The USDA considers farms with annual sales of less than $\$ 250,000$ to be small farms. By this criterion, small beef cattle operations account for $89 \%$ of calf sales, $48 \%$ of the total value of US beef cattle production, and control $74 \%$ of the land dedicated to beef cattle production. ${ }^{3}$ The largest category of small farms raising beef cattle are "residential/lifestyle" farms, one of several types of part-time farms identified by the USDA.

Recent research has improved our knowledge and understanding of western US beef cow-calf operators and their motivations for being in ranching. ${ }^{4}$ Data from a random survey of US Forest Service and Bureau of Land Management grazing permittees were used to identify 8 distinct clusters of ranchers. A key attribute for determining a survey respondent's placement in a cluster was based on a spectrum of preferences from ranching as a consumptive behavior (ie, consumption of the ranching lifestyle) to classic profit maximizing, business-oriented behavior. This research identified 2 primary groups of ranchers, hobbyists and professionals, with each comprising approximately $50 \%$ of the total number of survey respondents. The hobbyist group was further divided into 4 subgroups: small hobbyists, retired hobbyists, working hobbyists, and trophy ranchers. The professional rancher group was also divided into 4 subgroups: diversified family ranchers, dependent family ranchers, corporate ranchers, and sheepherders.

The Gentner and Tanaka ${ }^{4}$ study found that the profit motivation for being in ranching was a relatively low ranked objective for all 8 types of ranchers, with consumptive ranching objectives held by all groups. The low ranking of profit motive was particularly strong for the hobbyists and trophy ranchers. However, even diversified and dependent family ranchers and corporate ranchers (who have the highest dependence on ranching income) are strongly motivated to be in ranching for tradition, family, and lifestyle reasons. For all groups of ranchers, consumption motives outranked profit motives.

The National Animal Health Monitoring System (NAHMS) Beef '97 Study stratified respondents into 2 groups: those for whom cow-calf herds were the primary source of family income ( $14 \%$ of respondents) and those producers who keep cattle for supplemental income (69\%) or for some other reason than providing family income (17\%). ${ }^{5}$ Differences in management practices for "primary income" and "nonprimary income" cow-calf producers are striking. Breeding and calving management, animal health, feeding, marketing, and record keeping vary greatly between the 2 types of cow-calf producers, with significantly more inten- sive management practiced by the "primary income" producers. According to the NAHMS results, larger herds are not synonymous with primary income herds.

The NAHMS Beef '97 Study found that $81 \%$ of cowcalf producers kept some form of records, although $79 \%$ were hand-written only. ${ }^{6}$ With respect to identification of individual cows, use of branding (hot iron or freeze) was reported by $7 \%$ of producers, while $46 \%$ reported use of plastic or metal ear tags. Forty-seven percent of the NAHMS cow-calf producers indicated they use no form of individual cow identification, while $52 \%$ reported no identification of individual calves.

Research from other states also indicates relatively low management intensity among livestock producers. For example, a 2005 survey of Wyoming livestock producers found that 53 of 145 respondents (or 36.5\%) used animal identification as an annual management practice. ${ }^{7}$ Results for Montana ranchers who participated in NAHMS were reviewed by Paterson, ${ }^{8}$ who found that $27 \%$ of Montana ranchers make use of data collected from where their calves are finished. In a survey of Iowa beef producers, Lawrence and Schuknecht ${ }^{9}$ found that $25.7 \%$ of cow-calf producers use computerized cow herd performance records.

Our recent survey of $307 \mathrm{New}$ Mexico cow-calf producers found that more than $90 \%$ of the respondents brand their animals and that almost half use ear tags. ${ }^{10}$ Only 1 respondent indicated use of RFID ear tags. Two-thirds of the ranchers who responded to the survey said they did not keep individual animal performance or production records. Ranchers who keep records primarily maintain paper records only. Eight respondents $(2.6 \%)$ stated they use downstream cattle performance data as a management tool. More than half the respondents said their ranching operation was too small for record keeping, and several reported that their memories were sufficient for record keeping.

Overall, the results of our survey, review of other survey results, and other research lead us to conclude that there are low levels of management intensity, interest in individual animal record keeping, and interest in performance analysis on the part of many US cow-calf producers. However, the NAIS is being promoted as worthwhile to livestock producers because of performance record keeping and marketing opportunities (although USDA-APHIS notes that the agency is focused on animal identification as a means to control disease). The assumption that cow-calf producers' business-oriented motivations will lead to widespread voluntary adoption of management intensive animal identification technologies is not supported by data and research on the structure and nature of the cow-calf sector. Furthermore, it is not given that all commercially motivated cow-calf producers are by definition interested in individual animal identification. Some large New Mexico cow-calf producers do not individually identify all or any of their animals because they sell so many calves they don't believe it is cost effective to identify each animal or because they "don't like the look" of ear tags on their cattle. 
Also, our survey of New Mexico cow-calf producers found that one-fifth of the largest ranchers (eg, those with $>200$ head) believes that they are "too small" for individual animal record keeping.

It is interesting to contrast the New Mexico survey results, the NAHMS Beef '97 results, and survey results from other states with a Beef Magazine survey conducted in June 2005. ${ }^{11}$ According to the magazine, $83.4 \%$ of cattle producers who responded to their survey individually identify their cattle, and $12.3 \%$ use electronic ID tags. These results are undoubtedly due to selection bias as a result of a readership that likely includes a large percentage of cattle producers who practice intensive management, have traditional income objectives from ranching, and actively use performance data in their management decisions.

Vendors of electronic animal identification technology strongly emphasize the management benefits of using their technology. The vendors hope that cattle producers are interested in management information that can be collected, cataloged, and analyzed using their technologies. Thus, they are attempting to market their technologies based on attributes above and beyond the data collection necessary for compliance with NAIS. Technology vendors and others assume that in a voluntary identification system, cow-calf operators will be motivated to use electronic animal identification because of the potential benefits of additional productivity data and the possibility that calf buyers are likely to discount cattle that cannot be verified as to source or origin. Vendors and others assume that cattle producers have traditional businessoriented motivations, are concerned about individual animal productivity, and will use such data to create a comparative advantage over other producers. ${ }^{12}$

A mandatory NAIS will require technology and management changes by all cattle producers. Some producers may opt to buy their own electronic identification technology and incorporate management information available through an identification system into their existing management processes. Other producers may choose to contract with a third party (such as a veterinarian or sale barn) for collection and processing of traceability information. Blasi et $\mathrm{a}^{13}$ indicate that the majority of cow-calf operations will likely not be able to economically justify an investment in electronic animal identification technology (which could range from $\$ 4$ to $\$ 25$ per head per year, depending on herd size). Mark ${ }^{14}$ assumes that smaller cow-calf producers will contract with third parties for identification services and estimates that per head costs would be less than $\$ 5$ per head per year under such arrangements.

The cow-calf industry throughout the United States is characterized by a high percentage of small, lifestyle-oriented, consumption-motivated producers. Management-intensive technologies do not have a significant role in these types of cattle operations. Thus, it appears that the technology promoted by NAIS is very inconsistent with the goals of the majority of US cow-calf producers. Indeed, Ishmael, Blasi, and
Spire ${ }^{15}$ have concluded that individual animal ID is worth only what members of the cattle industry can get out of it for their own management purposes. This conclusion is based on those authors' observation that few buyers are demanding or paying for verification of cattle sources and processes. Thus, given the management profile of a large percentage of the US cow-calf industry, we conclude that individual animal ID has little value to them.

NAIS is a critical wedge issue between the commercially or business-oriented segment of the US cattle industry and the lifestyle-oriented segment. Lifestyle-oriented cow-calf producers do not tend to be highly motivated by traditional economic incentives. They have few incentives to adopt many new technologies. Furthermore, natural biological limits in cattle have resulted in few significant productivity increases in beef production over the past century when compared to other livestock species. In the beef cow-calf sector, there are few incentives or opportunities to use, adopt, or exploit technological advances compared to hogs or poultry.

The beef animal is basically a scavenger species. It is still cheaper to let the bull chase the cow through land-extensive production conditions than use artificial insemination. Landextensive production processes are generally not compatible with management-intensive technologies. Increases in management intensity are driven by the need and opportunity to increase returns per unit of input of capital and management. The technological stability of the US cow-calf industry is evidenced by the small change in the average size of a US beef cow herd over the past 30 or so years (from 40 in 1974 to 42 in 2002 according to the US Census of Agriculture).

The US dairy industry continues to move toward increased management intensity and larger-scale farm-level production. Dairy technology changes in the mid-20th century were influenced by changes in the federal milk pricing structure and continuing concern about the human health risks associated with contaminated and/or lower-quality milk. Technology- and policy-driven structural adjustment of the US dairy industry began in approximately 1950 and continues to this day. The average size of a US milk cow herd went from 5 in 1945, to 6 in 1950, to 26 in 1974, and to 99 in 2002 (from the U.S. Census of Agriculture).

Changes in quality control in farm-level milk production were driven by price differentials and health concerns. The result was an upgrading of dairy farm management through technology and education, marketing infrastructure, scientific production practices, Dairy Herd Improvement Association efforts, genetic improvements, artificial insemination, reduction in labor requirements on dairy farms and in milk transportation and processing, and concentration in the dairy industry. Retailing shifted from home delivery of bottled milk to an integrated national market for fluid milk and milk products. Assembly of dairy products in the United States is now accomplished with much larger and efficient units than at any time in history. Basically, multiple factors led to adoption of advanced technology throughout the US dairy 
industry. Yet even with all the forces for technology upgrading in the US dairy industry over the past half century, a 2002 survey of Vermont dairy farms found pail systems still used on $7.5 \%$ of the state's dairy farms. ${ }^{16}$

Boxed beef can be viewed as a parallel technological and market advance similar to the advent of refrigerated bulk tank Grade A milk handling. Boxed beef is an efficiency increasing technology that reduces uncertainty and reduces transport, handling, and meat-cutting costs throughout the marketing chain and increases product uniformity at the end of the marketing chain. Segmentation of retail beef marketing has been the end result. While some may argue that the quality of individual beef cuts has decreased as a result of changes in the grading system, overall beef product consistency has been enhanced and real prices have been reduced as a result of boxed beef technology. The feedlot and packing sectors have dramatically increased in size and concentration to achieve economies of scale. However, similar structural adjustment at the cow-calf producer level has not occurred. Most of the advances in technology and increases in efficiency in the beef industry have occurred beyond the farmgate.

Narrow adoption of "sophisticated" production technologies, limited increases in cow-calf producer efficiency measures, and the continued small average herd size can be attributed to the physiology of the beef animal, land-extensive production processes, as well as the lifestyle or consumptive motivations of many cow-calf producers. A large number of cow-calf producers are not primarily motivated to maximize production or profits, particularly if these objectives conflict with lifestyle, values, or ethical choices. Because of the diversity of firms and motivations within the US cattle industry, NAIS needs to accommodate many conflicting objectives. However, NAIS currently appears to be directed to the interests of the beef and cattle industry beyond the farmgate (or ranch). In a voluntary NAIS, cow-calf sector structure, diversity, and cost issues will be major impediments to system implementation. If NAIS becomes mandatory, we are likely to see a titanic culture clash between different segments of the US beef and cattle industry. We suspect that small-scale, traditional, residential/lifestyle, hobbyist, consumptive behavior cattle producers will not fade away as quietly or as quickly as small-scale dairy producers did in the face of nonstructurally neutral technology mandates.

If NAIS is to have any chance of success in the US cowcalf industry, it needs to put action into its oft-stated position of technological neutrality by working to include older, cheaper, more cost-effective identification and reporting technologies in the system. At the current time, RFID is the technology of choice, yet there is little evidence that any other technologies have been considered for the NAIS. Promoters of animal identification seemingly have a bias in favor of the latest technological innovation, such as RFID, biometric screening, and DNA typing, rather than simpler technologies that would be more appropriate for and acceptable to a wider range of cattle producers. This suggests that NAIS proponents have objectives in addition to rapid traceback in the event of a disease outbreak.

Authors are Professor, Department of Agricultural Economics and Agricultural Business, New Mexico State University, Las Cruces, NM 88003,rskaggs@nmsu.edu (Skaggs); and College Professor, Department of Agricultural Economics and Agricultural Business, Nerw Mexico State University, Las Cruces, NM 88003 (Crawford).

\section{References}

1. USDa Animal and Plant Health Inspection Service. 2006. National Animal Identification System (NAIS). A User Guide and Additional Information Resources. Draft version. November. Available at: http://animalid.aphis.usda.gov/nais/ naislibrary/documents/guidelines/User_Guide.html. Accessed 1 March 2007.

2. USDa National Agricultural Statistics Service. 2004. 2002 Census of agriculture, US data. Available at: http://www. nass.usda.gov/census/census02/volume1/us/st99_1_012_013. pdf. Accessed 21 June 2006.

3. CAsh, A. J. 2002. Where's the beef? Small farms produce majority of cattle. Agricultural Outlook, USDA Economic Research Service, pp. 21-24. December. Available at: http://www. ers.usda.gov/publications/agoutlook/Dec2002/ao297g.pdf. Accessed 21 June 2006.

4. Gentner, B. J., and J. A. Tanaka. 2002. Classifying federal public land grazing permittees. Journal of Range Management 55:2-11.

5. USDa Animal and Plant Health Inspection Service Veterinary Services. 1998. Importance of income in cowcalf management and productivity. September. Available at: http://nahms.aphis.usda.gov/beefcowcalf/beef97/bf97income. pdf. Accessed 21 June 2006.

6. USDA Animal and Plant Health Inspection Service Veterinary Services. 1998. National Animal Health Monitoring System (NAHMS). Part IV: Changes in the U.S. beef cow-calf industry, 1993-1997. May. Available at: http://nahms. aphis.usda.gov/beefcowcalf/beef97/bf97pt4.pdf. Accessed 21 June 2006.

7. Sarchet, B. A. 2005. Pilot survey and analysis of Wyoming cattle production (2004). May. Department of Agricultural and Applied Economics, University of Wyoming, Laramie, WY. Available at: http://agecon.uwyo.edu/WYLivestock/ 2005_05_03_Report_PartA.pdf. Accessed 21 June 2006.

8. Paterson, J. No date. Management of the cow herd: Survey responses of the Montana and U.S. rancher. Animal and Range Sciences Department, Montana State University, Bozeman, MT. Available at: http://www.animalrangeextension.montana. edu/Articles/Beef/herd_mgt.htm. Accessed 21 June 2006.

9. Lawrence, J. D., and S. Schuknecht. No date. Iowa beef producer profile, 2005: A survey of Iowa cow-calf and feedlot owners by the Iowa Beef Center. Iowa Beef Center at Iowa State University, Ames, IA. Available at: http://www. 
iowabeefcenter.org/content/2005SurveyReport.pdf. Accessed 21 June 2006.

10. Skaggs, R., And Crawford, T. In press. Livestock identification in New Mexico: Current status and implications for national animal identification. New Mexico State University Agricultural Experiment Station Research Bulletin.

11. Beef Magazine. 2005. What you told us. July. Available at: http://beef-mag.com/mag/beef_told_us/. Accessed 21 June 2006.

12. BeefStocker USA. 2005. Beef Stocker USA 2005 survey of the animal identification industry. Available at: http:// beefstockerusa.org/rfid/grid.htm. Accessed 21 June 2006.

13. Blasi, D. A., K. C. Dhuyvetter, M. F. Spire, M. P. Epp, and B. B. Barnhardt. 2003. A guide for electronic identification of cattle. Kansas State University Agricultural Experiment Station and Cooperative Extension Service.
14. Mark, D. R. 2004. Effects of animal identification on cattle market structure. Western Extension Marketing Committee, Livestock Marketing Information Center, and Western Center for Risk Management Education WEMC FS\#9-04. Available at: http://www.lmic.info/memberspublic/animalID/IDframe. html. Accessed 21 June 2006.

15. Ishmael, W., D. Blasi, and M. Spire. 2005. Management drives I.D. decisions. Stocker Facts, a product of BeefStockerUSA.org. April. Available at: http:// beefstockerusa.org/factsheets/ManagementDrives.pdf. Accessed 1 March 2007.

16. Parsons, B. 2003 (February). Survey looks at technology use On Vermont's farms. Agriview Online 67(4, April). Available at: http://www.uvm.edu/extension/agriview/av03feb15bp.htm. Accessed 1 March 2007. 


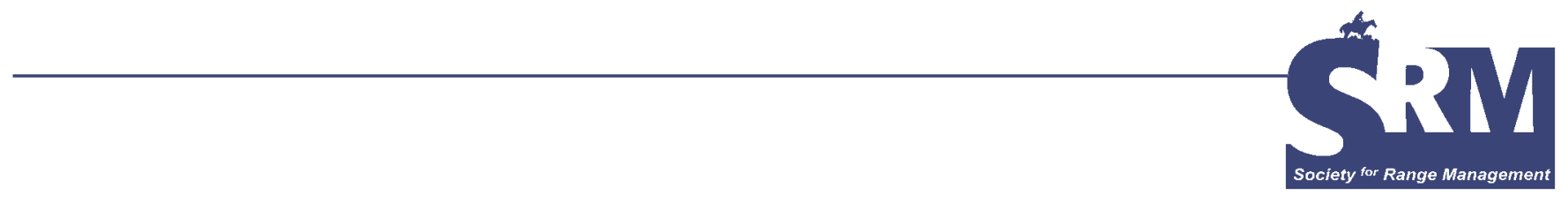

\section{Essays of a Peripheral Mind}

\section{Speaking other languages}

\section{By K. M. Havstad}

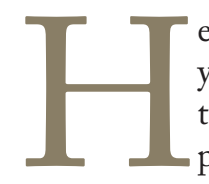

ere is an example of a serious commitment to your college education. In order to simply attend a university, you need to successfully complete your secondary education and pass your entrance exams, then get on a horse with a few belongings, ride for days to reach a rail line, embark on a 5- to 7-day train ride across the continent, attend classes taught in a foreign language you may not know very well at all, and seldom visit your home before your education is complete.

Early in October 2006, I met Dr. D. Avaadorj (Fig. 1), a soil scientist and member of the Mongolian Academy of Sciences working out of Ulaanbaatar, the capital city of Mongolia. I'd guess he was in his mid-60s and still very active in his discipline, in fact, still working at field sites across Mongolia on extensive campaigns to collect data and apply his knowledge to solving his country's resource use problems. His intense curiosity and intellectual capacity were quite in evidence and obviously lifelong traits. I hope to have his energy at his age. He had begun his formal education over 4 decades ago. Given the geopolitical landscape in Asia at that time, this meant that he attended universities in Russia and Germany. Of course, it also meant he learned his technical skills in German and Russian. To attend schools in Moscow and Berlin from Mongolia in the middle of the 20th century, he had to have the commitment outlined in the opening paragraph above. From that academic training through the early 1990s, he worked for over 3 decades in Mongolia under a Soviet influence. His fluency in Russian and German provided him with access to the technical information

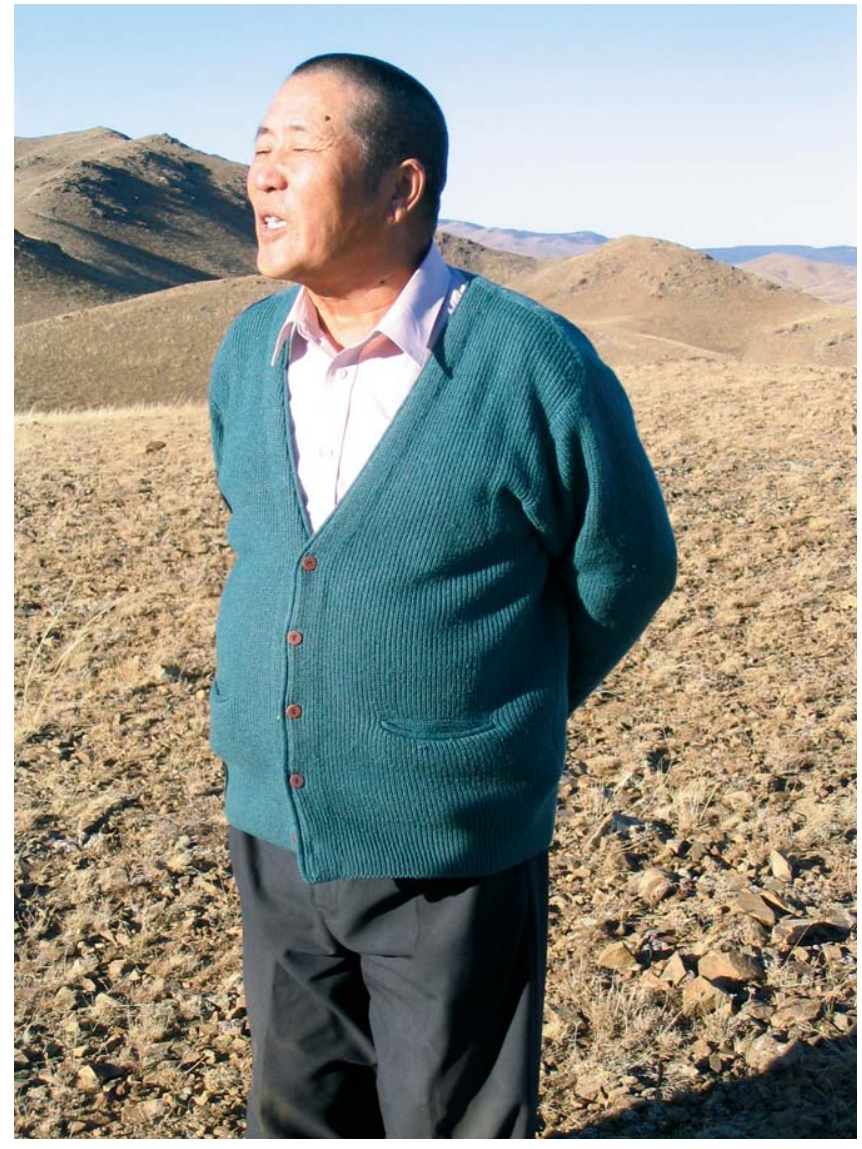

Figure 1. Dr. Avaadorj of the Mongolian Academy of Sciences. 
he needed during that period as he worked as a rangeland soil scientist.

Dr. Avaadorj's political, cultural, educational, and agricultural environment changed drastically, of course, in the early 1990s with the withdrawal of the Soviets, the collapse of the Soviet Union, and subsequent democratic elections in Mongolia. The changes accompanying the Soviet withdrawal were substantial, and it would be an easy and overly simplistic assessment, from an American perspective, to celebrate this change as nothing but positive. Certainly, with this shift from socialism, Mongolia became more accessible to the rest of the world. In reality, though, it has been a long road over the past 15 years, and democracy and a freer economy have not meant quick prosperity. There are many illustrations of the impacts of this change. For example, the loss of the Soviets' centralized veterinary services has resulted in an uneven privatized system that has contributed to frequent outbreaks of contagious animal diseases. With $65 \%$ of Mongolia's rural herders living at or below the poverty line (a social allowance per child may be just $\$ 2.50$ per month), veterinary services are not always readily available to all in an open-market system. There are also vast expanses of abandoned cropland where the Soviets had cultivated grains in the rich basin soils across Mongolia. These eroding landscapes are surrounded by clustered shells of abandoned combines and dairy barns that serve as a testament to that former presence. For a country with an 800-year history, these are the newest artifacts of Mongolia's human archaeology. In addition, natural disasters know no political orientations, and the severe summer droughts and heavy winters (dzuds) of 1999 and 2002 resulted in the death of nearly 10 million livestock, about one-third of the country's total herd. Overall, the Soviet absence left many voids, including the loss of access to considerable information accumulated by the Soviets important to management of Mongolian resources.

The Western world, both governments and donor organizations, has worked to fill these voids in the ensuing years. For a better introduction to this region, see the USDA Forest Service Proceedings RMRS-P-39 (Bedunah, McArthur, and Fernandez-Gimenez, 2006) for a set of papers on central Asia written for a special symposium during the 2004 SRM meeting in Utah (available at http://www.treesearch.fs.fed. us/pubs/22856, including writings by people in our profession with considerable experience in this part of the world, in particular, Dennis Sheehy, Don Bedunah, Doug Johnson, and Maria Fernandez-Gimenez, among others). In the summer of 2008, the International Rangeland Congress will be held in Hohhot, Inner Mongolia, within the People's Republic of China, and attendees will have an opportunity to tour this region as part of that Congress.
Mongolia is a stunning and immense landscape, the size of Alaska, with a history of rangeland livestock grazing for thousands of years. It is a pastoral environment, and pastoralism will be central to its future. As people like Robert Blench have observed about pastoralism around the world, it will survive not simply by adopting new technologies but by employing perspectives and policies rooted in understanding cultural settings of those resources (see http://www. fao-kyokai.or.jp/edocuments/document2.pdf). It will survive because people like Dr. Avaadorj will learn other languages to access information but eventually translate that information back into application in Mongolian and meld it with the rich history of information that exists within Mongolia. For Dr. Avaadorj and his colleagues, they are now being exposed to new ideas, concepts, methods, and approaches on rangeland management filtering in from North America. What it also means is that he, even now in his 60s, is trying to learn English, the current language of these ideas. Talking with him is through a translator, but it is obvious he is grasping quite a bit in English. In private moments he will engage in conversation with me in English. He is making a concerted effort to speak my language.

It has been many years since Dr. Avaadorj has had to ride a horse to reach the outside world from Mongolia. In fact, now the outside world arrives by airplane to Ulaanbaatar, climbs into Land Cruisers, and drives across these landscapes to see the Takhi, the wild horses of Mongolia. In a sense, we've come full circle. What I am reminded of in visiting with Dr. Avaadorj while also thinking about global issues of rangeland management is that much of our understanding of rangeland management is rooted in many different languages. Dr. Avaadorj has had to learn several other languages in order to practice his profession. And he is still learning new languages in order to maintain his relevance. Even though considerable technical information is now widely available in English, I'll never understand rangeland management around the globe (or even just in North America) by just knowing English. Too much relevant information is embedded outside the English-speaking world in the same fashion that Dr. Avaadorj recognizes that too much information is embedded outside Mongolia. Short of traversing a continent by horseback and train, I'll need to have a similar commitment as Dr. Avaadorj has demonstrated and learn to speak other languages as well.

Author is Supervisory Scientist, USDA, Agricultural Research Service, Jornada Experimental Range, MSC 3JER, New Mexico State University, PO Box 30003, Las Cruces, NM 88003, khavstad@nmsu.edu. 


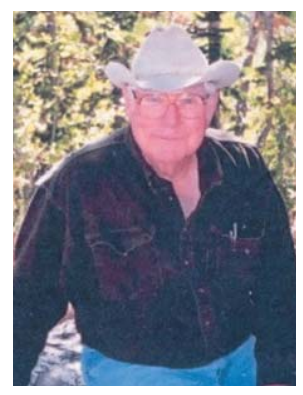

Thad Box

\section{Trail Boss Principles}

In March, 1882, Jim Flood's cow crew swam 3,200 Mexican cattle across the Rio Grande near Brownsville, Texas. Five months later they delivered their herd of 3,312 head to the Blackfoot Indian Agent in western Montana.

Their whole, true story is in Andy Adam's "Log of a Cowboy." The first-person narrative of the 1882 trail drive was required reading when I went to school. Some of the language is not politically correct for today's classrooms, but Adam's book is filled with simple common sense that is timeless. Take, for instance, Flood's instruction to greenhand cowboys on their first trail drive.

The Trail Boss said cattle should never know they were under restraint. They should not be driven, just keep something of interest in front of them-fresh forage, water, movement in the distance that peaks their curiosity. Point men should gently turn those that wander back toward the herd, and keep strays from entering. Cowhands at the rear keep any from turning back.

Occasionally it is necessary to stop cattle from milling or turn a stampede, but for the most part the task is simple. Make sure every step the cattle take is toward the destination-and let them get there because they want to go. The trick is to keep them content and constantly moving at their own pace, never aware they are driven.

Each hand was to pick 12 horses from the remuda. Flood urged each man to keep his horses healthy, rotate them, and let none go lame or become unridable. Train some horses for special chores like swimming a river. Not only would a good swimming horse keep its rider safe, but the success of the herd depended on special skills.

He told the cook to spare nothing for provisions because a well-fed crew was a happy one. He cautioned the hands to eat well, and have a dry bedroll so they could sleep comfortably when they had a chance. He did not downplay the rigors and hardships ahead. They all knew they would face flooded river crossings, long waterless stretches, and Indian raids. But if they got along as a team, stayed healthy, kept their mounts fresh, and thought first about the herd they would all—cattle and cowboys - arrive alive and on time.

The topic of this issue of Rangelands is "Improvements and Ranch Management." Jim Flood taught a whole curriculum in management in a few minutes: know your mission, have a plan, move steadily forward, keep equipment in working readiness, use specialists, stay healthy, work as a team, and care about the job. It was a business plan based on principles.

Those principles apply to almost anything. I've had occasion to interact with many different kinds of businesses. Almost all provided a good and needed product or service. Some violated basic principles. Most that failed lacked a strategic plan. Hard work going in the wrong direction leads to heartbreak.

We exist as land care professionals to promote sustainable rangelands. One of our guiding principles is to maintain basic ecological productivity - to keep options open for whatever use 
future generations want to make of the land. This argues that "improvements" and the ranch management plan be compatible with long-term stability rather than short-term need. Very different skills are involved in maintaining sustainable rangelands versus maximizing profit through a vegetation and soil mining operation.

Traditionally the ranch management plan has been a business plan to provide a living for the ranch family. It considered improvements to be structures or tools to improve efficiency in a livestock business: fences, water points, sheds, pens, chutes, the list goes on. It sometimes included manipulating vegetation types to grow plants more productive and palatable to domestic animals. Some range management plans, often those of public land agencies, were designed to rehabilitate deteriorated rangelands back to some historical base.

Times and range use has changed. The modern plan, or those for the future, must be geared to the land, not the product or use, if sustainability is our goal

Early range management developed a subcategory called range improvements. Jared Smith's "Experiments in Range Improvements" published by the US Department of Agriculture in 1898 was among the first professional papers. Smith advocated reseeding grasses, loosening the soil with harrows and plows, and cutting furrows to collect seeds and improve water penetration.

Some 35 years ago, as part of the process of revising Stoddart and Smith's classic range text, Art Smith and I evaluated all the range improvement work produced in the first threequarters of the 20th century. Most were how-to papers. Few were experiments based on principles.

Like the profession at that time, our book was geared primarily to managing rangeland for livestock production. We included the traditional range improvement practices in 2 chapters: Manipulating Range Vegetation and Range Improvements for Increasing Forage Production. We listed the physical "improvements" in an outline in a chapter on planning grazing use of the range. Such a book is now inadequate for sustainable rangelands with many different uses.

I taught a course called "Range Improvements" at least a dozen times in my career at 3 different universities on 2 continents. I never taught the same course twice. My concept of what was needed in such a course gradually changed as our profession changed.

When I started teaching in the 1960s, range improvement work was largely geared to rehabilitating overgrazed and abused lands. It was often driven by availability of military surplus machinery that allowed woody vegetation to be removed by crawler tractors pulling anchor chains, roller-choppers, and all sorts of Rube Goldberg devices to remove brush, loosen the soil, make pits, and improve water penetration. About the only difference between it and the 19th century range improvement work was the kind of equipment used.

The first few courses I taught were mostly how-to courses, full of recipes but with few principles. As range scientists began doing better science, running controlled experiments, and developing principles, my courses shifted from vocational how-to-kill-bad-stuff guides to courses with more soil and ecological principles. The last few times I taught range improvements, my classes were essentially basic ecology courses.

As I wrestled with what I might say in an essay on improvements and ranch management to a 21st century audience, three words kept popping into my mind-stick to principles. But the principles for management and restoring ecological productivity come from different fields.

The principles for running a ranch are those of a successful firm. They come from management science and business. Strategies will be different depending on what kind of products or services the ranch wants to produce-livestock, recreation, native plant seed, etc. Goals will be different if the strategy is to have a sustainable operation versus one that extracts wealth in a short time and externalizes its effects on the land.

Improvement principles are those of an ecological system. They are rooted in biology, soil science, and physics. Strategies tend to optimize rather than maximize, encourage stability over long time periods. Goals need to prevent closing out future options.

Sustainability of rangelands, the reason we exist, depends on continuous development of scientific principles for basic land productivity. It has little to do with what will be produced from that rangeland. It depends on our continuing to do good science. But it also depends on wise managers putting the science to use.

Long ago, down on the banks of the Rio Grande, Jim Flood told a bunch of green kids: Don't borrow trouble worrying about rivers, stampedes, and gunfights. Know where you're going. Have a plan to get there. Hold a challenge out front. Keep your horses fit. Train some to swim. Wrap your bedroll in a slicker. Eat well. Stay healthy. Have fun. Care about your charge.

Trail herds are history. Trail Bosses exist mainly in folklore. We have reduced our Trail Boss logo to a tiny speck atop a new, stylized, 21st century SRM logo. Without bifocals, you're likely to miss it. But our profession will serve the land well if we adopt the principles Trail Boss Jim Flood used in his 19th century cattle drive.

ThadBox,thadbox@comcast.net. 


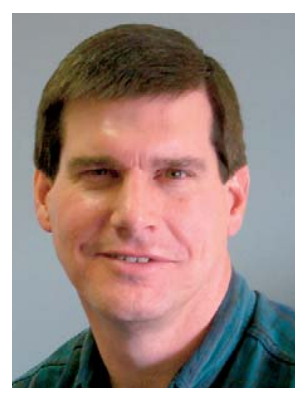

Jeff Mosley

\section{Browsing the Literature}

This section reviews new publications available about the art and science of rangeland management. Personal copies of these publications can be obtained by contacting the respective publishers or senior authors (addresses shown in parentheses). Suggestions are welcomed and encouraged for items to include in future issues of Browsing the Literature. Contact Jeff Mosley, jmosley@montana.edu.

\section{Animal Ecology}

Effects of a visual barrier fence on behavior and movements of black-tailed prairie dogs. N. S. Foster-McDonald, S. E. Hygnstrom, and S. P. Korte. 2006. Wildlife Society Bulletin 34:1169-1174. (School of Natural Resources, Univ of Nebraska, Lincoln, NE 68583). The SB Tensar snowfence did not control movements of black-tailed prairie dogs.

Response of plant and rodent communities to removal of prairie dogs (Cynomys gunnisoni) in Arizona. S. E. Bartz, L. C. Drickamer, and M. J. C. Kearsley. 2007. Journal of Arid Environments 68:422-437. (Dept of Biological Sci, Northern Arizona Univ, Box 5640, Flagstaff, AZ 86011). "We conclude that Gunnison's prairie dogs are not functioning as a keystone species in grasslands of northern Arizona."

\section{Grazing Management}

Alkaloid profiles, concentration, and pools in velvet lupine (Lupinus leucophyllus) over the growing season. S. T. Lee, M. H. Ralphs, K. E. Panter, D. Cook, and D. R. Gardner. 2007. Journal of Chemical Ecology 33:75-84. (USDA-ARS, Poisonous Plant Research Lab, 1150 East 1400 North, Logan, UT 84341). In velvet lupine, concentration of the alkaloid that causes livestock birth defects is highest in the plant's immature seeds.

Grassland songbirds in a dynamic management landscape: behavioral responses and management strategies. N. G. Perlut, A. M. Strong, T. M. Donovan, and N. J. Buckley. 2006. Ecological Applications 16:2235-2247. (The Rubenstein School of Environment and Natural Resources, Univ of Vermont, 81 Carrigan Dr, Burlington, VT 05405). Savannah sparrows and bobolinks had moderate reproductive success on rotationally grazed pastures in the northeastern United States.

Gunnison sage-grouse use of Conservation Reserve Program fields in Utah and response to emergency grazing: a preliminary evaluation. S. G. Lupis, T. A. Messmer, and T. Black. 2006. Wildlife Society Bulletin 34:957-962. (Dept of Wildland Resources, Utah State Univ, Logan, UT 84322). Suggests that high-intensity rotational livestock grazing can be used to enhance the quality of sage-grouse habitat in CRP fields.

Incorporating sheep into dryland grain production systems II. Impact on changes in biomass and weed density. P. G. Hatfield, A. W. Lenssen, T. M. Spezzano, S. L. Blodgett, H. B. Goosey, R. W. Kott, and C. B. Marlow. 2007. Small Ruminant Research 67:216-221. (Dept of Animal and Range Sciences, Montana State Univ, Bozeman, MT 59717). Burning or prescribed sheep grazing were equally effective in reducing weed biomass and density in 
wheat stubble fields. Prescribed sheep grazing is a viable tool for controlling weeds in dryland wheat fields.

Targeted grazing: A natural approach to vegetation management and landscape enhancement. K. L. Launchbaugh, J. W. Walker, and R. Daines [eds]. 2006. American Sheep Industry Association, Centennial, CO. 199 p. (\$25; American Sheep Industry Association, www.sheepusa.org/ targetedgrazing). Written by scientists and practitioners from across the United States, this handbook contains 18 chapters that synthesize the research literature and practical experiences about using prescribed (or targeted) livestock grazing to accomplish ecological objectives. Chapters include strategies for controlling invasive weeds, creating fuelbreaks, increasing timber growth and fruit production, improving wildlife habitat, and much more.

\section{Hydrology/Riparian}

Riparian area management: Grazing management processes and strategies for riparian-wetland areas. S. Wyman, D. W. Bailey, M. Borman, S. Cote, J. Eisner, W. Elmore, B. Leinard, S. Leonard, F. Reed, S. Swanson, L. Van Riper, T. Westfall, R. Wiley, and A. Winward. 2006. Technical Reference 1737-20, BLM/ST/ST-06/002+1737. Bureau of Land Management, Denver, CO. 105 p. (Printed Materials Distribution Service, Bureau of Land Management, PO Box 25047, Denver, CO 80225). This publication is the latest update of the BLM technical reference for managing livestock grazing in riparian ecosystems.

\section{Plant Ecology}

Evaluation of elemental allelopathy in Acroptilon repens (L.) DC. (Russian knapweed). C. Morris, C. A. Call, T. A. Monaco, P. R. Grossi, and S. A. Dewey. 2006. Plant and Soil 289:279-288. (C. Call, Dept of Wildland Resources, Utah State Univ, Logan, UT 84322). Although Russian knapweed is known to concentrate zinc in upper soil layers, this study found no evidence that elevated levels of zinc had allelopathic effects on desirable grasses.

Long-term interactions of climate, productivity, species richness, and growth form in relictual sagebrush steppe plant communities. N. E. West and T. P. Yorks. 2006. Western North American Naturalist 66:502-526. (Dept of Wildland Resources, Utah State Univ, Logan, UT 84322). In relict sagebrush steppe sites of southern Idaho, sagebrush and other shrubs have increased in relative abundance compared with herbaceous plants. These changes during the past 20 to 30 years are due more to the absence of fire than climate change or absence of livestock grazing.

Mechanisms underlying the impacts of exotic annual grasses in a coastal California meadow. H. M. Coleman, and J. M. Levine. 2007. Biological Invasions 9:65-71. (School of Environmental Science and Management, Univ of Cali- fornia, Santa Barbara, CA 93106). Native forbs were limited by insufficient sunlight reaching them through the canopy and litter of invasive annual grasses. Native forbs were not limited by insufficient water.

Performance of Bromus tectorum L. in relation to soil properties, water additions, and chemical amendments in calcareous soils of southeastern Utah, USA. M.E. Miller, J. Belnap, S. W. Beatty, and R. L. Reynolds. 2006. Plant and Soil 288:1-18. (US Geological Survey, 190 East Center St., Kanab, UT 84741). In southeastern Utah, fall establishment of cheatgrass and its growth in spring are limited by water availability, whereas winter growth is limited by low nutrient mobilization and uptake caused by cold temperatures.

\section{Rehabilitation/Restoration}

Carbon-negative biofuels from low-input high-diversity grassland biomass. D. Tilman, J. Hill, and C. Lehman. 2006. Science 314:1598-1600. (Dept of Ecology, Evolution, and Behavior, Univ of Minnesota, St. Paul, MN 55108). Seeded mixtures of native grasses produced dramatically more bioenergy than monocultures. Also, grass mixtures produced $51 \%$ more bioenergy per acre than corn grain ethanol.

Investigation of potential zooanthroponotic transmission of cryptosporidiosis and giardiasis through agricultural use of reclaimed wastewater. G. D. Di Giovanni, W. Q. Betancourt, J. Hernandez, N. W. Assadian, J. P. F. Margez, and E. J. Lopez. 2006. International Journal of Environmental Health Research 16:405-418. (Texas Agricultural Experiment Station, 1380 A\&M Circle, El Paso, TX 79927). Despite high levels of cryptosporidium and giardia in reclaimed wastewater used to irrigate pastures for grazing sheep, there was no evidence that the pathogens in the wastewater were transmitted to the sheep.

Long-term effects of tebuthiuron on Bromus tectorum. D. N. Blumenthal, U. Norton, J. D. Derner, and J. D. Reeder. 2006. Western North American Naturalist 66:420-425. (USDA-ARS, Crops Research Lab, 1701 Center Ave, Fort Collins, CO 80526). Eleven years after Wyoming big sagebrush sites were thinned with tebuthiuron, shrub cover was $31 \%$ in untreated sites vs $15 \%$ in treated sites, perennial grass cover was $9 \%$ in untreated vs $12 \%$ in treated sites, and cheatgrass cover was $1 \%$ in untreated sites vs $4 \%$ in treated sites.

Plants and breeding bird response on a managed Conservation Reserve Program grassland in Maryland. D. E. Gill, P. Blank, J. Parks, J. B. Guerard, B. Lohr, E. Schwartzman, J. G. Gruber, G. Dodge, C. A. Rewa, and H. F. Sears. 2006. Wildlife Society Bulletin 34:944-956. (Dept of Biology, Univ of Maryland, College Park, MD 20742). Results indicate that habitat selection by grassland birds is influenced more by vegetation structure than by plant species composition. Recommends that prescribed fire and herbicides be ap- 
plied frequently to sustain CRP grasslands and prevent tree and shrub encroachment.

Short- and long-term changes in elk use and forage production in sagebrush communities following prescribed burning. F. Van Dyke and J. A. Darragh. 2006. Biodiversity and Conservation 15:4375-4398. (Dept of Biology, Wheaton College, Wheaton, IL 60187). In south-central Montana, prescribed burning transformed mountain big sagebrushdominated sites into native herbaceous plant communities that persisted for at least 15 years without sagebrush reinvasion. Elk made increased use of these sites for at least 15 years after burning.

\section{Socioeconomics}

Addressing misconceptions about agriculture: Instructor's Guide. B. Wolanyk. 2006. American Farm Bureau Foundation for Agriculture, Washington, DC. Printed volume (46 p.) plus CD-ROM. (\$15; American Farm Bureau Foundation for Agriculture, 600 Maryland Ave, Suite 1000W, Washington, DC 20024). This guide covers 35 key issues and is designed for classroom use at the high school and college levels. Written in an easy-to-understand format with step-by-step directions, the guide includes ready-to-use scripts and PowerPoint presentations on CD-ROM.

Biological invasions: recommendations for US policy and management. D. M. Lodge, S. Williams, H. J. MacIsaac, K. R. Hayes, B. Leung, S. Reichard, R. N. Mack, P. B. Moyle, M. Smith, D. A. Andow, J. T. Carlton, and A. McMichael. 2006. Ecological Applications 16:2035-2054. (Dept of Biological Sci, Univ of Notre Dame, PO Box 369, Notre Dame, IN 46556). This position paper from the Ecological Society of America recommends the federal government assume more responsibility for all aspects of invasive-species management in the United States.
Custom rates for Idaho agricultural operations 20052006. P. E. Patterson and R. L. Smathers. 2006. Univ of Idaho Extension Service Bulletin 729. 16 p. (Univ of Idaho Extension Service, Moscow, ID; www.info.ag.uidaho.edu). Summarizes survey data for custom farming services such as haying, chisel plowing, and grass seeding. During the past 6 years, custom rates have increased less than ownership and operating costs for equipment.

Effect of certified health programs on the sale price of beef calves marketed through a livestock videotape auction service from 1995 through 2005. M. E. King, M. D. Salman, T. E. Wittum, K. G. Odde, J. T. Seeger, D. M. Grotelueschen, G. M. Rogers, and G. A. Quakenbush. 2006. Journal of the American Veterinary Medical Association 229:1389-1400. (M. Salman, College of Veterinary Medicine and Biomedical Sci, Colorado State Univ, Fort Collins, CO 80523). A study involving 3 million calves found that preconditioned calves (vaccinated and weaned before delivery) sold for higher prices every year during a 10-year period. Price premiums ranged from $\$ 1$ to almost $\$ 8$ per hundredweight.

\section{Soils}

The invasive plant species Centaurea maculosa alters arbuscular mycorrhizal fungal communities in the field. D. L. Mummey and M. C. Rillig. 2006. Plant and Soil 288:8190. (Division of Biological Sci, Univ of Montana, Missoula, MT 59812). Spotted knapweed invasion of native grassland reduces the diversity and abundance of arbuscular mycorrhizal fungi.

Jeff Mosley is Professor of Range Science and Extension Range Management Specialist, Department of Animal and Range Sciences, Montana State University, Bozeman, MT 59717. 


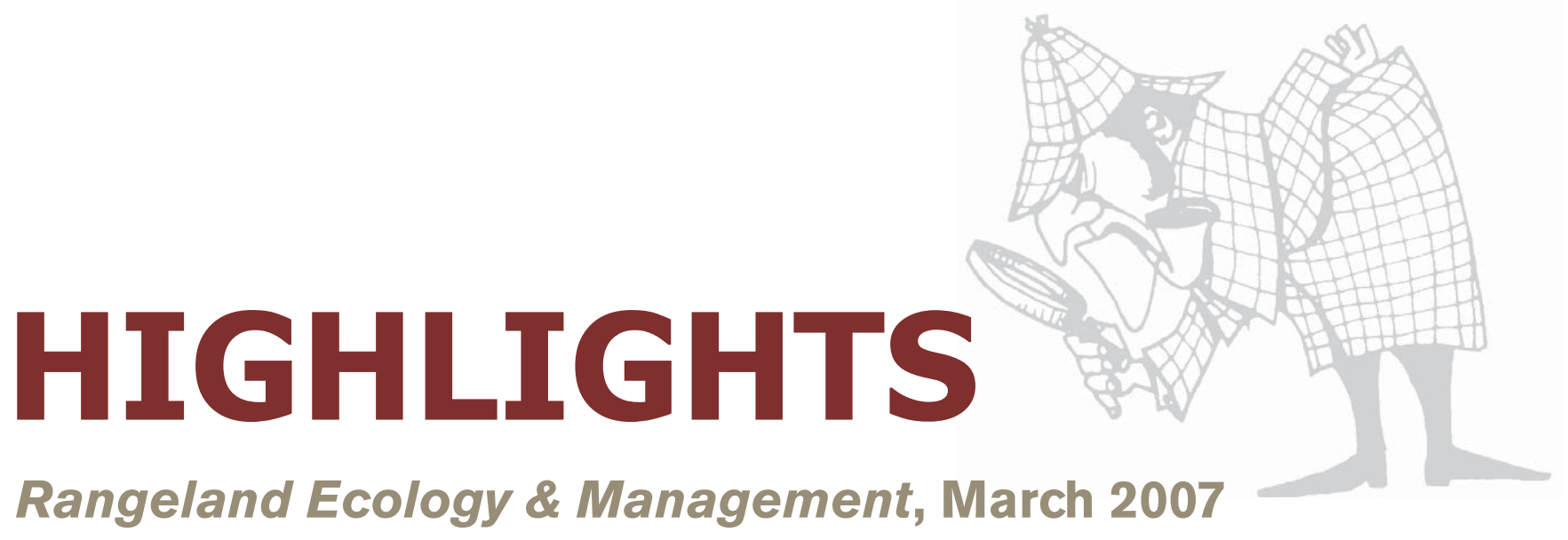

\section{Spatial Patterns of Pinyon-Juniper Woodland Expansion in Central Nevada}

Peter J. Weisberg, Emanuele Lingua, and Rekha B. Pillai

Conifer expansion in the Great Basin has received much attention, but little is known concerning how recent expansion rates have varied with spatial scale and across the landscape. We used historical air photos to quantify changes in treedominated area over the past three decades for a $25-\mathrm{km}^{2}$ area in central Nevada. Recent woodland expansion has been dominated by infilling of trees establishing in small openings, has progressed most rapidly at lower elevations, and is far more rapid on moister slope aspects and more well-developed soils. Management treatments involving removal of trees should be viewed in a long-term and site-specific context.

\section{Assessment of Expert Opinion: Seasonal Sheep Preference and Plant Response to Grazing}

Meg L. Pollock, Colin J. Legg, John P. Holland, and Chris M. Theobald

Expert opinion is often used in decision making and in rangeland models, but variation between experts is rarely taken into account. We asked nine experts about sheep preferences for Scottish rangeland plants at different times of the year and about plant responses to grazing at different times of the year. We found substantial agreement between experts on sheep preferences, but considerable uncertainty and disagreement about plant responses, especially on the impact of grazing in winter. This is important because seasonal grazing regimes for conservation are being developed-understanding their impact on vegetation is needed in order to meet management objectives.

\section{Forest Service Grazing Permittee Perceptions of the Endangered Species Act in Southeast- ern Arizona}

Julie Lorton Conley, Maria E. Fernandez-Gimenez, George B. Ruyle, and Mark Brunson
Much of the conflict over threatened and endangered (T\&E) species is centered on the presence and management of public land livestock grazing. This study reports the results of a survey of grazing permittees on one national forest about their attitudes regarding the Endangered Species Act and the management of T\&E species. Perceptions of negative impact and attitudes toward T\&E species policies were more related to attitudes toward federal regulation than the number of listed species on allotments or the potential for restrictions on those allotments. However, not all ranching operations perceive negative impacts from $\mathrm{T} \& \mathrm{E}$ species policies and many permittees would support efforts to recover $T \& E$ species.

\section{Using Weather Data to Explain Herbage Yield on Three Great Plains Plant Communities}

Alexander J. Smart, Barry H. Dunn, Patricia S. Johnson, Lan Xu, and Roger N. Gates

Understanding the drivers that account for plant production from different plant communities receiving similar climatic inputs can assist managers in making informed decisions about stocking rates and timing of grazing. We compared climatic drivers of herbage production for three plant communities of the Clayey ecological site in southwestern South Dakota. Herbage production was best predicted by models that included current year spring (April-June) precipitation, day of the last spring freeze, and previous year spring precipitation. Our study enables managers to make timely informed decisions regarding stocking rates and timing of grazing on this ecological site in western South Dakota.

\section{Texas Wintergrass and Buffalograss Response to Seasonal Fires and Clipping}

\section{R. James Ansley and Michael J. Castellano}

Effects of seasonal fires combined with grazing on rangeland grasses are poorly understood. We quantified effects of repeated winter fires, repeated summer fires, and clipping (to simulate grazing) on yields and percentage of live tissue of C3 Texas wintergrass (Nassella leucotricha) and C4 buffalo- 
grass (Buchlöe dactyloides). Results suggest: 1) both species were tolerant of summer fire, 2) fire with or without clipping stimulated buffalograss production, and 3) buffalograss was more tolerant than Texas wintergrass to combined effects of clipping plus fire. Different responses of $\mathrm{C} 3$ and $\mathrm{C} 4$ grass species to seasonal fire and grazing should be considered when determining management protocols.

\section{Long-Term Vegetation Productivity and Trends Under Two Stocking Levels on Chihuahuan Desert Rangeland}

\section{Godfrey Khumalo, Jerry Holechek, Milt Thomas, and Francisco Molinar}

In recent years many Chihuahuan Desert ranchers have become interested in light stocking as a tool to avoid risk of damaging their rangelands during drought and as a hedge against drastic destocking when cattle prices are often unfavorable. We compared vegetation cover, productivity, and composition over an 11-year period on 2 lightly- and 2 conservatively-stocked pastures. Light stocking had no benefit over conservative stocking in terms of increasing perennial grass productivity, but perennial grass cover was better maintained under light than conservative stocking. During the period of our study, climatic conditions rather than grazing treatment exerted the overriding influence on vegetation cover, composition, and productivity.

\section{Influence of Forest Mangement and Previous Herbivory on Cattle Diets}

\section{Kenric J. Walburger, Timothy DelCurto, and Martin Vavra}

We documented the effects of timber harvest and herbivory on nutritional quality and botanical composition of steer diets in grand fir (Abies grandis) and ponderosa pine (Pinus ponderosa) forests. Crude protein, in vitro organic matter digestibility, acid detergent fiber, and neutral detergent fiber were only affected by season of use. Within both sites, graminoids were the major constituent of the diet (65-91\%), forbs were intermediate $(8-31 \%)$, and shrubs were least $(0.2-3.5 \%)$. Timing of grazing had a greater influence on diet quality, but previous herbivory and/or timber harvest had a greater influence on diet composition.

\section{Effects of Wildlife on Cattle Diets in Laikipia Rangeland, Kenya}

\section{Wilfred O. Odadi, Truman P. Young, and}

\section{J. B. Okeyo-Owuor}

Little is known about how wildlife affect the diets of cattle, despite the fact that most livestock share their ecosystems with wildlife. Using a replicated set of large-scale exclosures in a savanna rangeland in Kenya, we quantified the diets of cattle both in the presence and in the absence of wildlife.
When in competition with wildlife, cattle shifted their diet, in particular eating fewer forbs (especially Commelina spp.) during the dry season. This research demonstrates that even moderate densities of wildlife can have significant effects on cattle diets, and potentially reduce livestock performance.

\section{Blackland Tallgrass Prairie Vegetation Dy- namics Following Cessation of Herbicide Application}

\section{Karen R. Hickman and Justin D. Derner}

Conservation of the endangered Blackland Tallgrass Prairie of Texas has focused on acquisition of remnants, the majority having a history of herbicide application.

We studied short-term responses of the plant community following cessation of long-term herbicide application. Substantial increases in plant cover from 1998 to 2000 were observed for annual forbs, but $\mathrm{C} 4$ perennial grass cover only marginally increased; thus dominance shifted from $\mathrm{C} 4 \mathrm{pe}-$ rennial grasses to annual forbs. Conservation efforts need to be cognizant that dramatic short-term effects on vegetation dynamics will occur following cessation of herbicide applications, and enhancement of perennial forbs might require seeding or transplanting species.

\section{Differences in Food Ingestion and Diges- tion Among Sheep Classified as High or Low Sagebrush Consumers}

M. J. Fraker-Marble, K. L. Launchbaugh, and J. W. Walker

We examined behavioral and digestive traits of sheep identified as high or low consumers of sagebrush. High sagebrush consumers ate the same amount of sagebrush as low consumers when they had unrestricted access to a basal ration of alfalfa pellets. When animals were restricted to $75 \%$ of their recommended energy requirement, sheep identified as high consumers ate more sagebrush than low consumers. In vivo digestibility of a diet containing 10\% fresh sagebrush and 90\% alfalfa/grass hay was higher for high sagebrush consumers than low consumers. Sheep that willingly consumed high amounts of sagebrush were able to digest diets containing sagebrush more efficiently than low sagebrush consumers.

\section{Learning Through Foraging Consequences: A Mechanism of Feeding Niche Separation in Sympatric Ruminants}

\section{Scott L. Kronberg and John W. Walker}

When two or more species of ruminants forage on the same area of rangeland, they seldom if ever eat the same plants or parts of the same plants. If desired, we could manage their foraging more effectively with a better understanding of the mechanisms underlying their plant selection. In this paper, it is argued that the learning-through-foraging-consequences 
model of diet selection offers a unique explanation for the diets selected by sympatric ruminant species. Fortunately, this model implies that management interventions such as supplementation of ruminants can be used to alter their diet selection and thus provide a valuable management tool.

\section{The Influence of Gap Size on Sagebrush Cover Estimates With the Use of Line Inter- cept Technique}

\section{Chad S. Boyd, Jon D. Bates, and Rick F. Miller}

Sagebrush cover is often estimated using the line intercept method; however, a lack of standardized protocols can lead to conflicting estimates. We measured sagebrush canopy intercept using 5-, 10-, and 15-cm-gap sizes and compared live and dead sagebrush canopy cover estimates resulting from each gap size. Total cover estimates were not related to gap size, live canopy cover estimates increased with increasing gap size, and cover of dead material decreased with increasing gap size. Use of a standardized gap size will enhance comparabil- ity of canopy cover estimates among studies and will decrease between-year sampling error for repeat monitoring.

\section{A Passive Application Watering System for Rangeland Plots}

Patrick E. Reece, Ann E. Koehler, W. Douglas Whisenhunt, Jerry D. Volesky, and Walter H. Schacht

Interactions between precipitation regimes and optimum air temperatures for growth of different species often have measurable effects on peak standing herbage and species composition. Therefore, we developed the portable Passive Application Watering System (PAWS) which is suitable for applying water over a wide range of slope, soil texture, and residual herbage conditions with little or no runoff. Application rates were $5 \mathrm{~mm} \cdot \mathrm{hr}^{-1}$ and $40 \mathrm{~mm} \cdot \mathrm{hr}^{-1}$, which correspond to the permeability of clay loam and silt loam, respectively. We have successfully used the PAWS in 3 research projects on range sites with sandy and loamy soil texture classes. 
Water Harvesting from Low-Standard Rural Roads. By Bill Zeedyk. April 2006. A Joint Publication from The Quivira Coalition, and Zeedyk Ecological Consulting LLC, The Rio Puerco Management Committee-Watershed Initiative, and the New Mexico Environment Department-Surface Water Quality Bureau. 46 p. Book free from: The Quivira Coalition, 1413 Second Street, Suite \#1, Santa Fe, NM 87505. Phone 505-820-2544. (S\&H charge of $\$ 4$ for the first copy and $\$ 2$ for each additional copy in the same order.)

This book addresses the construction and maintenance of unpaved rural roads including strategies, techniques, and practices for dealing with problems frequently encountered by land owners, land managers, and maintenance personnel.

There are nine major sections to the book: 1) Assessing Needs and Opportunities; 2) Reading the Landscape: Geology, Topography, Hydrology, and Soils; 3) Reading the Roadway; 4) Road System Planning and Management Strategies and Practices; 5) Treatments; 6) Survey and Design: Placing Treatments on the Ground; 7) Monitoring: Are Maintenance Practices Effective? 8) Streams, Wetlands, Springs and Cienegas; 8) Tools and Equipment; and 9) Getting the Job Done. Included are 5 Appendices covering Glossary, Weights and Measures, Permits and Clearances, Recommended Reading, and Maintenance Treatments.

Although the term "water harvesting" is in the book title, the majority of the information relates to rural road maintenance. It is not an engineering design manual but does provide sufficient information that would allow the reader to assess and rectify poor rural roads.

There are numerous simple figures, illustrations, and photos which illustrate the points in the text. The concepts are easy to follow and understand with a single reading. The entire book can be read in less than an hour. The photos are in color, showing various aspects of field sites and installation procedures. The photos are supplemented with good simple line drawings depicting various construction concepts.

Included in the book are descriptions for ways of managing roads to reduce off-site erosion and ways to restore damaged areas. The author makes frequent reference to managing the runoff water, or water harvesting, for some beneficial use.

Of special note is Appendix E: Maintenance Treatments. It is a simple table showing: Treatment Type, Where/When Used, Purpose and Conditions of Use, and Cautions. It takes you directly to the best technique to remedy a specific problem without having to go through the entire publication to find what you want.

\section{Gary Frasier, Editor-in-Chief, Rangelands.}

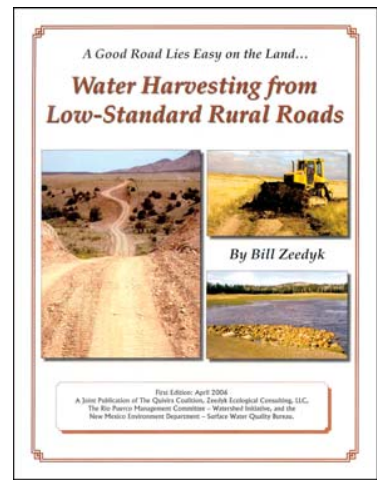




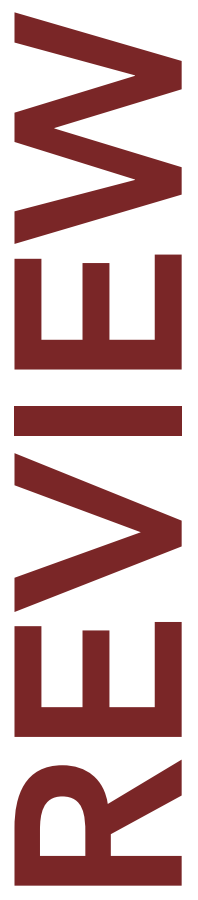

An Introduction to Induced Meandering: A Method for Restoring Stability to Incised Stream Channels. 3rd ed. By Bill Zeedyk. April 2006. A Joint Publication from Earth Works Institute, The Quivira Coalition, and Zeedyk Ecological Consulting. 16 p. Book free from:The Quivira Coalition, 1413 Second Street, Suite \#1, Santa Fe, NM 87505. Phone 505-820-2544 or print from the website at www.quiviracoalition. org.

This book is an illustrated field guide providing a general description of technology for inducing meandering in small channels. It is not an engineering design manual.

There are three sections to the book: 1). Concepts and Terminology, 2) Induced Meandering Procedures, and 3) Types and Locations of Structures.

The book, in a 5- $\times 8$-inch format, is easy to carry to the field with simple figures, illustrations, and photos which illustrate the points in the text. The concepts are easy to follow and understand with a single reading. The entire book can be read in less than an hour. The photos are in color, showing various aspects of field sites and installation procedures. The photos are supplemented with good simple line drawings depicting various construction concepts.

The book is a good handout for field tour discussions with general contractors, volunteers, project managers, and government officials with limited engineering background who might not have a familiarity with general small stream morphology. It provides a good introduction to the basic techniques of inducing meandering for small stream restoration.

Gary Frasier, Editor-in-Chief, Rangelands.

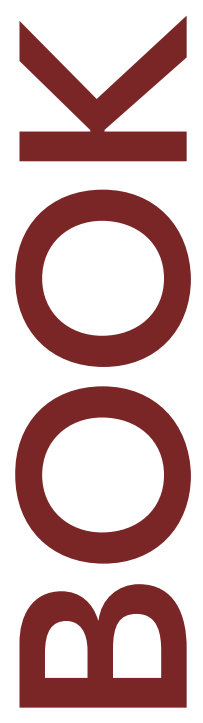

(n)


An Introduction to Erosion Control. 2nd Ed. By Bill Zeedyk and Jan-Willem Jansens. March 2006. A Joint Publication from Earth Works Institute, The Quivira Coalition, and Zeedyk Ecological Consulting. 24 p. Book free from: The Quivira Coalition, 1413 Second Street, Suite \#1, Santa Fe, NM 87505. Phone 505-820-2544 or print from the website at www.quiviracoalition.org.

This book provides a general description of some simple erosion control techniques for rangeland watersheds. It is not an engineering design manual.

The book is an illustrated field guide showing both the problem of soil erosion on rangelands and some simple solutions. It is well-suited as a handout for field tour discussions with general contractors, volunteers, project managers, and government officials with limited engineering background who might not have training in soil erosion processes or remedies. It provides a good introduction to some basic techniques for reducing soil loss by water.

There are five sections to the book: 1) An Introduction to Erosion Control, 2) Landscape Degradation Processes, 3) General Soil Healing Techniques, 4) Healing Techniques for Gullies and Headcuts, and 5) Not Recommended.

The book, in a 5- $\times 8$-inch format, is easy to carry to the field with simple figures, illustrations, and photos which illustrate the points in the text. The concepts are easy to follow and understand with a single reading. The entire book can be read in less than an hour. The photos are in color showing various aspects of field sites and installation procedures. The photos are supplemented with good simple line drawings depicting various construction concepts.

On the inside of the back cover is a simple table labeled "When to Use What." It gives the Technique, the page where it is discussed, and "When to Use." It takes you directly to the best technique to remedy a specific problem without having to go through the entire publication to find what you want.

Of special note is the section titled "Not Recommended." It has simple drawings and a good discussion of where the techniques will not work and why they might actually increase soil erosion.

Although most of the descriptions and discussion refer to arid and semiarid rangelands in the southwestern United States, the concepts are applicable to many parts of the world.

Gary Frasier, Editor-in-Chief, Rangelands.

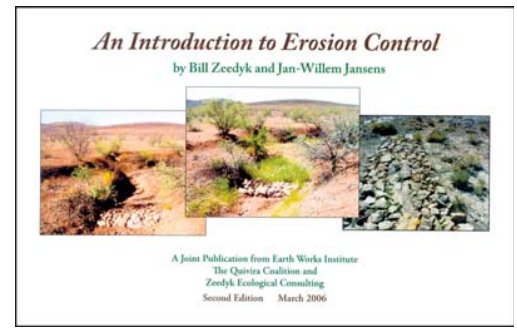




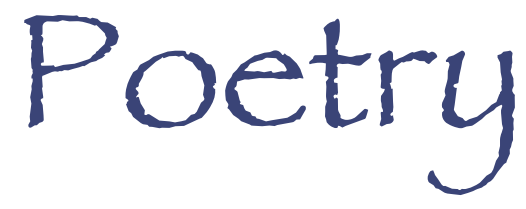

Inyo

I wrote this poem not long after we sold our ranch in 1985. The winter prior to selling we had subleased some of our ranch for a producer with a bunch of yearling crossbred steers. Those things hit the ground running and never quit until they were loaded back on trucks the following fall. They swam the river, climbed the mountains, and invaded every neighbor's ranch for miles (as far as 15 miles away). The poem is about the last 10 or 12 head that we couldn't find when we gathered the bunch. I finally cut their tracks and found they had headed up into the White Mountains and were watering at a little spring I didn't even know existed. They saw me on horseback and headed off to parts unknown. I took off at a run to get them to turn toward the Valley; my dog got there too and was nipping and their noses, which turned them. It was a wild and crazy run off the mountains to the Valley. It was a hoot.

My memory drifts to that day

when I was a cowboy far away.

Off in the distance I can see

a little dust trail following me.

We have just made a wild and crazy run

down off the White Mountains, oh what fun!

My horse and me, and that old blue dog

she's now off in the distance at a slow jog.

On a mountain up near the sky

after renegade steers was why.

The steers made a wild and crazy dash

we three took off quick as a flash.

We tried to head to the valley wide

that little blue dog still at my side.

Near the head of the bunch we turned the herd the little dog listened to my words.

She snapped at the leaders and turned their heads and to the valley below the steer bunch sped.
The hours were long, the day was hot we were soon all a tired and weary lot.

The heat was taking its heavy toll my old blue dog began to slow.

But on she came at a steady pace not to be left from the frantic race.

Distance grew between the horse and dog though on she came at a steady slow jog.

I'm back to the camp long before the dog unsaddle my horse and I wait for the dog.

Off in the distance I could see that little dust trail heading toward me.

And she still keeps a trotting along she'll be to me before too long.

At last a final dash and run again she's having lots of fun.

She runs and jumps and wiggles and squeals she wants to show me she has lots of zeal.

A tired and worn out dog she is but dignity and grace she gives.

Whenever I get down and blue I remember that day I once knew.

With a little dust trail following me and I was a cowboy, it was great to be.

Yes I was a cowboy for a part of my life and I had a blue dog to help with my strife.

A long hard distance I'll have to go to find a better friend than my Inyo. 


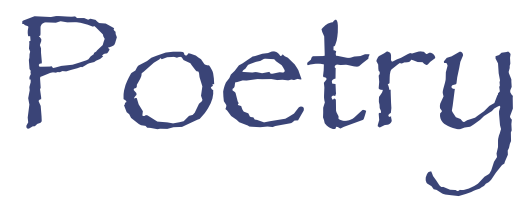

\section{Not Everyone Loves the West}

Come, all you poetical cowboys;

Let's get something off of our chests.

Though we would not exchange

Our home on the range,

Not everyone loves the West.

Some think that it's too rough and tumble, Which makes them so sad and depressed.

That they want to take it

And change and remake it

Then maybe they'd love the West.

They say if we shoot at grizzlies and wolves, We'll be in great peril of arrest.

We shouldn't be bitter

If they chew up our critters;

That's how it should be in the West.

They say that the oilmen and miners

Should call a timeout to their quests.

Although we remark

That they'd freeze in the dark,

They're sure it'd be good for the West.

Remove all the cattle and sheep from the range

Is a thought that is often expressed.

They'd find it enticin'

To give it back to the bison,

Though those critters near ate up the West.

Perhaps we ought to convince 'em

That on the two coasts they are blessed.

That there they should stay

To work and to play;

Life's really too rough in the West.
Where a blizzard congeals your bloodstream, No matter how warmly you're dressed,

And a barbed wire fence

Is your sole defense

From the wind that blows 'cross the West.

An' what if your faithful and trusty cayuse

Unloads you, miles from your nest?

You'd tramp over the plains,

With your feet feelin' pain,

From the boots that folks wear in the West.

And suppose that grizzly takes one look at you

And decides that your chops are the best?

At Figueroa and Main,

You may top the food chain,

But that ain't how it works in the West.

So you take the city and we'll take the range,

Though we're glad to have you as a guest.

Enjoy hospitality,

Keep an eye on reality;

Then we'll all get along in the West. 


\section{Letters to the Editor}

Gary:

Your editorial on subdivisions and the impacts of small tract grazing by new owners of the land was on target ("Frasier's Philosophy," Rangelands 28(6):2). It would be good to see something in Rangelands about these kinds of developments. I see it all the time in Montana and elsewhere-i.e., spotted knapweed horse pastures. These are often the worse abuses out there.

George Wuerthner

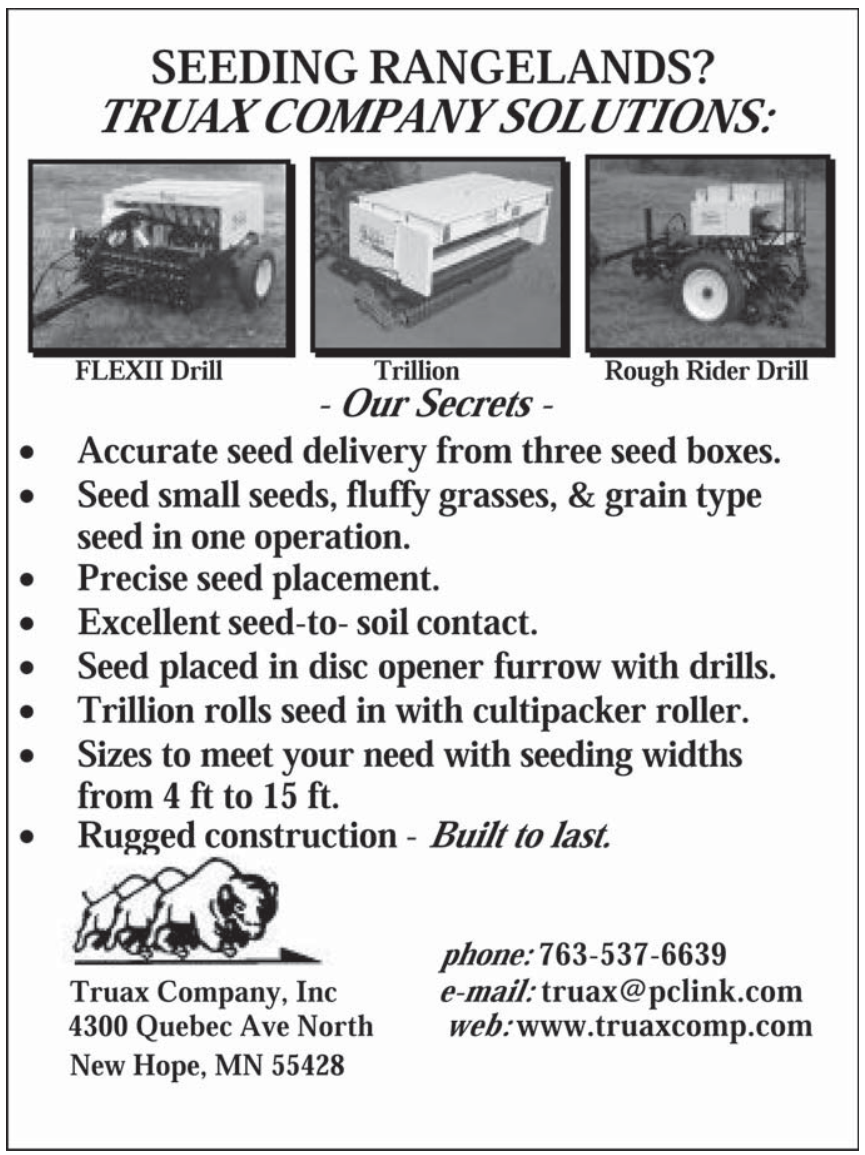

